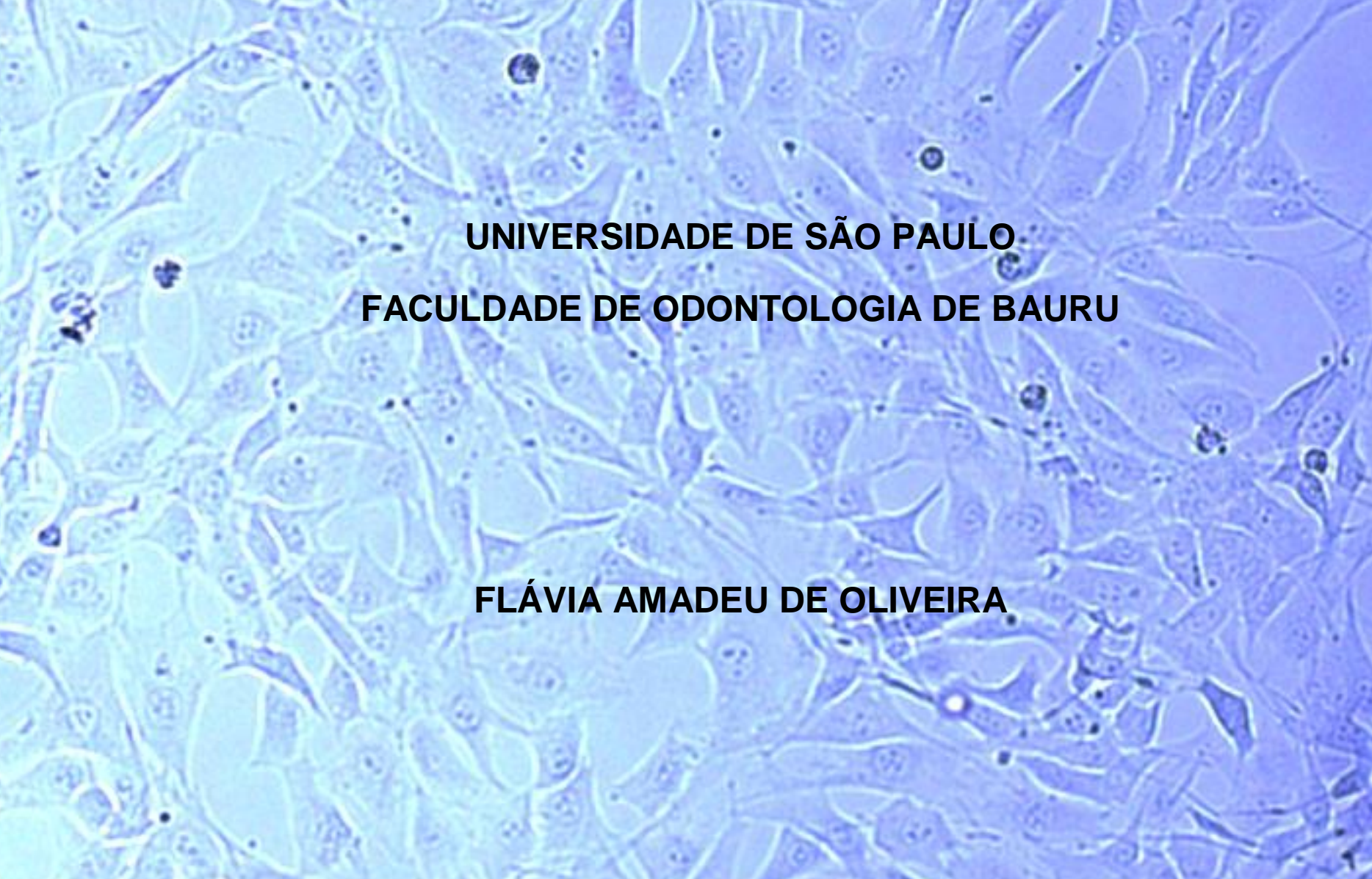

Efeito dos laseres de baixa intensidade na proliferação e diferenciação de osteoblastos humanos

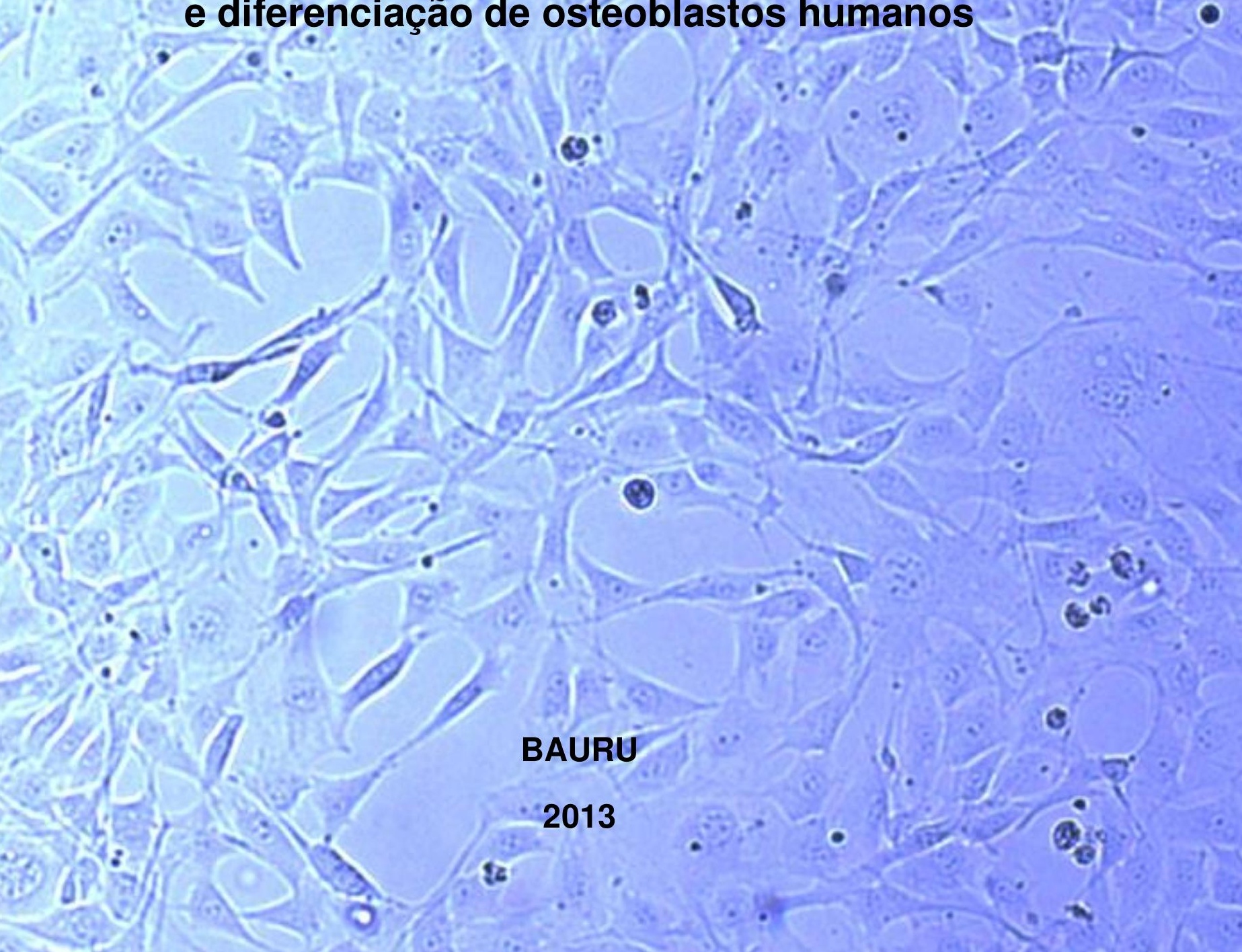




\title{
Efeito dos laseres de baixa intensidade na proliferação e diferenciação de osteoblastos humanos
}

\author{
Dissertação/Tese apresentada a Faculdade de \\ Odontologia de Bauru da Universidade de São Paulo \\ para obtenção do título de Mestre em Ciências no \\ Programa de Ciências Odontológicas Aplicadas, na \\ área de concentração Biologia Oral.
}

Orientador: Prof. Dr. Rodrigo Cardoso de Oliveira

Versão Corrigida

BAURU 


\begin{tabular}{|l|}
\hline Oliveira, Flávia Amadeu de \\
EL4e $\quad$ Efeito dos laseres de baixa intensidade na \\
proliferação e diferenciação de osteoblastos humanos / \\
Flávia Amadeu de Oliveira. - Bauru, 2013. \\
147 p. : il. ; $31 \mathrm{~cm}$. \\
Dissertação (Mestrado) - Faculdade de Odontologia \\
de Bauru. Universidade de São Paulo \\
Orientador: Prof. Dr. Rodrigo Cardoso de Oliveira \\
\end{tabular}

Nota: A versão original desta dissertação encontra-se disponível no Serviço de Biblioteca e Documentação da Faculdade de Odontologia de Bauru - FOB/USP

Autorizo, exclusivamente para fins acadêmicos e científicos, a reprodução total ou parcial desta dissertação/tese, por processos fotocopiadores e outros meios eletrônicos.

Assinatura:

Comitê de Ética da FOB-USP

Protocolo $\mathrm{n}^{0}:$ : 95/2011

Data: 05 de Setembro de 2011 


\title{
DEDICATÓRIA
}

\begin{abstract}
À Deus,
Pelo amor incondicional. Por direcionar os meus caminhos sempre para o bem e me dar perseverança para continuar. Por me permitir encontrar pessoas maravilhosas com quem convivo e estar presente em todos os momentos da minha vida.
\end{abstract}

Aos meus pais Genésio e Cristina,

Que sempre fizeram e fazem o impossível para me proporcionar uma boa educação. Queridos pais, vocês me ensinaram tanto...cuidaram-me, deram-me amor, bons princípios, amizade, compreensão, educação e apoio para que eu pudesse ser um pouquinho melhor a cada dia. A vocês, meu eterno amor e gratidão. Com certeza o aprendizado continua...

À minha única irmã, Fabiana,

Que sempre apoiou minhas escolhas e acreditou em meus sonhos. Somos irmãs, sobretudo de alma. Ajudamos, acreditamos, lutamos, vencemos, perdemos, choramos, sorrimos... sempre juntas. Obrigada pela nossa amizade...você é única.

Ao meu eterno George,

Pelo amor singelo e sincero. Por me apoiar em todos os momentos de minha vida e muitas vezes abdicar de suas escolhas para me fazer mais feliz. Por estar sempre perto, pelo amor, pela compreensão nos momentos de ausência, pela preocupação e dedicação. Obrigada por acreditar em mim. 


\section{AGRADECIMENTO ESPECIAL}

\section{À Adriana Arruda Matos,}

Uma amiga que vou levar para toda a vida. Você lutou comigo até o último momento para que esse dia chegasse, pela simples bondade...sempre me incentivando e acreditando que tudo ia dar certo. Nunca irei esquecer o que fez por mim. Obrigada pelo auxílio, pela disponibilidade, pelas conversas e também pelas caronas! 


\section{AGRADECIMENTOS}

Ao meu orientador Prof. Dr. Rodrigo Cardoso de Oliveira, sempre disposto a ajudar e abrindo portas para novos conhecimentos e oportunidades. Sua generosidade e exemplo de profissionalismo tornam os dias de trabalho mais confortáveis. Obrigada pela acolhida, dedicação e confiança.

À Profa. Dra. Camila Peres Buzalaf, minha mestra e amiga, que não mede esforços para me ajudar, ensinar, que acredita em meu potencial para lecionar e pesquisar. Obrigada pela orientação, paciência, dedicação e pelo apoio constante. Seu carisma e competência faz com que eu tenha vontade de melhorar a cada dia. Seus ensinamentos estarão comigo por toda minha vida, sempre.

À Aline de Lima Leite, uma amiga sem igual. Sempre disposta a ajudar e não mede esforços para resolver meus problemas de laboratório, sanando minhas dúvidas e contribuindo para o meu crescimento profissional. Sua competência me inspira e a cada conversa nossa eu aprendo um pouco mais. Obrigada por toda a ajuda.

À Priscila Maria Aranda Salomão, pela amizade e apoio constantes. Obrigada por tornar os dias de trabalho mais divertidos e estar sempre disposta a ajudar.

À Mariana Rodrigues Santesso, uma menina meiga que sempre está disposta a ajudar os outros. Sua ajuda foi indispensável para que eu pudesse finalizar esta pesquisa. Obrigada pela companhia e pelo trabalho intenso de irradiar as células.

À minha eterna "queurinha" Eliane Maria de Ávila, pessoa muito querida que não mede esforços para me ajudar. Você mora em meu coração...obrigada por tudo!

Aos professores Ana Carolina Magalhães, Flávio Augusto Cardoso de Faria e Antônio de Castro Rodrigues, agradeço por ter tido a oportunidade de assistir suas aulas. A 
competência, o dom e a vontade de ensinar os tornam exímios no que fazem e me inspiram para melhorar cada vez mais minha didática.

Aos amigos verdadeiros do CIP, Heliton Gustavo de Lima, Karen Pinke, Rafaela Alves da Silva Alavarce, Taiane Gardizani, Amanda Amaral Pereira, Márcia Graeff, Nara Lígia Martins Almeida, Pepe Burgos, Profa. Dra. Carla Andreotti Damante e Paula Karam que proporcionam um ótimo ambiente de trabalho e estão sempre dispostos a ajudar.

Ao Thiago José Dionísio, pela boa vontade de ajudar nos experimentos de RT-PCR e por estar sempre disposto a sanar minhas dúvidas.

À Profa. Dra. Ana Paula Campanelli, por ter cedido uma parte do seu tempo para que eu pudesse realizar a citometria de fluxo e por toda a ajuda.

Aos amigos da Bioquímica, Luana Polioni Al-Ahj, Talita Ventura, Senda Charone, Fernanda Zucky, Aline Dionízio, Mileni Fernandes, Lívia Comar, Camila Roque, Isabela Tomazini, Alessandra Cury, Flávia lano, Heloísa Pereira, Aline Castilho, Kellen Gasque, Lucas Fedameda, Priscila Muno e Mel Bellini por tornar o ambiente de trabalho mais agradável.

Ao Prof. Dr. André Luis Shinohara, pelo incentivo e apoio à pesquisa. Obrigada pelas conversas incentivadoras e conselhos! Eles certamente me impulsionaram com garra e vontade de aprender.

À querida Profa. Dra. Silvana Pasetto, pelo incentivo e apoio à pesquisa no início da minha jornada acadêmica. Nunca irei me esquecer do seu carinho e determinação!

À Profa. Dra. Marilia Rabelo Afonso Buzalaf pela acolhida e oportunidade de poder fazer parte do laboratório de bioquímica. 
Ao Prof. Dr. José Mauro Granjeiro e sua equipe por nos ceder gentilmente os osteoblastos humanos e pela parceria com nosso grupo de pesquisa.

Aos funcionários do laboratório de bioquímica Aline de Lima Leite, Larissa Grizzo Thomassian, Thelma Lopes Silva e Ovídio dos Santos Sobrinho por estarem sempre dispostos a nos auxiliar.

Ao prof. Dr. Vinicius Carvalho Porto e aos funcionários do Centro Integrado de Pesquisa, Márcia Sirlene Zardin Graeff, Rafaela Alves da Silva Alavarce, Renato Pereira Murback, Marcelo Milanda Ribeiro Lopes e Neusa Caetano Barbosa pela disposição em ajudar.

À Fundação de Amparo à Pesquisa do Estado de São Paulo-FAPESP, pelo apoio financeiro para a realização desta pesquisa. Processo ํo. 2010/14289-4.

À Faculdade de Odontologia de Bauru, pela oportunidade de fazer parte desta instituição tão renomada.

À Vera Rufino, por nos atender prontamente sempre que precisamos e pela disposição em ajudar.

Aos amigos, pelo carinho e compreensão nos momentos em que precisei estar ausente.

Agradecimento especial a todos que me auxiliaram na irradiação das células, Mariana, Fabiana, George e Taiane, que contribuíram para que aqueles dias de trabalho intenso fossem menos árduos... 
Toda nossa ciência, comparada com a realidade, é primitiva e infantil - e, no entanto, é a coisa mais preciosa que temos."

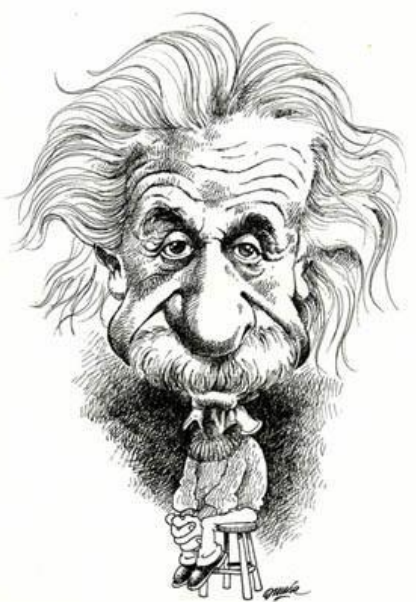

Albert Einstein (1879-1955) 


\section{RESUMO}

Dentre os vários compostos utilizados na pesquisa e na terapia de doenças osteo-degenerativas, a fototerapia com laseres de baixa potência (LLLT) e os diodos emissores de luz (LEDs) vem sendo investigada com o intuito de avaliar seus efeitos no metabolismo ósseo. Estes, que possuem comprimentos de ondas específicos, atuam na biomodulação das células, funcionando como um agente terapêutico, reequilibrando e normalizando a sua atividade. No entanto, pouco se sabe sobre o efeito dos diferentes espectros na proliferação e diferenciação de osteoblastos humanos, bem como seus efeitos no metabolismo celular como a síntese e a ativação de proteínas sinalizadoras envolvidas nesses processos. Diante disso, o objetivo deste trabalho foi avaliar, comparativamente, a influência da fototerapia com LLLT e LED na proliferação e diferenciação de osteoblastos humanos. Além disso, investigamos o envolvimento da ativação da via de sinalização ERK1,2 nestas respostas, utilizando o seu inibidor específico e/ou avaliando a sua ativação durante a proliferação e após fototerapia. Para esse estudo, osteoblastos humanos (HOAL) foram cultivados em meio de cultura DMEM suplementado com $10 \%$ de soro fetal bovino (SFB) e incubados em estufa de $\mathrm{CO}_{2}$. As células foram irradiadas pontualmente com os laseres vermelho $(660 \mathrm{~nm})$, infravermelho $(780 \mathrm{~nm})$ e LED (637nm), nas doses de 10, 20 e $50 \mathrm{~J} / \mathrm{cm}^{2}$ na potência de $40 \mathrm{~mW}$, após adesão celular. Após 24, 48, e 72 horas foram realizados os ensaios de redução do MTT (brometo de 3-(4,5-dimetiltiazol-2-yl)-2,5- difeniltetrazólio) e cristal violeta (CV) para avaliar a viabilidade das células e após 72 horas foi realizada a análise da proliferação por citometria de fluxo nos quais os resultados sugerem aumento de células viáveis ou proliferação quando estimuladas pelos diferentes espectros. Após a verificação do efeito positivo dos laseres e LED na viabilidade e/ou proliferação, foi realizada a análise da ativação da proteína intracelular ERK por western blotting usando anticorpo específico após 10 minutos da irradiação pontual. Mostramos que a irradiação das células HOAL com LLLT, na dose de $10 \mathrm{~J} / \mathrm{cm}^{2}$, aumentou significativamente a fosforilação da ERK1/2 em relação ao controle. Para os ensaios de diferenciação, as células receberam pontualmente o estimulo a cada 6 dias e após os períodos de 07 , 14,21 e 28 dias foram realizados os ensaios da atividade de fosfatase alcalina (ALP), expressão gênica do colágeno I (COL1A1) e SPARC (osteonectina) por RT-PCR em tempo real e ensaio de mineralização com vermelho de alizarina. De um modo geral, não foram observados diferenças na atividade da ALP entre os grupos tratados em relação ao controle. A expressão gênica do COL1A1 e SPARC foi aumentada, no qual o LED em ambas doses apresentou maior eficácia em aumentar a expressão desses genes. No que se refere à mineralização, foram observadas pequenas diferenças quanto a deposição de cálcio. Dessa forma, a LLLT e LED, nesse regime de aplicação modulou positivamente o metabolismo dos osteoblastos humanos em relação à viabilidade, porém, no processo de mineralização foram observadas poucas diferenças.

Palavras-chave: Fototerapia. LLLT. LED. Osteoblastos. ERK. 


\section{ABSTRACT \\ Low level laser effects in proliferation and differentiation of human osteoblasts}

Among the various compounds used in research and bone degenerative diseases therapy, phototherapy with low level laser (LLLT) and light emitting diodes (LEDs) has been investigated in order to evaluate its effects on bone metabolism. Those, who have specific wavelengths, act in biomodulation cells functioning as a therapeutic agent, rebalancing and normalizing their activity. However, little is known about the effect of the different spectra in the proliferation and differentiation of human osteoblasts and their effects on cellular metabolism as well as the synthesis and activation of signaling proteins involved in these processes. Therefore, the aim of this study was to compare the influence of LLLT and LED phototherapy in the proliferation and differentiation of human osteoblasts. In addition, we investigated the involvement of activation of ERK1,2 signaling pathway these responses using its specific inhibitor and/or evaluating their activation during the proliferation and after phototherapy. For this study, human osteoblasts (HOAL) were cultured in DMEM culture medium supplemented with $10 \%$ fetal bovine serum (FBS) and incubated in $\mathrm{CO}_{2}$ incubator . Cells were irradiated with punctual red lasers $(660 \mathrm{~nm})$, infrared $(780 \mathrm{~nm})$ and LED $(637 \mathrm{~nm})$ at doses of 10,20 and $50 \mathrm{~J} / \mathrm{cm}^{2}$ in power $40 \mathrm{~mW}$, after cell adhesion. After 24 , 48, and 72 hours, MTT assay (- (4,5- dimethylthiazol-2- yl) -2,5 - diphenyltetrazolium bromide 3 ) and violet crystal (CV) were performed to assess the viability of cells and after 72 hours, was performed of proliferation analysis by flow cytometry. The results suggest an increase in viable and proliferation of cells when stimulated by different spectra. After checking the positive effect of lasers and LED viability and/or proliferation, analysis of ERK activation of intracellular protein by western blotting using a specific antibody was performed 10 minutes after the spot irradiation. We show that irradiation of HOAL cells with LLLT at a dose of $10 \mathrm{~J} / \mathrm{cm}^{2}$, significantly increased the phosphorylation of ERK1/2 compared to control. For differentiation assays, cells promptly received stimulation every 6 days and after periods of $07,14,21$ and 28 days testing the activity of alkaline phosphatase (ALP), gene expression of type I collagen (COL1A1) and SPARC (osteonectin) were performed by Real Time RT-PCR and mineralization experiment with alizarine red. In general, no differences in the activity of ALP between the treated groups compared to the control were observed. The gene expression was increased, and SPARC COL1A1, where in the LED in both doses showed greater effectiveness in increasing the expression of these genes. With respect to mineralization, small differences in the deposition of calcium were observed. Thus, LLLT and LED, this enforcement regime, positively modulated the metabolism of human osteoblasts during the cell viability, but in the process of mineralization few differences were observed.

Keywords: Phototherapy. LLLT. LED. Osteoblasts. ERK. 


\section{LISTA DE ILUSTRAÇÕES}

\section{- FIGURAS}

Figura 1 - Modelo de remodelamento ósseo

Figura 2 - Fotomicrografia dos tipos celulares

Figura 3 - Diodo emissor de luz ( $637 \pm 15 \mathrm{~nm}$ ) e Laser de baixa potência: laser vermelho $(660 \mathrm{~nm})$ e laser infravermelho $(780 \mathrm{~nm})$

Figura 4 - Imagem ilustrativa da placa do ensaio Redução do MTT após incubação e posterior dissolução dos cristais de formazan com DMSO

Figura 5 - Imagem ilustrativa da placa do ensaio de viabilidade cristal violeta após adição de citrato de sódio a 0,05 mol.L-1

Figura 6 - Imagens da técnica Western blotting

Figura 7 - Citômetro de fluxo FACSCalibur (BD Biosciences) para aquisição das amostras.

Figura 8 - Imagem ilustrativa do ensaio fosfatase alcalina

58

Figura 9 - Quantificação total de proteínas pelo Método de Bradford

59

Figura 10 Sistema de Real-Time RT-PCR ViiA ${ }^{\mathrm{TM}} 7$ (Applied Biosystems) .......

Figura 11 Deposição de cálcio pelas células HOAL e MC3T3-E1 pelo corante vermelho de alizarina

Figura 12 Efeito do LLLT na viabilidade de osteoblastos humanos (HOAL) avaliado por redução do MTT nos períodos de 24, 48 e 72 horas.... 
Figura 13 Efeito da LLLT na viabilidade de osteoblastos humanos (HOAL) avaliado por cristal violeta nos períodos de 24, 48 e 72 horas

Figura 14 Histograma representativo da proliferação das células HOAL........... 72

Figura 15 Histogramas do efeito da fototerapia na proliferação das células HOAL realizados por citometria de fluxo no período de 72 horas......

Figura 16 Efeito dos diferentes espectros na proliferação dos osteoblastos humanos HOAL no período de 72 horas

Figura 17 Ativação da ERK em células HOAL após diferentes fototerapias.... 76

Figura 18 Histogramas do efeito da fototerapia na proliferação das células HOAL na presença do inibidor de ERK PD98059 no período de 72 horas

Figura 19 Efeito da inibição de ERK na proliferação das células HOAL induzida pelos diferentes espectrosL no período de 72 horas

Figura 20 Atividade de ALP em HOAL e MC3T3-E1 nos períodos de 7, 14, 21 e 28 dias de cultivo

Figura 21 Efeito dos diferentes tipos de laser e LED na atividade de fosfatase alcalina

Figura 22 Efeito dos diferentes espectros na expressão gênica de COL1A1 (A) e SPARC (B) em osteoblastos humanos

Figura 23 Deposição de cálcio pelas células HOAL e MC3T3-E1 pelo corante vermelho de alizarina 
Figura 24 Análise quantitativa da coloração com vermelho de alizarina nas células HOAL e MC3T3-E1 nos períodos de 14, 21 e 28 dias.

Figura 25 Diferentes espectros na análise quantitativa da deposição de cálcio por meio da coloração com vermelho de alizarina nas células HOAL nos períodos de $07,14,21$ e 28 dias. 


\section{LISTA DE ABREVIATURAS E SIGLAS}

ALP - Fosfatase alcalina óssea

AML3 - Acute myeloid leukemia 3

ANOVA - Análise de Variância

ATCC - American Type Culture Collection

Bglap - Bone gamma-carboxyglutamic acid-containing protein (gene da osteocalcina)

BMPs - Proteínas morfogenéticas do osso

BSP - Sialoproteína óssea

Cbfa1 - Core binding factor 1

CFSE - Carboxyfluorescein diacetate, succinimidyl Ester

COL1A 1 - gene do colágeno tipo 1 alfa 1

CV - Cristal violeta

DMEM - Dulbecco's Modified Eagle's Medium

DO - Densidade óptica

ECL - Enhanced chemiluminescence

ERK 1,2 - Quinase regulada por sinal extracelular 1,2

FDA - Food and drug Administration

GaAlAs - Arseneto de gálio e alumínio

He-Ne - Laser de Hélio e Neônio

HOAL - Osteoblastos humanos

IGF-I - Fator de crescimento insulínico-I

JNK - c-Jun NH(2)-terminal protein kinases

$\mathrm{J}$ - Joules

$\mathrm{J} / \mathrm{cm}^{2}$ - Joules por centímetro quadrado

LEDs - Diodos emissores de luz

LEF - Fator estimulador linfoide

LLLT - Terapia com laser de baixa potência

M - Molar

MAPKs - Proteínas quinases ativadas por mitógeno

MC3T3-E1 - Pré-osteoblastos de linhagem murina

MEK - Quinase ativadora da MAP quinase 
MEM - Minimum Essential Medium Eagle

$\mathrm{mg}$ - Miligrama

$\mathrm{mM}$ - Milimolar

MMPs - Metaloproteinases de matriz

MTT - Brometo de 3-(4,5-dimetiltiazol-2-yl)-2,5-difeniltetrazólio

$\mathrm{mW}$ - Miliwatts

NASA - National Aeronautics and Space Administration

nm - Nanômetro

OCN - Osteocalcina

OPG - Osteoprotegerina

OPN - Osteopontina

p38 - proteína quinase p38 ativada por mitógeno

p-ERK - ERK fosforilada

PLC - Fosfolipase C

PKC - Fosfoquinase $C$

p-NP - para-nitrofenol

p-NPP - para-nitrofenilfosfato

PVDF - Polyvinylidene difluoride

RT-PCR em tempo real - Transcrição Reversa da Reação em Cadeia da Polimerase em tempo real

RANK - Receptor ativator de fator nuclear Kappa B

RANKL - Ligante do Receptor ativador de fator nuclear Kappa B

Runx2 - Runt related transcription factor 2

SFB - Soro fetal bovino

SPARC - Proteína secretada ácida rica em cisteína (osteonectina)

TA - Temperatura ambiente

TCF - Fator de transcrição de células T

TGF- $\beta 1$ - Fator de crescimento transformador beta 1

$\mathrm{W} / \mathrm{cm}^{2}$ - Watts por centímetro quadrado

Wnts - Drosophila Wingless and mouse Int-1

$\mu \mathrm{g}$ - Micrograma

$\mu \mathrm{L}-$ Microlitro 


\section{SUMÁRIO}

1 INTRODUÇÃO 23

2 REVISÃO DE LITERATURA 29

2.1 O TECIDO ÓSSEO 29

2.1.1 Células do tecido ósseo 31

2.2 MARCADORES DE FORMAÇÃO ÓSSEA E DIFERENCIAÇÃO OSTEOGÊNICA 33

2.3 FOTOTERAPIA NA FORMAÇÃO ÓSSEA 36

3 PROPOSIÇÃO

4 MATERIAL E MÉTODOS 49

4.1 CULTIVO DE OSTEOBLASTOS HUMANOS (HOAL) E MC3T3-E1 49

4.2 FOTOTERAPIA 51

4.3 ENSAIO DE VIABILIDADE CELULAR 52

4.3.1 Redução do MTT 53

4.3.2 Cristal Violeta $\quad 54$

4.4 WESTERN-BLOTTING 54

4.5 ENSAIO DE PROLIFERAÇÃO 56

4.6 ENSAIO DA ATIVIDADE DA FOSFATASE ALCALINA (ALP) 56

4.7 QUANTIFICAÇÃO TOTAL DE PROTEÍNA 58

4.8 RT-PCR EM TEMPO REAL (TRANSCRIÇÃO REVERSA DA REAÇÃO EM CADEIA DA POLIMERASE EM TEMPO REAL) 59

4.9 ENSAIO DE MINERALIZAÇÃO 60

4.10 ANÁLISE ESTATÍSTICA 62

5 RESULTADOS 65

5.1 ANÁLISE DA VIABILIDADE CELULAR 65

5.1.1 Redução do MTT 65

5.1.2 Cristal Violeta 66

5.2 EFEITO DOS DIFERENTES ESPECTROS NA PROLIFERAÇÃO CELULAR 71

5.3 ANÁLISE DA ATIVAÇÃO DA PROTEÍNA INTRACELULAR ERK 
5.4 EFEITO DA INIBIÇÃO DE ERK NA PROLIFERAÇÃO INDUZIDA PELOS DIFERENTES ESPECTROS $\quad 77$

5.5 ATIVIDADE DA ALP: HOAL X MC3T3-E1 80

5.6 EFEITO DAS DIFERENTES FOTOTERAPIAS NA ATIVIDADE DA ALP 82

5.7 ANÁLISE DO RT-PCR EM TEMPO REAL 84

5.7.1 Efeito dos diferentes espectros na expressão gênica do Colágeno I (COL1A1) 84

5.7.2 Efeito dos diferentes espectros na expressão gênica do SPARC 84

5.8 CARACTERIZAÇÃO DO POTENCIAL DE MINERALIZAÇÃO DAS CÉLULAS HOAL $\quad 86$

5.9 EFEITO DOS DIFERENTES ESPECTROS NA MINERALIZAÇÃO 87

6 DISCUSSÃO 91

7 CONCLUSÕES 99

REFERÊNCIAS 103

ANEXOS 121 


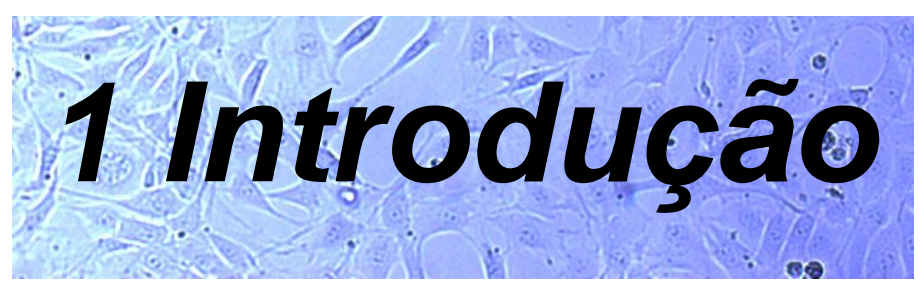





\section{INTRODUÇÃO}

O tecido ósseo atua como um suporte/proteção para o corpo, além de ser um reservatório de cálcio e fosfato, e um local para hematopoiese. O osso consiste de camadas de hidroxiapatita intercaladas com uma variedade de proteínas que constituem a matriz óssea e com osteoblastos, os quais secretam a matriz proteica. $A$ estrutura do osso é mantida por uma relação delicada entre células do tecido ósseo que são os osteoblastos e osteoclastos, o primeiro está associado com a formação de novo osso e o último com a reabsorção óssea. Estudos sugerem que os osteoblastos são necessários para a reabsorção efetuada pelos osteoclastos. Os mecanismos de regulação do metabolismo ósseo são complexos e envolvem interações entre as células ósseas, fatores locais e sistêmicos (WATROUS \& ANDREWS, 1989).

Durante o desenvolvimento do esqueleto, os osteoblastos realizam sua função em vários estágios de diferenciação e maturação. Os osteoblastos são derivados de células tronco mesenquimais, que se diferenciam em precursores de osteoblastos, seguido por osteoblastos maduros e osteócitos (KATO et al., 2001). In vivo, os osteoblastos maduros são encontrados na matriz osteóide, que é produzida por proteínas secretadas por essas células e fatores de crescimento (ZOUANI et al., 2013).

A diferenciação osteogênica é estimulada por diversos fatores, como as proteínas morfogenéticas do osso (BMPs) (KOMORI et al., 1997; OTTO et al., 1997), a via das Wnts (Drosophila Wingless and mouse Int-1), envolvidas na osteoblastogênese e que sinalizam por meio da $\beta$-catenina (via canônica) (DAVIS \& ZUR NIEDEN, 2008) ou fosfolipase ou fosfoquinase $C$ (via não-canônica) (KOHN \& MOON, 2005), o fator de transcrição Runt related transcription factor 2 (Runx2) que é fundamental para a diferenciação de osteoblastos (KOMORI et al., 1997; OTTO et al., 1997) e a via das proteínas quinases ativadas por mitógeno (MAPKs) que é uma das principais vias de sinalização envolvidas na proliferação e diferenciação celular (KOLCH, 2000). Estas compreendem as vias denominadas ERK1,2 (quinase regulada por sinal extracelular 1,2), p38 e JNK (c-Jun NH(2)-terminal protein Kinases) (SCHINDELER \& LITTLE, 2006).

Além disso, há vários marcadores bioquímicos que caracterizam a formação óssea, como a fosfatase alcalina óssea (ALP), proteínas da matriz 
extracelular incluindo o colágeno tipo I, osteonectina (SPARC), osteocalcina (OCN), osteopontina (OPN), sialoproteína óssea (BSP) e proteoglicanas as quais são secretadas e depositadas por osteoblastos maduros e alinhadas sobre a superfície óssea (YOUNG et al., 1992; BIANCO et al., 1993; MUNDLOS \& OLSEN, 1997).

Dentre os vários compostos utilizados na pesquisa e na terapia de doenças ósseo-degenerativas, a fototerapia vem sendo amplamente investigada com o objetivo de avaliar seus efeitos no metabolismo ósseo. Ao longo dos últimos anos, a laserterapia tem sido realizada em experimentos in vitro e na clínica por ser uma técnica não invasiva e de grande utilidade nos diferentes campos de medicina, incluindo odontologia e ortopedia (COBB, 2006).

Dentre os tipos de laseres empregados para fins clínicos e experimentais, o laser diodo é um dos mais utilizados. Laseres de alta e baixa potência servem a diferentes propósitos clínicos (PEARSON \& SCHUCKERT, 2003). O laser de alta potência tem um efeito térmico e são utilizados para cortar, coagular e vaporizar, tornando-o útil para aplicações cirúrgicas e antibacterianas. Já o laser de baixa potência não possui efeitos térmicos, mas são usados por apresentar um efeito bioestimulatório auxiliando em processos de cicatrização e regeneração de tecidos (BOUVET-GERBETTAZ et al., 2009).

Além do efeito bioestimulatório, a terapia com laser de baixa potência (LLLT) também possui propriedades antiinflamatórias (DE PAULA EDUARDO et al., 2010; PEJCIC et al., 2010) e efeitos analgésicos (DE PAULA EDUARDO et al., 2010) características que em conjunto conferem ao paciente um pós-operatório mais confortável, com possibilidade de redução do uso de medicamentos (DAMANTE, 2007).

Além da LLLT, os diodos emissores de luz (LEDs) vêm sendo utilizados como agentes terapêuticos por promoverem efeitos biológicos semelhantes aos dos laseres. Os LEDs são um tipo especial de diodo semicondutor que emite luz quando conectado a um circuito elétrico e, que tem se mostrado eficaz em experimentos in vitro e em modelos animais (VREMAN et al., 1998; CHANG et al., 2005; TRIDENTE \& DE LUCA, 2012).

O efeito dos laseres e LEDs em culturas de células ósseas é bastante estudado. Segundo Pyo et al. (2012), a terapia com laser de baixa potência induz a 
expressão de BMP-2, osteocalcina e do fator de crescimento transformador $\beta 1$ (TGF$\beta 1)$ em cultura de osteoblastos humanos.

A atividade de fosfatase alcalina e a expressão gênica de ALP, Runx2, osteocalcina, colágeno tipo I, e sialoproteína óssea foram aumentados quando estimulados com LLLT em osteoblastos da sutura palatina mediana de ratos após expansão rápida da maxila (DA SILVA et al., 2012). Kiyosaki et al. (2010) avaliaram o efeito da LLLT em pré-osteoblastos da linhagem murina MC3T3-E1 e observaram aumento significativo de IGF-I (insulin-like growth factor I) e da produção de BMP, por meio da expressão de Runx2 e fosforilação de ERK. Kim et al. (2009) avaliaram o efeito do LED na diferenciação osteogênica de células tronco mesenquimais e observaram aumento de mineralização por meio da coloração com vermelho de alizarina, aumento da atividade de fosfatase alcalina (ALP) e da expressão de mRNA de osteocalcina, colágeno tipo I, osteopontina e Runx2, sugerindo que a diferenciação osteogênica é reforçada pela exposição à luz LED. Porém, como ocorre em todos os estudos com laser e LED, ainda não há parâmetros completamente definidos para sua utilização. Diante disso, para melhor compreensão de tais efeitos biológicos produzidos pela fototerapia foi necessário o presente estudo para avaliar marcadores ou via de sinalização intracelular alvos para intervenção terapêutica os quais poderão no futuro, auxiliar no tratamento de pacientes após sofrerem cirurgias ou traumas nas áreas ortopédicas e odontológicas. 


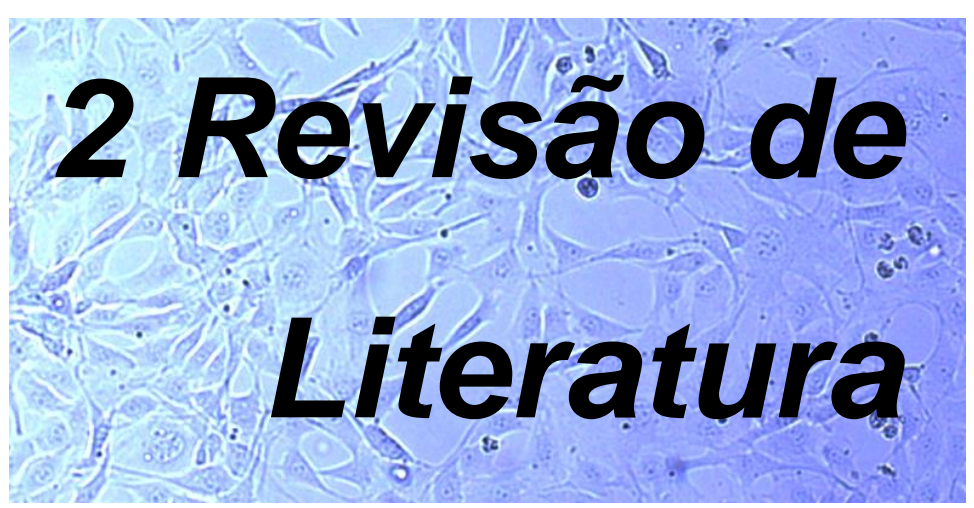





\section{REVISÃO DE LITERATURA}

\subsection{O TECIDO ÓSSEO}

O desenvolvimento do esqueleto (modelação óssea) e manutenção do esqueleto na vida pós-natal (remodelação óssea) exigem a coordenação precisa da atividade de vários tipos de células, incluindo células osteoprogenitoras, osteoblastos, osteócitos e osteoclastos (STAINS et al., 2013).

O tecido ósseo atua como um suporte estrutural para o organismo, local responsável pela hematopoiese e um dos principais reservatórios metabólicos de cálcio e fosfato. $\mathrm{O}$ osso consiste de camadas de hidroxiapatita intercaladas com uma variedade de proteínas que constituem a matriz óssea (WATROUS \& ANDREWS, 1989). A matriz óssea é composta pela porção inorgânica, no qual são encontrados principalmente os íons cálcio e fosfato, porém também estão presentes os íons magnésio, potássio, sódio, bicarbonato e citrato. O cálcio e o fósforo formam cristais com estrutura semelhante da hidroxiapatita. A porção orgânica da matriz é formada por proteínas colagênicas (aproximadamente 95\%) e não colagênicas, como as proteoglicanas e glicoproteínas (JUNQUEIRA \& CARNEIRO, 2006).

O colágeno é a proteína mais abundante e ubíqua em animais multicelulares (WEINS et al., 2010). Os colágenos compreendem uma grande família de proteínas multiméricas com até 38 genes que dão origem a 20 diferentes tipos colágenos. Após a síntese de uma grande cadeia de polipeptídeos, esta torna-se entrelaçada com duas outras cadeias de estrutura helicoidal formando uma estrutura tripla. Cada triplex pode conter três cadeias idênticas ou duas ou três cadeias diferentes, dependendo do tipo de colágeno. O principal colágeno triplex em tecidos mineralizados é o colágeno tipo I. O colágeno tipo I é a proteína mais abundante nos seres humanos, que auxilia na manutenção e integridade de vários tecidos por meio de suas interações com superfícies celulares, outras moléculas da matriz extracelular e fatores de crescimento e de diferenciação (DI LULLO et al., 2002) e além de sua abundância no tecido ósseo, também é encontrado em demasia na córnea, tendões e derme (DI LULLO et al., 2002; KISHIMOTO et al., 2013).

As contribuições dos componentes não colagênicos da matriz extracelular para a resistência óssea são pouco definidas e suas funções são limitadas 
principalmente a elementos não arquitetônicos da matriz óssea (BALOOCH et al., 2005; KAVUKCUOGLU et al., 2007; MOCHIDA et al., 2009). As proteínas não colágenas compreendem um total de aproximadamente $10 \%$ da matriz orgânica (OLSZTA et al., 2007). Algumas delas interagem com fibrilas de colágeno e pode funcionar como "cola" aumentando a resistência do osso à fratura. As proteínas não colágenas também facilitam a nucleação de cristais, seu crescimento, forma e orientação (QIU et al., 2004; POUNDARIK et al., 2009) e, consequentemente, estão envolvidas na formação de blocos de construção fundamentais do tecido ósseo, que são as fibrilas de colágeno mineralizadas (SROGA, 2012).

A estrutura óssea é mantida por uma interação entre os osteoblastos e osteoclastos, onde os primeiros estão associados com a deposição de matriz óssea e formação óssea, e os últimos com a reabsorção óssea. (WATROUS \& ANDREWS, 1989). O osso deve apresentar algumas características como rigidez, flexibilidade e leveza para tornar possível as funções básicas do esqueleto como a sustentação e o movimento. Em particular, o tecido ósseo possui uma propriedade específica que a distingue de outros tecidos, que é a capacidade de responder aos estímulos fisiológicos e patológicos por meio da indução da reabsorção e formação de novo osso (CAETANO-LOPES et al., 2007).

Os mecanismos de regulação do metabolismo ósseo são complexos, pouco compreendidos e envolvem interações entre as células do osso, matriz óssea, além de fatores locais e sistêmicos. (WATROUS \& ANDREWS, 1989).

Ao longo da vida, o osso é continuamente renovado em uma sequência caracterizada pela remoção de osso pelos osteoclastos e sua substituição pelos osteoblastos (PARFITT, 2008; KHOSLA et al., 2010). Esse processo, chamado de remodelamento ósseo possui 3 fases: a fase de reabsorção e a de reversão, ambas de curto período, é seguida da fase de formação, de período mais prolongado e caracterizada pela produção de matriz celular com deposição de camadas progressivas de osteoblastos. Desta forma, alterações que acarretem na falência em produzir massa óssea durante o crescimento e desenvolvimento, ou na excessiva reabsorção óssea e/ou na formação inadequada do osso em resposta à reabsorção óssea durante o remodelamento são determinantes de várias doenças ósseas (PARFITT et al., 1995). O esquema do remodelamento ósseo está representado na Figura 1. 


\subsubsection{Células do tecido ósseo}

Os osteoblastos têm um papel fundamental na criação e manutenção da arquitetura esquelética; estas células são responsáveis pela deposição de matriz óssea e pela regulação dos osteoclastos. Os osteoblastos são células mononucleares especializadas (CANHÃO et al., 2005) que, quando ativadas, um grande complexo de Golgi e um retículo endoplasmático rugoso abundante são visíveis. Além disso, os osteoblastos formam junções com osteoblastos adjacentes e possui regiões da membrana plasmática especializadas no tráfego vesicular e secreção (MACKIE, 2004). Como se diferenciam eles adquirem a capacidade de secretar matriz óssea (GORI et al., 2000). Finalmente, alguns osteoblastos ficam presos na sua própria matriz óssea que dá origem aos osteócitos que, gradualmente, param de secretar a matriz osteóide (MACKIE, 2004). Os osteócitos são as mais abundantes células do osso; estas se comunicam umas com as outras e com o meio circundante por meio de extensões de sua membrana plasmática (MANOLAGAS, 2000; KNOTHE et al., 2004). Portanto, osteócitos são orientados a atuar como mecanosensores, instruindo os osteoclastos onde e quando reabsorvem osso e os osteoblastos onde e quando se formam novo osso (MANOLAGAS, 2000; SEEMAN \& DELMAS, 2006).

Os osteoclastos são células gigantes multinucleadas associados à reabsorção óssea. Essas células geralmente são derivadas da fusão de células progenitoras mononucleares de células tronco hematopoiéticas (ASH et al., 1980; SCHEVEN et al., 1986). A reabsorção óssea está associada com o aumento da produção de enzimas citoplasmáticas, como fosfatase ácida, esterase não específica (IBBOTSON et al., 1984) e anidrase carbônica e, com aumento da atividade fagocitária pelos osteoclastos (GAY et al., 1983).

A osteoclastogênese é regulada pelo contato célula-célula entre osteoblastos, células estromais e progenitores de osteoclastos, no microambiente ósseo. Alguns mediadores envolvidos na diferenciação de osteoclastos incluem o receptor activator of nuclear factor- $k B$ ligand (RANKL), o receptor activator of nuclear factor-kB (RANK) e o receptor solúvel osteoprotegerina (OPG) (LACEY et al., 1998). O RANKL interage com o seu receptor RANK, expresso na superfície de préosteoclastos, induzindo a diferenciação e fusão destas células. A OPG, secretada pelos osteoblastos, interage na ligação RANK-RANKL, bloqueando-a por meio de sua 
ligação ao RANK, prevenindo assim a diferenciação e ativação dos osteoclastos. (LACEY et al., 1998; CAETANO-LOPES et al., 2007). Camundongos RANKLknockout apresentaram grave osteopetrose, com completa ausência de osteoclastos (KONG et al., 1999). Desta maneira, o equilíbrio entre RANKL e OPG determina a formação e atividade dos osteoclastos. (LACEY et al., 1998; CAETANO-LOPES et al., 2007).

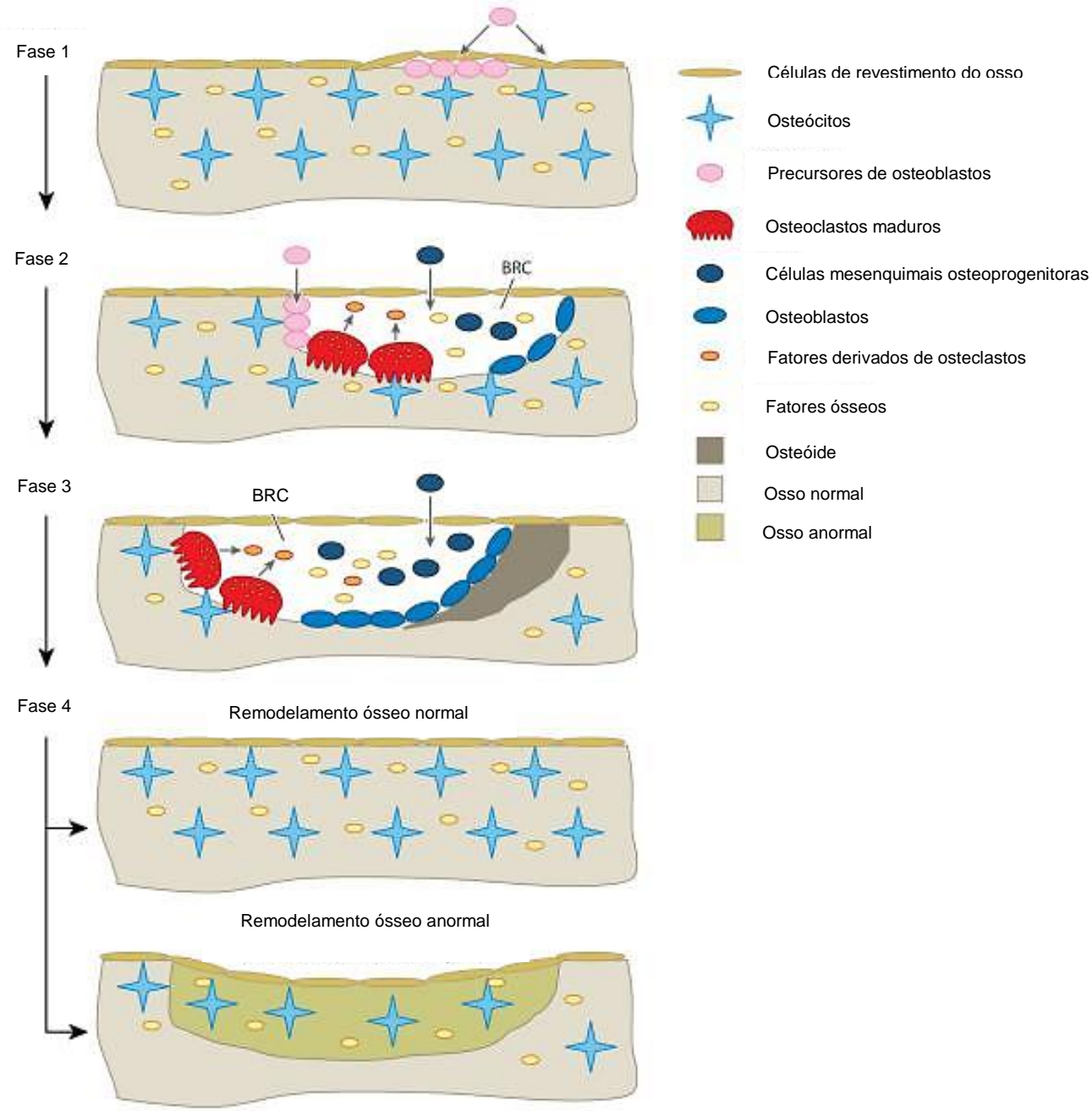

Fonte: Feng \& McDonald, 2011.

Figura 1 - Modelo de remodelamento ósseo. O processo de remodelação consiste em quatro fases distintas mas que ocorrem simultaneamente: Fase 1: iniciação/ativação da remodelação óssea em um local específico. Fase 2: reabsorção óssea e recrutamento de células-tronco mesenquimais (MSCs) e osteoprogenitoras. Fase 3: diferenciação dos osteoblastos e síntese de matriz osteóide. Fase 4: mineralização da matriz osteóide e conclusão da remodelação óssea. Na remodelação óssea normal, não há nenhuma alteração na massa óssea e de força depois de cada ciclo de remodelação. Porém, na remodelação óssea anormal em certas condições patológicas, tais como a osteoporose, provoca redução da massa óssea e de força. BRC: compartimento de remodelação óssea. 


\subsection{MARCADORES DE FORMAÇÃO ÓSSEA E DIFERENCIAÇÃO OSTEOGÊNICA}

Durante o desenvolvimento do esqueleto, ocorre a diferenciação de osteoblastos e a deposição de matriz óssea, processo altamente coordenado por interações entre fatores endócrinos, parácrinos e autócrinos (DATTA et al., 2008).

A diferenciação osteogênica é estimulada por diversos fatores como, por exemplo, as proteínas morfogenéticas do osso (BMPs) (KOMORI et al., 1997; OTTO et al., 1997). As BMPs são uma classe de morfógenos pertencentes a superfamília do fator de crescimento transformador-beta (TGF- $\beta$ ), que foram originalmente descobertas devido as suas capacidades de indução óssea (CANALIS et al., 2003; CHEN et al., 2004; GRANJEIRO et al., 2005; REDDI \& REDDI, 2009). A família BMP contém mais de 20 membros, com uma grande variedade de funções, incluindo a padronização e desenvolvimento embrionário (DALE \& JONES, 1999), renovação e diferenciação de células-tronco (WATABE \& MIYAZONO, 2009) e homeostase do tecido (ANDERSON et al., 2009). As BMPs, como fatores de crescimento autócrinos e parácrinos, são sintetizadas e liberadas pelos osteoblastos e armazenadas na matriz óssea (YAMAGUCHI, 1995; ROSEN \& WOZNE, 2002; AGAS et al., 2013). Além das BMPs, há a via das Wnts (Drosophila Wingless and mouse Int-1), segunda principal via de sinalização envolvida na osteoblastogênese. As Wnts são categorizadas por seu sinal de forma canônica ou não-canônica. O sinal da via canônica é por meio da ß-catenina, uma proteína de sinalização, que pode introduzir o núcleo e interagir com o fator de transcrição de células T / Fator estimulador linfoide (TCF / LEF) para ativar a transcrição de genes alvo. Enquanto que a sinalização das Wnt não-canônica não requer a $\beta$-catenina (DAVIS \& ZUR NIEDEN, 2008) ou seja, sinalizam por meio de proteínas como a fosfolipase $C$ (PLC) e fosfoquinase $C(P K C)$, que regula a liberação de cálcio intracelular (via Wnt/Ca $\left.{ }^{2+}\right)(K O H N \&$ MOON, 2005; LIN \& HANKENSON, 2011).

Além disso, alguns fatores de transcrição foram descritos como essenciais na formação óssea. Nesse sentido, o fator de transcrição, do inglês Runt related transcription factor 2 (Runx2) é fundamental para a diferenciação de osteoblastos, uma vez que camundongos depletados do gene Runx2 não têm osteoblastos e ossos formados (KOMORI et al., 1997; OTTO et al., 1997). 
O Runx2, também conhecido como core binding factor 1 (Cbfa1) e anteriormente como acute myeloid leukemia 3 (AML3) foi identificado como o fator de transcrição mais importante para a diferenciação e controle dos osteoblastos. Pertencente à família Runt de fatores de transcrição que são expressos por células mesenquimais e também no início do desenvolvimento do esqueleto além de estar presente em osteoblastos ao longo de sua diferenciação (LIAN et al., 2004; MARIE, 2008). Osteoblastos expressam altos níveis de expressão de Runx2 in vitro e in vivo. Além disso, as BMPs regulam positivamente a expressão gênica de Runx2 in vitro (DUCY et al., 1997).

Há vários marcadores bioquímicos que caracterizam a formação e a reabsorção óssea. Os primeiros incluem a fosfatase alcalina óssea (ALP), uma enzima produzida pelos osteoblastos e essencial para a mineralização óssea (YOUNG et al., 1992; BIANCO et al., 1993; MUNDLOS \& OLSEN, 1997). A ALP está entre os primeiros genes funcionais expressos no processo de calcificação e, dessa forma, está envolvida nos processos iniciais da mineralização. Portanto, a ALP é expressa precocemente no desenvolvimento e observada na superfície da célula e em vesículas de matriz (GOLUB \& BOESZE-BATTAGLIA, 2007).

Além disso, várias proteínas da matriz extracelular incluindo a osteocalcina, osteopontina, colágeno tipo I, sialoproteína e proteoglicanas são secretadas e depositadas por osteoblastos maduros, os quais são alinhados sobre a superfície do osso (YOUNG et al., 1992; BIANCO et al., 1993; MUNDLOS \& OLSEN, 1997).

A presença de vias de sinalização intracelulares confere às células a capacidade de acoplar a ativação de receptores de membrana à alvos intracelulares críticos, gerando respostas coordenadas, tanto na manutenção da homeostase celular quanto na ocorrência de processos biológicos mais complexos, tais como proliferação, diferenciação celular e apoptose $(\mathrm{KOLCH}, 2000)$. Nesse sentido, as proteínas quinases ativadas por mitógeno (MAPKs) formam um antigo conjunto de serina/treonina-quinases que medeiam respostas de uma variedade de estímulos. As MAPKs estão presentes em todos os organismos eucarióticos, incluindo fungos, plantas, Drosophila e mamíferos. Tais proteínas passaram por um processo de diversificação durante a evolução inicial da vida dos vertebrados, o que sugere que as MAPKs tem sido fortemente adaptadas a partir de suas origens para regular as funções específicas dos vertebrados (LI et al., 2011). Além disso, moléculas 
acessórias, tais como as fosfatases, que servem para regular a sinalização MAPK, também parecem ter ganho da diversidade de eucariotos superiores, e estas concedem complexidade suficiente para o sistema de MAPK para regular muitas funções distintas do tecido (MORRISON \& DAVIES, 2003). Trabalhos recentes identificaram as MAPKs que regulam a formação de osso pelos osteoblastos, demonstrando que essas proteínas são transdutoras de sinais centrais na regulação da massa óssea (GE et al., 2007; GREENBLATT et al., 2010; ZOU et al., 2011). Estas observações assumem particular importância uma vez que a maioria dos ligantes secretados que regulam a atividade dos osteoblastos parece sinalizar em parte, por meio de vias MAPK. Assim, mais estudos sobre os caminhos da MAPK em osteoblastos são fundamentais para a compreensão da regulação fisiológica da massa óssea (GREENBLATT et al., 2013). Portanto, a via das proteínas quinases ativadas por mitógeno (MAPKs) é uma das principais vias de sinalização envolvidas em diversas funções celulares, incluindo a proliferação e diferenciação celular $(\mathrm{KOLCH}, 2000)$. Estas compreendem as vias denominadas ERK 1,2 (quinase regulada por sinal extracelular 1,2), p38 e JNK (SHINDELER \& LITTLE, 2006).

A ERK possui duas isoformas, a ERK1 (MAPK3) e ERK2 (MAPK1), ambas expressas em osteoblastos e é ativada pela MEK (Mitogen-activated protein kinase) 1 e MEK2. Camundongos com deleção germinativa de ERK1 e uma deleção condicional de Erk2 (Erk1 ${ }^{-/}$Erk2 ${ }^{\text {Prx1 }}$ camundongo), tiveram redução substancial na mineralização óssea, o que demonstra a importância da ERK para o processo de mineralização em osteoblastos (MATSUSHITA et al., 2009; GREENBLATT et al., 2013). O papel fisiológico da via das MAPK em osteoblastos ainda não está completamente elucidado. Trabalhos na literatura suportam a teoria de que a ativação desta via é estimulatória durante a diferenciação osteogênica, enquanto outros demonstram o contrário (SCHINDELER \& LITTLE, 2006).

Ge et al. (2007) demonstraram o papel da via ERK-MAPK na função dos osteoblastos in vivo. Utilizando-se de estratégias transgênicas envolvendo expressão seletiva de formas ativas e negativas do intermediário da MAPK (MEK1) em osteoblastos, os autores demonstraram que a ativação desta via estimulou a diferenciação osteogênica e o desenvolvimento do esqueleto por mecanismo dependente da ativação de Runx-2. 
Li et al. (2010) sugerem que a ERK em sua forma ativada pode ligar-se a promotores de osteocalcina (OCN) e sialoproteina óssea (BSP) em osteoblastos por meio da associação de ERK e Runx2, levantando a ideia de que a atividade de ERK pode ser regulada diferencialmente no contexto de promotores específicos dos osteoblastos. Porém, mais pesquisas são necessárias para identificar a variedade de genes ligados a ERK e a importância funcional desta associação.

\subsection{FOTOTERAPIA NA FORMAÇÃO ÓSSEA}

Os laseres são classificados em baixa e alta potência, dependendo do comprimento de onda. O laser de baixa potência (LLLT) ou de baixa intensidade possui comprimentos de onda entre 488 e 904nm no espectro eletromagnético, entre a faixa de luz visível e próximo ao infravermelho (BABAPOUR et al., 1995). Acima de $904 \mathrm{~nm}$ estão os laseres de alta potência. Essa variação no comprimento de onda irá influir no efeito biológico produzido por cada tipo de radiação (RATZ, 1995; WALSH, 1997).

O comprimento de onda da irradiação com laser difere de acordo com a natureza química do meio utilizado como emissor de radiação. Existem três tipos de meios: sólidos (rubi 694nm), líquidos (corantes orgânicos que eluem-se em solventes) e gasosos (hélio-neônio 632,8nm e gás carbônico 10.600nm) (CARROLL \& HUMPHREYS, 2006).

Em relação ao grupo dos meios sólidos existem os semicondutores, onde faz parte os laseres: arseneto de gálio (904nm), arseneto de gálio-alumínio (660, 820, 870, 880nm), alumínio-gálio-índio-fósforo (660, 780nm) (BABAPOUR et al., 1995).

Devem ser observados os seguintes parâmetros para obtenção de uma resposta biológica efetiva: densidade de energia (dose ou fluência), expressa em Joules por centímetro quadrado $\left(\mathrm{J} / \mathrm{cm}^{2}\right)$ é o parâmetro que avalia a possibilidade de estímulo ou inibição dos efeitos terapêuticos do laser (RIBEIRO \& ZEZELL, 2004), densidade de potência (intensidade) que é a potência de saída de luz por unidade de área medida em Watts por centímetro quadrado $\left(\mathrm{W} / \mathrm{cm}^{2}\right)$, ou seja, é a quantidade de energia por unidade de área transferida ao tecido, além disso, o comprimento de onda, o tipo de regime de aplicação do laser e a quantidade de irradiações são parâmetros que devem ser considerados (DAMANTE, 2007). 
A absorção da radiação pelo tecido ou célula ocorre de maneira seletiva por moléculas sensíveis a determinados comprimentos de onda (WELCH et al., 1989; CARROL \& HUMPHREYS, 2006). Tais moléculas são chamadas cromóforos. Para comprimentos de onda do espectro dos laseres de baixa potência, os cromóforos são tipicamente metais ou moléculas que contém átomos metálicos em sua estrutura, como por exemplo, o grupo heme das globinas (hemoglobina, mioglobina) e dos citocromos (KARU, 1999). A energia emitida nesse tipo de laser é tão baixa que não ocorre evento térmico e a elevação da temperatura não ultrapassa 0,5ㄷ (BABAPOUR et al., 1995). No espectro dos laseres de alta potência, a radiação é absorvida principalmente pelas moléculas de água do tecido. Nesse último caso, a absorção da radiação por moléculas de água, juntamente com a alta concentração de energia emitida, faz com que a energia seja convertida em calor (BABAPOUR et al., 1995).

A fotobiomodulação é uma tecnologia onde se utiliza a luz emitida do laser para modular certas funções celulares e, ocorre a partir da absorção de radiação do laser de baixa potência por cromóforos celulares (BABAPOUR et al., 1995). Embora os mecanismos envolvidos não estejam completamente compreendidos, há evidências de que o principal evento seja o aumento do metabolismo oxidativo por meio da foto-oxidação do citocromo c, uma proteína da membrana mitocondrial de mamíferos que é transportadora de elétrons na fase de síntese de ATP (KARU et al., 2004; EELLS et al., 2004; KARU et al., 2005; WINTERLE \& EINARSDÓTTIR, 2006). Esses dados corroboram com os de Pastore et al. (2000) nos quais observaram que a irradiação com LLLT aumentou o transporte de elétrons e com os de Karu et al. (1995) os quais observaram aumento da síntese de ATP.

Além dos laseres vermelho e infravermelho, os quais emitem luz coerente e colimada, os denominados Diodos Emissores de Luz (LEDs) são semelhantes aos laseres de baixa potência, diferenciando-se na formação da luz. Enquanto o diodo de um laser está contido dentro de uma cavidade ressonântica, onde promove fótons que são amplificados pela emissão estimulada da luz e proporciona feixes de luz coerentes e colimados, o LED é desprovido dessa cavidade óptica, e a luz emitida não apresenta coerência e colimação, mas produz uma banda de espectro eletromagnético próxima a do laser (CORAZZA et al., 2007). Um diodo emissor de luz é um tipo especial de díodo semicondutor que emite luz quando conectado a um circuito elétrico. Os dispositivos do diodo emissor de luz geralmente contêm nitrato de gálio, índio ou 
nitreto como elemento semicondutor que se sobrepõem melhor do que as fontes de luz convencionais (VREMAN et al., 1998). Os LEDs tem-se mostrado eficazes em experimentos in vitro e em modelos animais (VREMAN et al., 1998; CHANG et al., 2005; TRIDENTE \& DE LUCA, 2012).

Os laseres de baixa intensidade são caracterizados como agentes terapêuticos, por apresentarem propriedades analgésicas (TAM, 1999; SAKURAI et al., 2000), por promoverem aumento da microcirculação local e permeabilidade vascular (KARU, 1989; KREISLER et al., 2003; HENRIQUES et al., 2010), além de acelerarem a cicatrização de feridas (TUNÉR \& HODE, 1996), características que em conjunto conferem ao paciente um pós-operatório mais confortável, com possibilidade de redução do uso de medicamentos (DAMANTE, 2007). Os efeitos do laser na cicatrização de feridas têm sido atribuídos ao estímulo de vários sistemas biológicos como aumento da proliferação de fibroblastos e sua atividade celular (MESTER et al., 1985; SOUNDRY et al., 1988; ALMEIDA-LOPES et al., 2001; KREISLER et al., 2002; PEREIRA et al., 2002; MARQUES et al., 2004; AZEVEDO et al., 2006; FUJIHARA et al., 2006; EDUARDO et al., 2007), bem como aumento da produção de colágeno (PEREIRA et al., 2002; MARQUES et al., 2004), da síntese de DNA (LOEVSCHALL \& ARENHOLT-BINDSLEV, 1994; SKINNER et al., 1996), modulação positiva da produção dos fatores de crescimento (DAMANTE, 2007) e redução na produção de prostaglandinas (SAKURAl et al., 2000). Além dessas propriedades, pesquisas recentes demonstram que a fototerapia representa uma das várias ferramentas utilizadas com o objetivo de estimular e/ou aumentar a formação óssea (MERLI et al., 2005; NISSAN et al., 2006; KIM et al., 2009; RIBEIRO \& MATSUMOTO, 2008). Essas características podem ser positivamente associadas também às cirurgias ósseas otimizando os processos operatórios nas áreas ortopédicas e odontológicas.

O efeito dos laseres em culturas de células ósseas é bastante estudado. Estudos recentes, utilizando osteoblastos obtidos de calvária de ratos em período embrionário fetal, mostraram que a irradiação com laser, aumentou a formação de nódulos ósseos (OZAWA et al., 1995, 1998). Além disso, Fujimoto et al. (2010) demonstram que a terapia com laser, na densidade de energia de 0,96-3,82 J/ $\mathrm{cm}^{2}$, em células de linhagem murina MC3T3-E1 resultou no aumento da mineralização da mesma por meio da modulação das BMPs. Da Silva et al. (2012), investigaram o efeito da LLLT (dose de $160 \mathrm{~J} / \mathrm{cm}^{2}$ ) em osteoblastos derivados da sutura mediana palatina 
de ratos após expansão rápida da maxila, no qual observou-se o aumento da atividade de ALP, aumento da mineralização e da expressão de mRNA de ALP, Runx2, osteocalcina, colágeno tipo I e sialoproteína, quando comparados ao grupo controle. Aleksic et al. (2010) relataram que a irradiação com laser (dose de 0,7 a 17,2 J/cm²) aumenta a proliferação de osteoblastos da linhagem MC3T3-E1 por meio da ativação da via de sinalização MAPK-ERK.

Trabalho do nosso grupo de pesquisa demonstrou que a aplicação pontual de infravermelho e laser vermelho (na dose de $5 \mathrm{~J} / \mathrm{cm}^{2}$ ) por 8 segundos em préosteoblastos da linhagem MC3T3-E1 aumentou significativamente a viabilidade celular e atividade da fosfatase alcalina e metaloproteinases de matriz 2 (MMP-2), enquanto não modulou a atividade das metaloproteinases 9 (MMP-9) sugerindo que eles podem apresentar efeito promissor na regeneração óssea (OLIVEIRA et al., 2013). Além disso, foi demonstrado que o laser pulsado de baixa intensidade aplicado às culturas de osteoblastos, obtidos de calvária de ratos ou de linhagem, induz aumento da atividade mitocondrial (PIRES OLIVEIRA et al., 2008), proliferação (SHIMIZU et al., 2007; RENNO et al., 2009; XU et al., 2009; FÁVARO-PÍPI et al., 2011), síntese de DNA e RNA (FÁVARO-PÍPI et al., 2011), diferenciação (PIRES OLIVEIRA et al., 2008), enquanto promove a inversão da relação RANKL/OPG, sugerindo inibição da diferenciação osteoclástica (XU et al., 2009).

Estudos realizados com osteoblastos humanos oriundos de osso mandibular e cultivados sob disco de titânio após irradiação, mostraram que a LLLT (GaAlAs) nas doses de 1,5 ou $3 \mathrm{~J} / \mathrm{cm}^{2}$, aumenta a proliferação, diferenciação e a produção de TGF- $\beta 1$ (Fator de crescimento transformador- $\beta 1$ ), portanto o laser estimula a formação óssea por meio da sinalização mediada por TGF- $\beta$, sugerindo que a irradiação modula a atividade das células e os tecidos circundantes do material de implante (KHADRA et al., 2005).

Stein et al. (2005) demonstraram que a irradiação com laser He-Ne 632 $\mathrm{nm} ; 10 \mathrm{~mW}$ ) em osteoblastos derivados de osso humano, quando cultivados na superfície de titânio, promoveu aumento do número de células, aumento da atividade de ALP e da expressão de osteopontina e sialoproteína óssea (PETRI, 2008). No entanto, os mecanismos intracelulares envolvidos no efeito dos laseres nas células ósseas ainda não foram completamente elucidados. 
Nas últimas décadas, alguns pesquisadores demonstraram a aplicabilidade dos LEDs terapêuticos em estudos experimentais e clínicos revelando a eficiência fotobiomoduladora celular semelhante à do laser de baixa intensidade (CORTI et al., 2006; SACONO et al., 2008). Diante das evidencias demonstradas pela National Aeronautics and Space Administration (NASA) quanto à aplicação do LED, a Food and Drug Administration (FDA) aprovou testes clínicos da aplicação de LEDs na cicatrização de feridas em humanos, devido ao insignificante risco de lesões na pele (WHELAN et al., 2001; VOLPATO, 2009).

A razão do aumento de pesquisas buscando comparar os efeitos da fototerapia com o uso de LEDs em substituição ao laser é que, diferentemente do comprimento de onda, a sua coerência ou sua falta não é um fator importante para o efeito biomodulador (SMITH, 1991). Assim, os LEDs apresentam grande potencial de ação, além de apresentarem menores custos que os laseres. Karu (1989), analisando os resultados clínicos sob o aspecto das diferentes fontes de luz, afirmou que não se pode concluir que os lasers têm maior potencial terapêutico que os LEDs. Em experimento desenvolvido em nível celular, evidenciou-se que luz não coerente com o mesmo comprimento de onda, intensidade e tempo de irradiação promoveram o mesmo efeito biológico. $\mathrm{O}$ autor afirma ainda que a propriedade de coerência do laser não é importante quando a região irradiada é superficial ou pouco profunda (KARU, 1989). Portanto, os efeitos da fototerapia com diferentes fontes de luz parecem promissores nesse campo. Kim et al. (2009) sugeriram um aumento da diferenciação osteogênica de células tronco mesenquimais por meio da irradiação com LED.

Além disso, osteoblastos da calota craniana de ratos cultivados em superfícies de implantes foram irradiados com LED (660nm) por uma ou três vezes resultando em aumento significativo do número de células (CANKAYA et al., 2011). Peng et al. (2012) investigaram o efeito do LED, nas doses de 0,1, 2 e $4 \mathrm{~J} / \mathrm{cm}^{2}$, na diferenciação de células mesenquimais da medula óssea com ou sem suplementos osteogênicos. No grupo sem suplementos osteogênicos, o LED, em todas as doses, estimulou significativamente a proliferação celular. No grupo com suplementos osteogênicos, o LED aumentou a atividade da fosfatase alcalina e formação de nódulos mineralizados, além de estimular a expressão de Bglap (bone gammacarboxyglutamic acid-containing protein), gene da osteocalcina e Runx2, mas diminuiu a proliferação celular. Embora seja bastante descrito na literatura o efeito positivo da 
fototerapia na osteogênese, os parâmetros para a sua utilização como a dose e o regime de aplicação não são completamente compreendidos até o momento. 


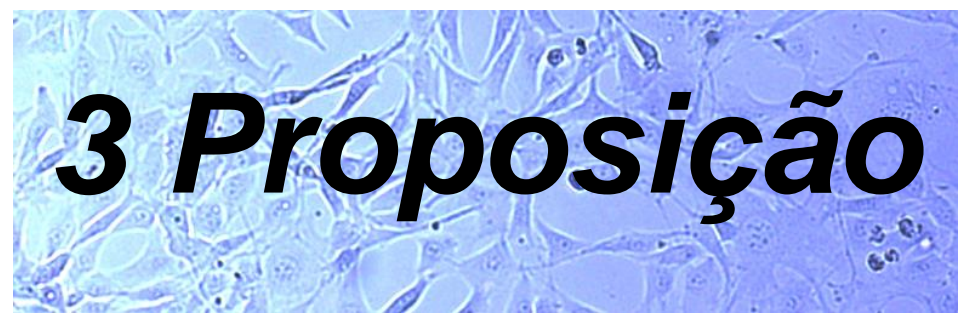





\section{PROPOSIÇÃO}

O objetivo deste trabalho foi avaliar a influência dos laseres de baixa potência e diodo emissor de luz na proliferação e diferenciação de osteoblastos humanos, além dos mecanismos intracelulares induzidos pelos mesmos nestas células.

Objetivos específicos:

- Avaliar o efeito de diferentes fototerapias na viabilidade e/ou proliferação celular e ativação de ERK;

- Quantificar o efeito dos diferentes espectros na diferenciação osteogênica por meio da atividade enzimática da fosfatase alcalina e da expressão gênica de colágeno tipo I e SPARC;

- Analisar o potencial de mineralização dos osteoblastos humanos (HOAL) frente aos estímulos com as diferentes fototerapias. 


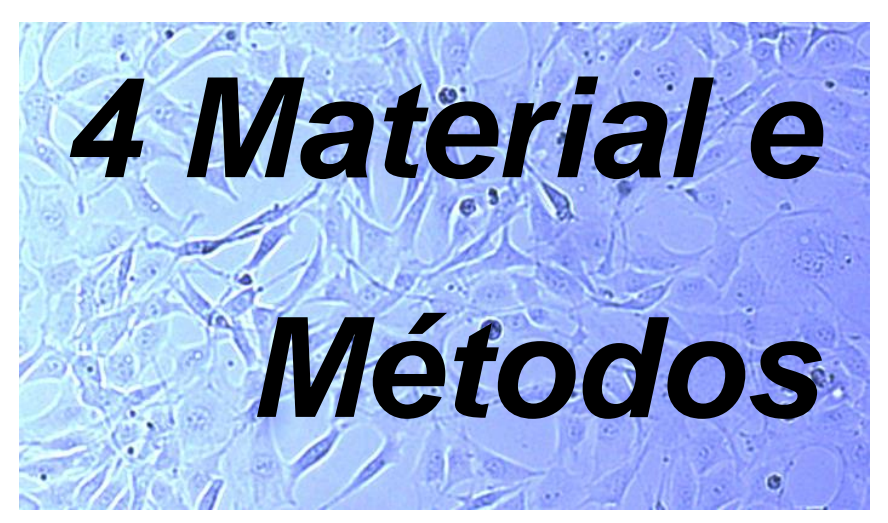





\section{MATERIAL E MÉTODOS}

Inicialmente foram realizados ensaios de caracterização dos osteoblastos humanos (HOAL) visando conhecer o fenótipo e função uma vez que são oriundos de explantes, constituindo portanto, linhagem primária, em comparação com préosteoblastos imortalizados de linhagem murina (MC3T3-E1), células bastante estudadas. Após testes preliminares, foram realizados os ensaios com a aplicação dos diferentes tipos de laser e LED em osteoblastos humanos (HOAL).

\subsection{CULTIVO DE OSTEOBLASTOS HUMANOS (HOAL) E MC3T3-E1}

Os osteoblastos humanos (HOAL) (Figura 2A) foram doados pelo grupo de pesquisa do Prof. Dr. José Mauro Granjeiro e tiveram a aprovação do comitê de ética em Pesquisa da Faculdade de Medicina da Universidade Federal FluminenseUFF (CEP CMM/HUAP n 232/08) e aprovação do comitê de ética em Pesquisa com Seres Humanos da Faculdade de Odontologia de Bauru ( $n^{\circ}$ 95/2011) (Anexo 1). As células foram coletadas no Hospital Universitário Antônio Pedro-UFF a partir de explantes ósseos obtidos em cirurgias ortopédicas (artroplastias). Os explantes foram tratados em colagenase $0,25 \%$ por 2 horas e depois acondicionados em garrafas plásticas de $25 \mathrm{~cm}^{2}$ em meio de cultura DMEM (Nutricell) suplementado com 10\% SFB. Células de linhagem murina MC3T3-E1 (ATCC - American Type Culture Collection) (Figura 2B) foram cultivadas em meio MEM (Nutricell) contendo nucleosídeos adenosina, citidina, deoxycitidina, deoxyadenosina, deoxyguanosina, guanosina, timidina e uridina (Sigma) e 10\% SFB (ZAMBUZZI et al., 2009). Para a expansão, ambas células foram tripsinizadas com EDTA (1 mM) e tripsina $(0,25 \%)$ por 5 minutos a $37^{\circ} \mathrm{C}$ seguida de inativação da tripsina com meio contendo SFB. Após centrifugação a $500 \mathrm{~g}$ por 10 minutos, o pellet foi ressuspendido em meio MEM 10\%SFB (MC3T3-E1) e DMEM 10\% SFB (HOAL) e cultivadas em garrafas na densidade de $0,5 \times 10^{4}$ células $/ \mathrm{cm}^{2}$. Para a confecção do banco de células, as mesmas foram congeladas em meio contendo $20 \%$ SFB e $5 \%$ DMSO (dimetilsulfóxido) ( $1 \mathrm{x}$ $1^{6}$ ) a $-80^{\circ} \mathrm{C}$ por 24 horas e após esse tempo, armazenadas em nitrogênio líquido. Para os experimentos, alíquotas foram descongeladas e cultivadas (passagens entre 10 e 15), conforme descrito acima. As trocas de meio foram realizadas a cada 3 dias. 


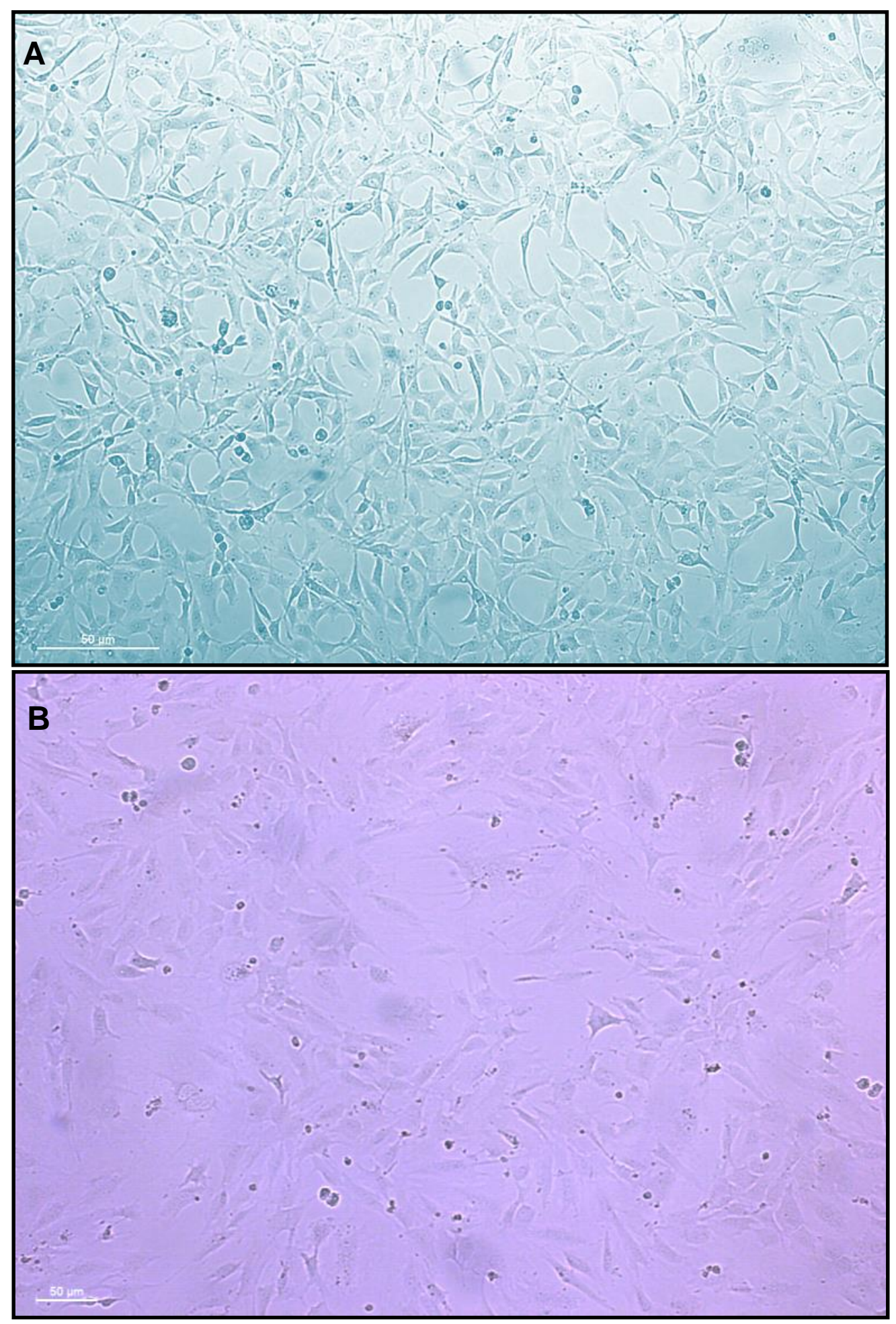

Figura 2 - Fotomicrografia dos tipos celulares. (A) Osteoblastos humanos (HOAL) e (B) Préosteoblastos de camundongo (MC3T3-E1). Microscópio de fase invertida LEICA/ DM IRBE, objetiva $10 \mathrm{X}$. 


\subsection{FOTOTERAPIA}

As células HOAL foram irradiadas pontualmente com laser de baixa potência de Arseneto de Gálio e Alumínio (GaAlAs), no comprimento de onda de luz visível de 660nm (laser vermelho) ou 780nm (infravermelho), potência de $40 \mathrm{~mW}$ e densidade de energia de $10 \mathrm{~J} / \mathrm{cm}^{2}, 20 \mathrm{~J} / \mathrm{cm}^{2}$ e $50 \mathrm{~J} / \mathrm{cm}^{2}$ (modelo Twin Flex Evolution da MMOptics Ltda - São Carlos, SP) e diodo emissor de luz (LED) (637 $\pm 15 \mathrm{~nm} ; 40 \mathrm{~mW}$; $10 \mathrm{~J} / \mathrm{cm}^{2}, 20 \mathrm{~J} / \mathrm{cm}^{2}$ e $50 \mathrm{~J} / \mathrm{cm}^{2}$ ) (protótipo CePOF/IFSC/USP - São Carlos, SP) (Figura 3). A aplicação do laser e do LED foi feita por baixo da placa. Em placas de 96 poços, a estimulação do laser foi realizada com a ponteira estática (parada) por apresentar diâmetro semelhante ao do poço $(6,4 \mathrm{~mm})$. Em placas de 24 poços a irradiação foi feita com movimentos circulares pelo poço apresentar diâmetro maior $(15,4 \mathrm{~mm})$ que a ponteira do laser. As doses de 10, 20 e $50 \mathrm{~J} / \mathrm{cm}^{2}$ que correspondem a 10, 20 ou 50 segundos de estimulação, respectivamente, foram definidas nos primeiros ensaios de viabilidade com o intuito de verificar a dose de maior estimulação. Portanto, nos experimentos posteriores, as células HOAL foram irradiadas somente com doses que apresentaram maior viabilidade celular (10 e $50 \mathrm{~J} / \mathrm{cm}^{2}$ ), verificadas previamente nos ensaios de MTT e cristal violeta (CV). Para os ensaios de viabilidade e proliferação, as células receberam até 2 irradiações (após 24 horas de adesão celular) com intervalo de 6 horas. Para os ensaios de diferenciação e mineralização, as células receberam apenas uma irradiação a cada seis dias. 


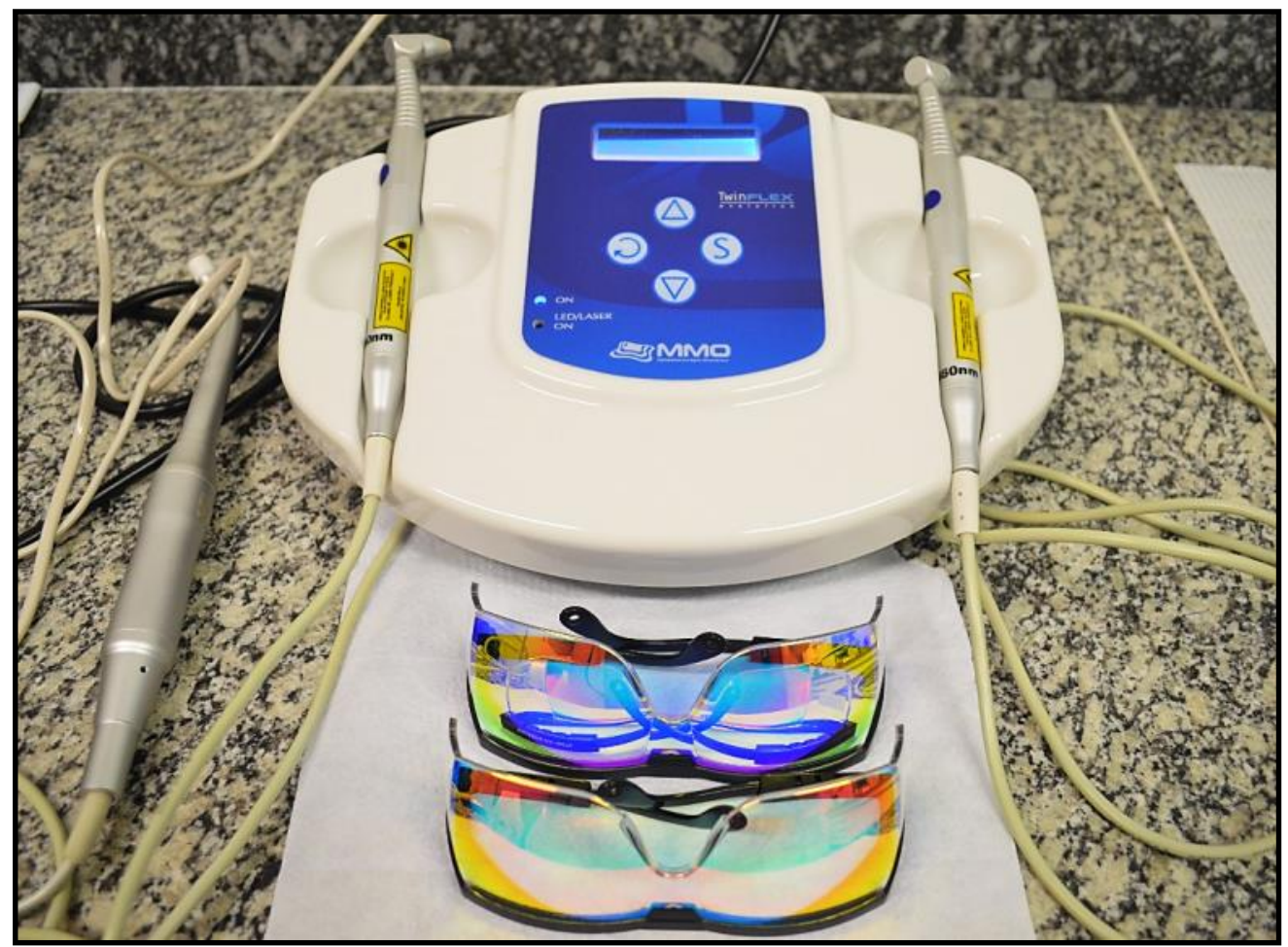

Figura 3 - Diodo emissor de luz (637 $\pm 15 \mathrm{~nm})$ (à esquerda) e Laser de baixa potência: laser vermelho $(660 \mathrm{~nm})$ e laser infravermelho $(780 \mathrm{~nm})$ (à direita).

\subsection{ENSAIO DE VIABILIDADE CELULAR}

A viabilidade celular foi avaliada após 24, 48 e 72 horas a partir da última aplicação das fototerapias, por ensaio de redução do MTT e CV, descritos nos itens a seguir. O plaqueamento celular foi realizado em placas de 96 poços na densidade de $2 \times 10^{3}$ células/poço em meio DMEM/10\% SFB. Após a adesão, as células foram cultivas em meio de cultura contendo SFB a 5\%, fazendo com que as células entrem em sub-estímulo para proliferação sem provocar morte celular, evidenciando assim, os efeitos da fototerapia (VOLPATO, 2009). O delineamento experimental foi feito como se segue: (1) As células aderentes foram irradiadas com uma aplicação de cada fototerapia; (2) As células aderentes foram irradiadas por duas vezes com 6 horas de diferença entre as irradiações. Para cada condição, o grupo de controle não recebeu nenhum tratamento de fototerapia, porém, sofreu as mesmas condições experimentais. 


\subsubsection{Redução do MTT}

O ensaio da redução do MTT (brometo de 3-(4,5-dimetiltiazol-2-yl)-2,5difeniltetrazólio) (Figura 4) analisa a atividade mitocondrial das células (MOSMANN, 1983). O MTT, solúvel em água, é convertido em um composto chamado formazan, o qual é insolúvel. O formazan, de cor azul purpúrea, é solubilizado e, então, sua concentração é determinada pela densidade óptica no espectrofotômetro (FLUOstar OPTIMA, BMG Labtech, Offenburg, Alemanha).

Após 24, 48 e 72 horas da irradiação, o sobrenadante foi removido e então as células foram lavadas com PBS 1X. Foi adicionado $110 \mu \mathrm{L}$ da solução contendo $0,5 \mathrm{mg}$ de $\mathrm{MTT} / \mathrm{mL}$ em meio com vermelho de fenol. As células foram incubadas a 37은 C por 4 horas e protegidas da luz. Após esse tempo foi adicionado em cada poço $200 \mu \mathrm{L}$ de DMSO (dimetilsulfóxido). A leitura das placas foi realizada no Leitor de ELISA com filtro de $562 \mathrm{~nm}$.

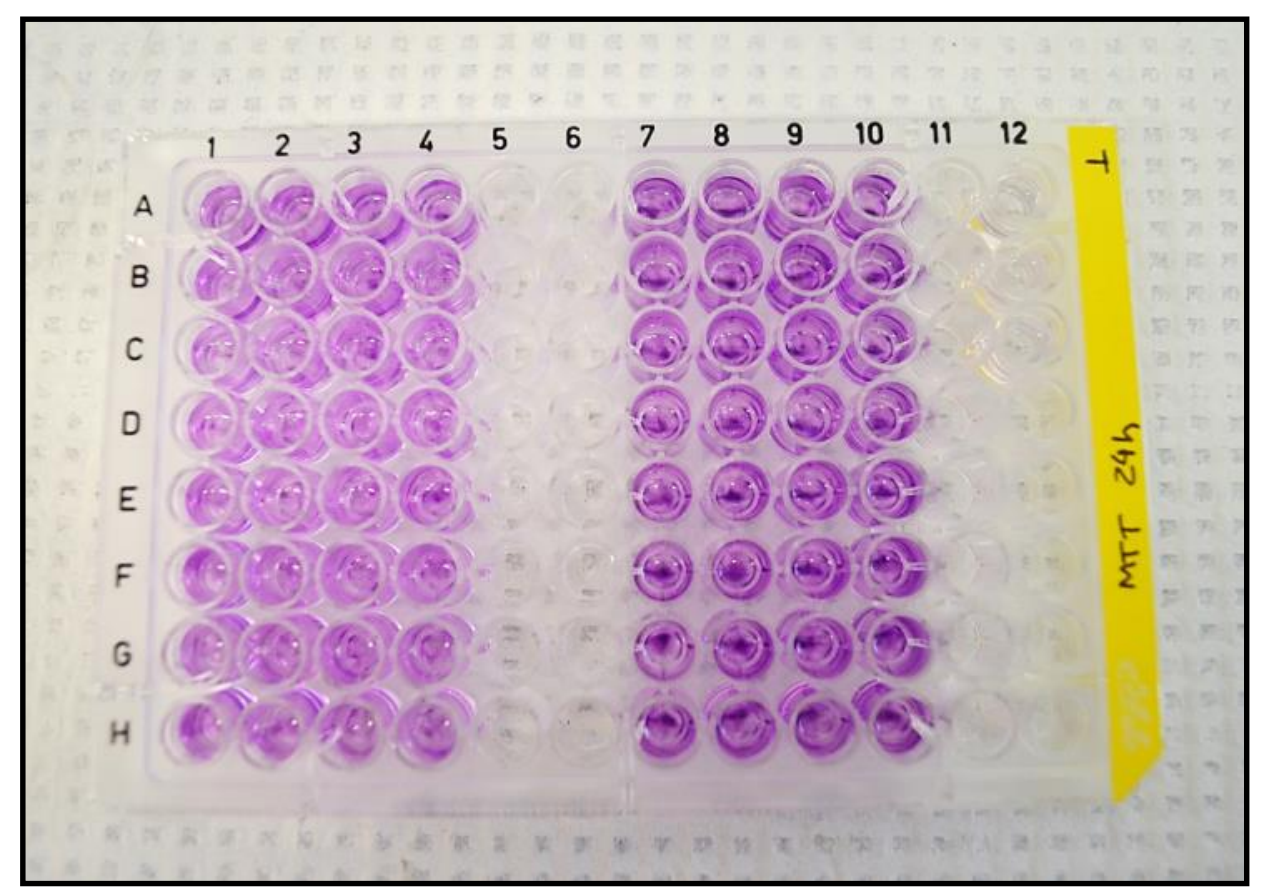

Figura 4 - Imagem ilustrativa da placa do ensaio Redução do MTT após incubação e posterior dissolução dos cristais de formazan com DMSO. 


\subsubsection{Cristal Violeta}

O teste de cristal violeta é utilizado para determinar a viabilidade por corar o DNA celular (KUENG et al., 1989) (Figura 5). Após 24, 48 e 72 horas, o sobrenadante foi removido e as células foram lavadas com PBS 1X. Em seguida foi adicionado $200 \mu \mathrm{L}$ de metanol $100 \%$ por 10 minutos. Após esse tempo, o metanol foi removido e adicionou-se $200 \mu \mathrm{L}$ da solução de cristal violeta $0,2 \%$ em etanol $2 \%$ por 3 minutos. Em seguida o corante foi removido e as células foram lavadas novamente com PBS 1X. Por fim, acrescentou-se $200 \mu \mathrm{L}$ da solução de citrato de sódio 0,05 mol. $\mathrm{L}^{-1}$ com etanol $50 \%$ durante 10 minutos. A leitura das placas foi realizada no Leitor de ELISA (FLUOstar OPTIMA, BMG Labtech, Offenburg, Alemanha) com filtro de $540 \mathrm{~nm}$.

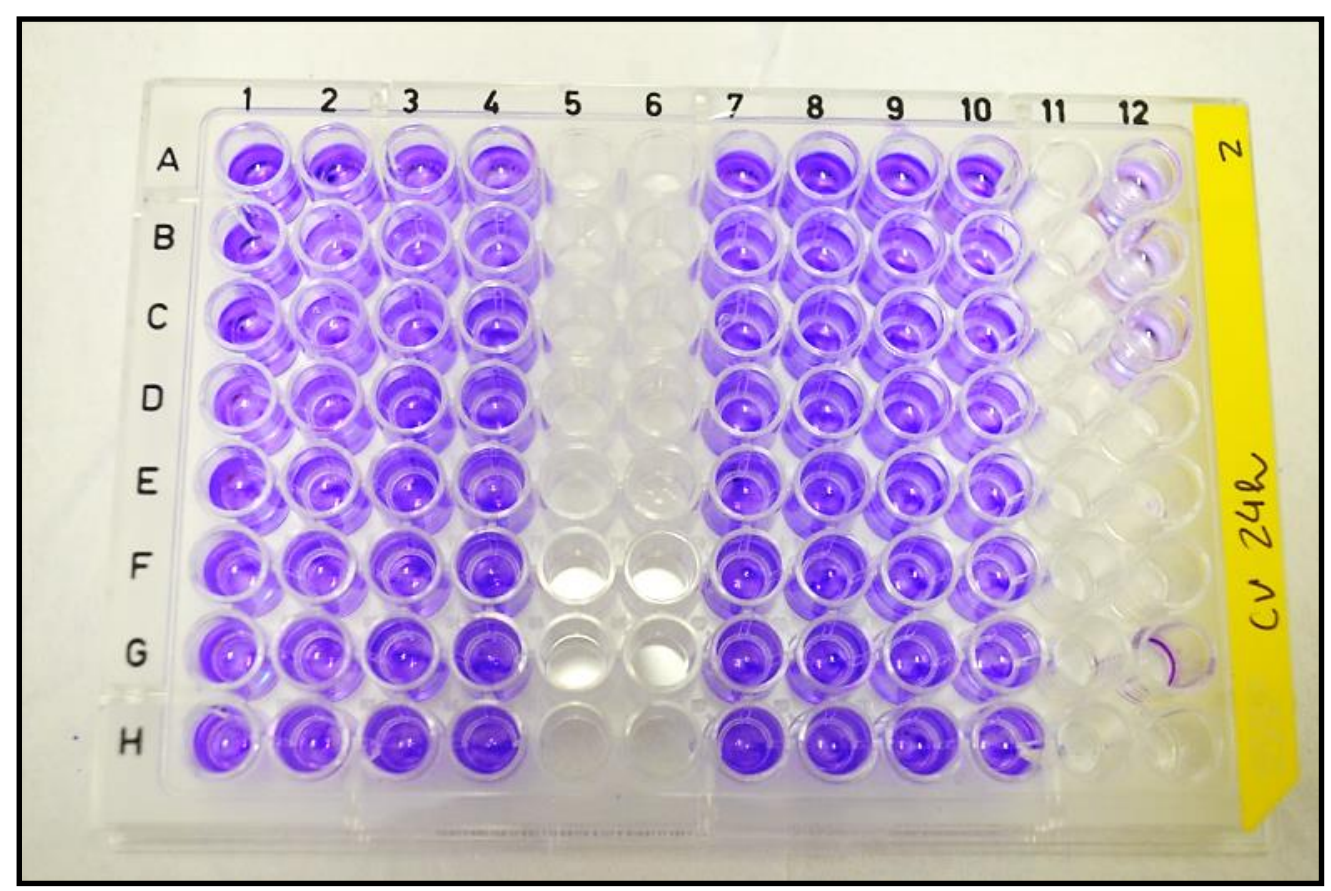

Figura 5 - Imagem ilustrativa da placa do ensaio de viabilidade cristal violeta após adição de citrato de sódio a 0,05 mol.L-1.

\subsection{WESTERN BLOTTING}

As células foram plaqueadas na densidade de $4 \times 10^{4}$ células/poço em placas de 24 poços. O número de amostragem foi 24 por grupo. A expressão da ERK 
fosforilada ( $p$-ERK) no lisado celular foi avaliada após a aplicação pontual do laser vermelho $\left(10\right.$ e $\left.50 \mathrm{~J} / \mathrm{cm}^{2}\right)$, infravermelho $\left(10\right.$ e $\left.50 \mathrm{~J} / \mathrm{cm}^{2}\right)$ ou LED $\left(10\right.$ e $\left.50 \mathrm{~J} / \mathrm{cm}^{2}\right)$. Após 10 minutos (KIYOSAKI et al., 2010) a $37^{\circ} \mathrm{C}$, as células HOAL foram lisadas com um tampão contendo 50nM tris-HCL (pH 7.4), $25 \mathrm{mM} \mathrm{KCL}, 5 \mathrm{mM} \mathrm{MgCl}$, e 0,2\% Nonidet P-40) suplementado com inibidores de proteases (Roche Diagnostics) e inibidor de fosfatase (0,2 M de Ortovanadato de Sódio - Calbiochem). Os lisados de cada condição foram unidos em um único tubo $(n=24)$, a seguir sonicado e centrifugado a $1.000 \mathrm{rpm}$ por $10 \mathrm{~min}$ a $4^{\circ} \mathrm{C}$. As amostras de proteínas $(40 \mu \mathrm{g})$ foram aplicadas à eletroforese (120V; 20mA por gel; aproximadamente 90 minutos) em gel de poliacrilamida $(10 \%$ Tris- $\mathrm{HCl})$ e posteriormente transferidas à membrana de PVDF (polyvinylidene difluoride) (Figura 6). Esta foi imuno-marcada com anticorpos policlonais primários de coelho anti-p-ERK (Cell Signaling) seguidos por anticorpos secundários anti-lgG de coelho conjugados com HRP (Horseradish Peroxidase - Cell Signaling) e reagente prime ECL (enhanced chemiluminescence) para detecção (Amersham Biosciences). As densidades relativas das bandas foram determinadas por meio de análise de densitometria, utilizando o programa Image J (National Institutes of Health Image-NHI). Os valores da densidade obtidos foram corrigidos pela subtração dos valores do background.

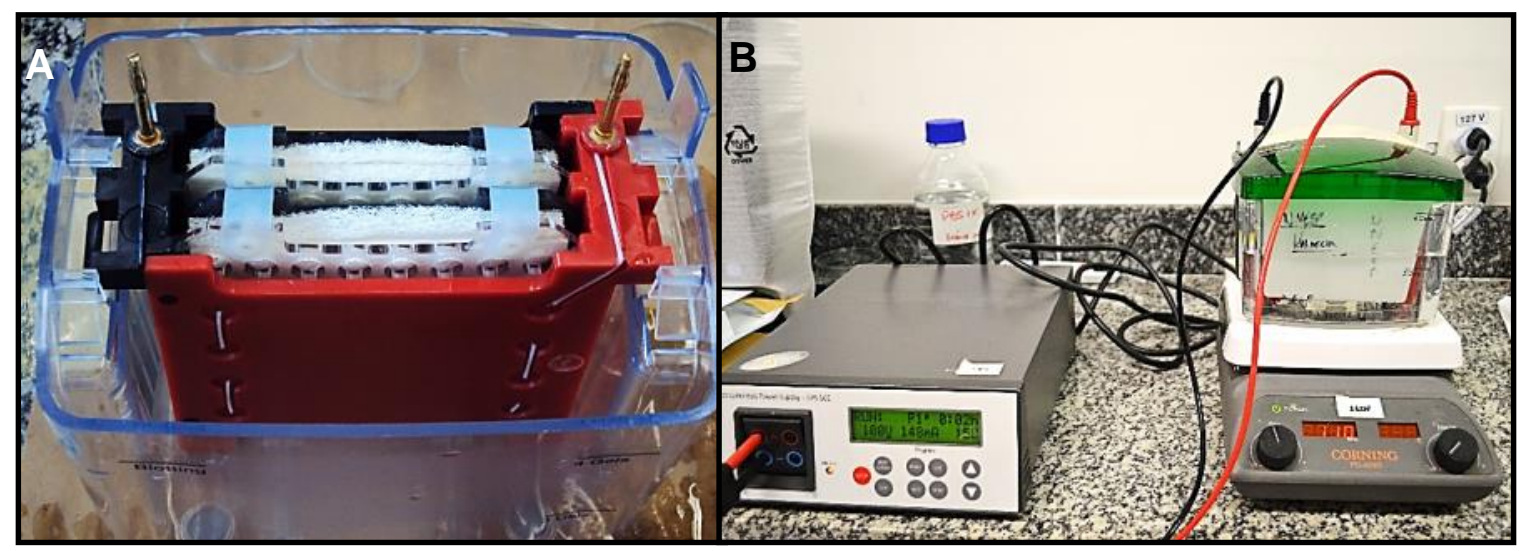

Figura 6 - Imagens da técnica Western blotting. (A) Sistema de transferência. (B) Fase de Transferência das proteínas, do gel para a membrana de PVDF. 


\subsection{ENSAIO DE PROLIFERAÇÃO}

A proliferação celular foi realizada por meio da marcação das células com o composto fluorescente CFSE (carboxyfluorescein diacetate, succinimidyl Ester) e avaliação por citometria de fluxo. Para tanto, osteoblastos humanos na densidade de $3 \times 10^{5}$ (por condição experimental) foram marcados com CFSE (concentração de10 $\mu \mathrm{M})$ por $10 \mathrm{~min}$ a $4^{\circ} \mathrm{C}$, conforme o protocolo do fabricante (Molecular Probes). Após lavagemcom PBS, as células marcadas foram plaqueadas em placas de 24 poços e após aderência o meio foi substituído por DMEM 10\% SFB e as células irradiadas por duas vezes (com intervalo de 6 horas). Foi utilizado nos grupos apropriados o inibidor de ERK (PD98059) para avaliar seu efeito na modulação dessa proteína, no processo de proliferação. Após 72 horas, as células foram tripsinizadas e adquiridas subsequencialmente em FACsorting (BD Biosciences). As análises foram feitas usando o programa CellQuest (CellQuest software, BD) (Figura 7).

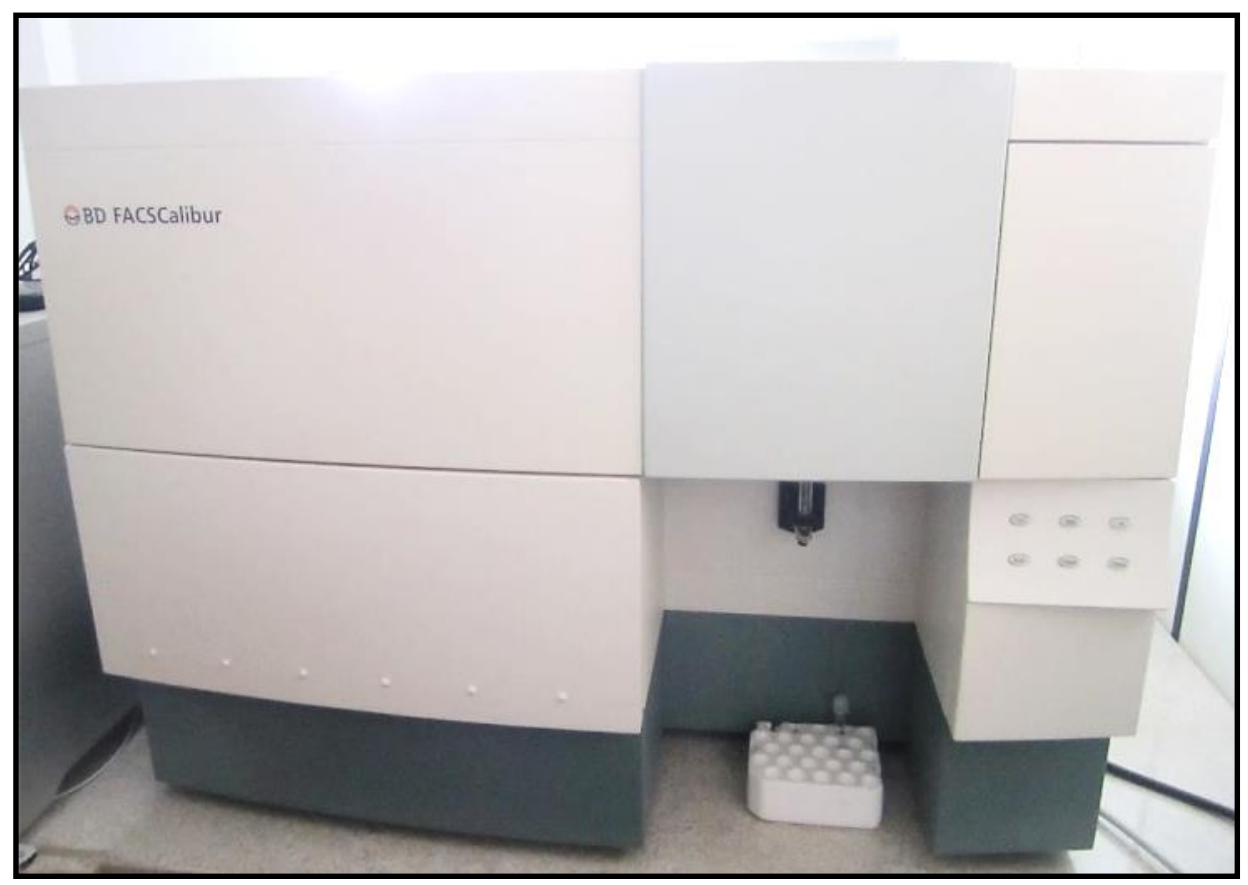

Figura 7 - Citômetro de fluxo FACSCalibur (BD Biosciences) para aquisição das amostras.

\subsection{ENSAIO DA ATIVIDADE DA FOSFATASE ALCALINA (ALP)}

Para conhecer o perfil da atividade da ALP das células HOAL foram plaqueadas em placas de 24 poços na densidade de $4 \times 10^{4}$ células/poço em meio 
DMEM com 10\% SFB. Após a adesão, as células foram cultivadas em DMEM/10\%SFB acrescido de ácido ascórbico $(50 \mu \mathrm{g} / \mathrm{mL})$ e $10 \mathrm{mM}$ de $\beta$-glicerofosfato. Para fins comparativos, como controle positivo da atividade enzimática, préosteoblastos de linhagem MC3T3-E1 (na mesma densidade) foram cultivados concomitantemente em meio de cultura MEM (Minimum Essential Medium Eagle).10\% SFB e nucleosídeos acrescido de ácido ascórbico e $\beta$-glicerofosfato. Após 7, 14, 21 e 28 dias, o extrato protéico do lisado celular foi obtido por meio da adição de $200 \mu \mathrm{l}$ do tampão contendo $10 \mathrm{mM}$ de Tris $\mathrm{pH} 7,5,0,5 \mathrm{mM} \mathrm{MgCl}_{2}$ e $0,1 \%$ Triton X-100. A atividade da ALP é dada pela conversão do pNPP (p-nitrofenilfosfato), substrato da enzima, a p-nitrofenol, produto de coloração amarela em meio alcalino (Figura 8). Para tanto, o meio de reação foi adicionado em placa de 96 poços (solução contendo tampão glicina (25mM, pH 9,4), acrescido de $2 \mathrm{mM}$ de $\mathrm{MgCl}_{2}$ e $1 \mathrm{mM}$ de pNPP). Após incubação por 30 minutos a $37^{\circ} \mathrm{C}$ (tempo necessário para a estabilização), foram adicionados $50 \mu \mathrm{l}$ das amostras por poço (ressuspensas em 10mM Tris $\mathrm{HCl} \mathrm{pH7,5;0,5mM} \mathrm{MgCl} ; 0,1 \%$ Triton $\mathrm{X}-100)$. A placa foi mantida a $37^{\circ} \mathrm{C}$ durante aproximadamente 40 minutos. A reação foi paralisada com $\mathrm{NaOH} 1 \mathrm{M}$. O produto final ( $p$-nitrofenol) foi quantificado a $405 \mathrm{~nm}$ e os resultados foram expressos como atividade em nmol de $p$-nitrofenol $x$ min $^{-}$ ${ }^{1} \mathrm{x} \mathrm{mg}^{-1}$ de proteína. Quando apropriado, foram realizados os ensaios da atividade da ALP com aplicação da fototerapia. 


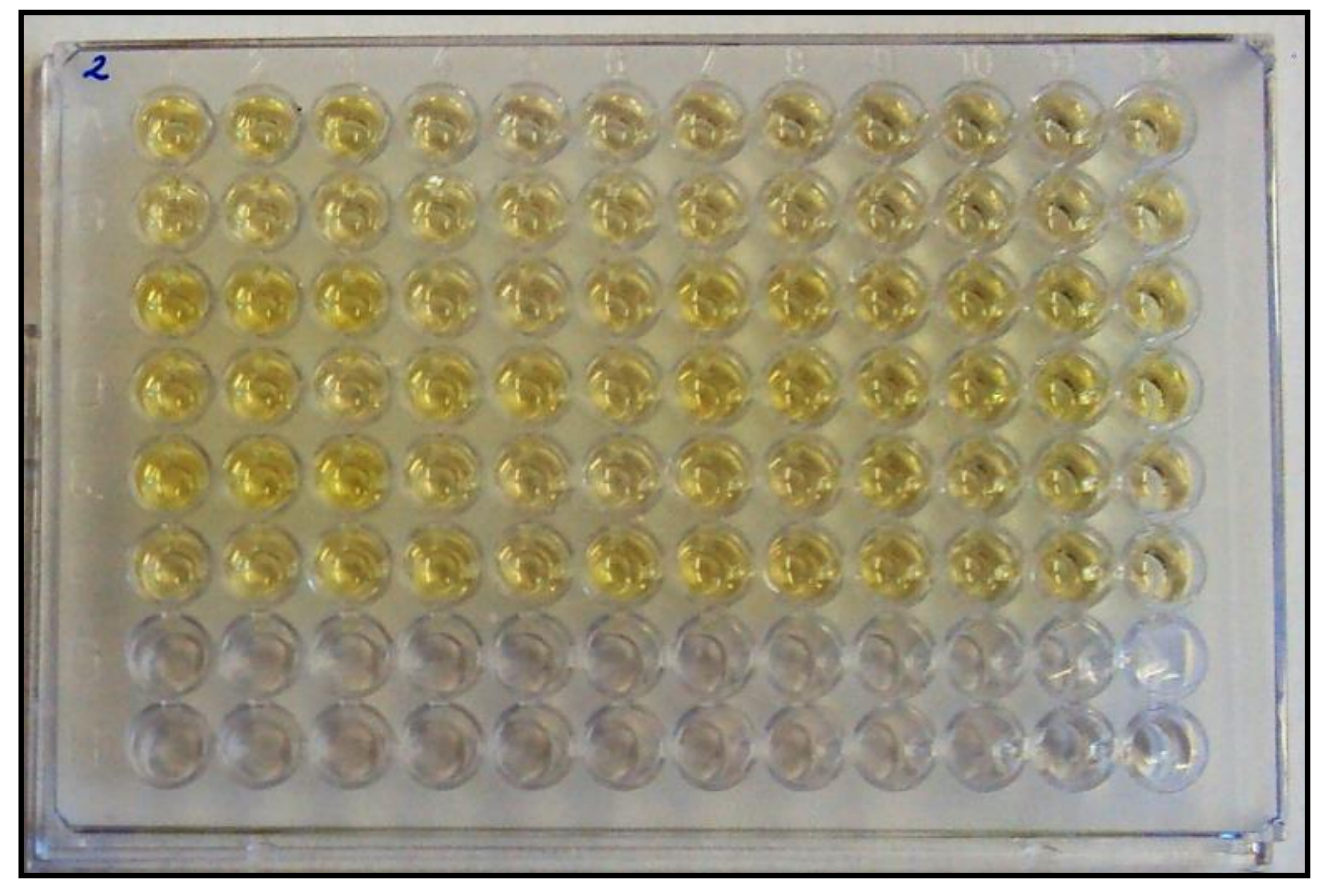

Figura 8- Imagem ilustrativa do ensaio fosfatase alcalina. A atividade da ALP é dada pela conversão do pNPP (p-nitrofenilfosfato), substrato da enzima, em p-nitrofenol, produto de coloração amarela.

\subsection{QUANTIFICAÇÃO TOTAL DE PROTEÍNA}

A quantificação de proteína total foi calculada pelo Método de Bradford (HAMMOND \& KRUGER, 1988). Em placa de 96 poços, foi realizada a curva padrão a partir de $2 \mathrm{mg} / \mathrm{mL}$ de albumina bovina sérica. Em seguida, as amostras foram diluídas (em volume final de $150 \mu \mathrm{L}$ ) e pipetadas na placa. A seguir, adicionou-se $150 \mu \mathrm{L}$ (diluição 1:1) do reagente de Bradford (BioRad) em todos os poços (Figura 9). Após 15 min, a leitura da placa foi realizada a 405nm em espectrofotômetro. 


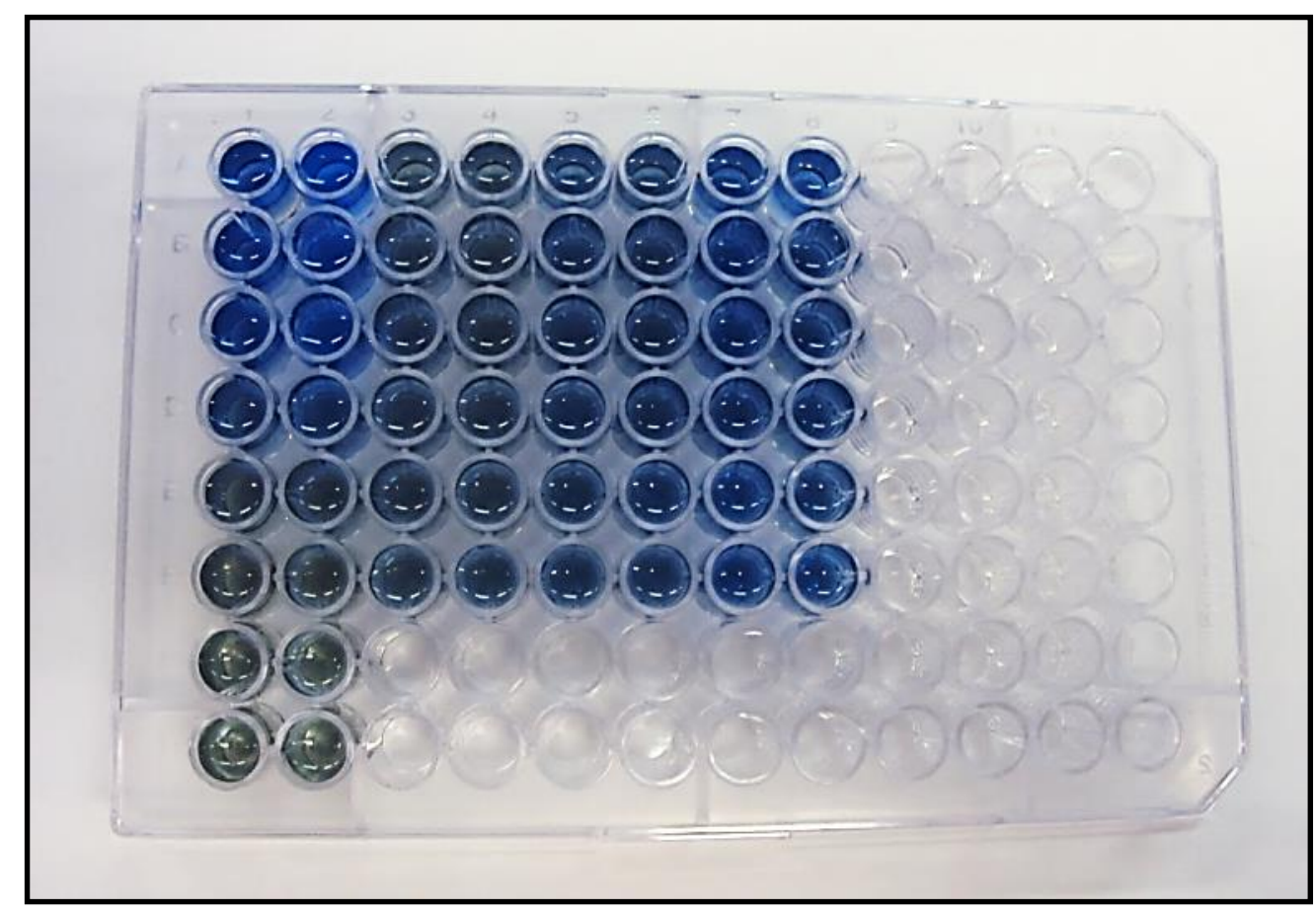

Figura 9 - Quantificação total de proteínas pelo Método de Bradford.

\subsection{RT-PCR EM TEMPO REAL (TRANSCRIÇÃO REVERSA DA REAÇÃO EM CADEIA DA POLIMERASE EM TEMPO REAL)}

As células foram plaqueadas na densidade de $5 \times 10^{2}$ células por poço em placas de 96 poços. Após 24 horas da adesão celular foi feita a troca por um meio osteogênico (DMEM suplementado com 10\% de SFB acrescido de ácido ascórbico $(50 \mu \mathrm{g} / \mathrm{mL})$ e beta-glicerofosfato $(10 \mathrm{mM})$ para induzir a diferenciação celular e em seguida foi aplicado a fototerapia com laser vermelho $\left(10\right.$ e $\left.50 \mathrm{~J} / \mathrm{cm}^{2}\right)$, infravermelho (10 e $50 \mathrm{~J} / \mathrm{cm}^{2}$ ) ou LED (10 e $50 \mathrm{~J} / \mathrm{cm}^{2}$ ). A troca do meio foi realizada a cada 3 dias e as irradiações a cada 6 dias. Após 7, 1421 e 28 dias o RNAm foi extraído e transcrito para cDNA por meio do kit TaqMan® Gene Expression Cells-to-CT ${ }^{\mathrm{TM}}$ (Applied Biosystems), conforme recomendações do fabricante. Em seguida, as amostras de cDNA foram incubadas com Taqman $\circledast$ Gene Expression master mix e com Taqman ${ }^{\circledR}$ Gene Expression assay (Applied Biosystems) para SPARC (gene da osteonectina) e COL1A1 (gene do colágeno tipo I) e lidas no Sistema de Real-Time RT-PCR ViiATM7 (Applied Biosystems) (Figura 10). A $\beta$-actina foi utilizada como controle endógeno. 


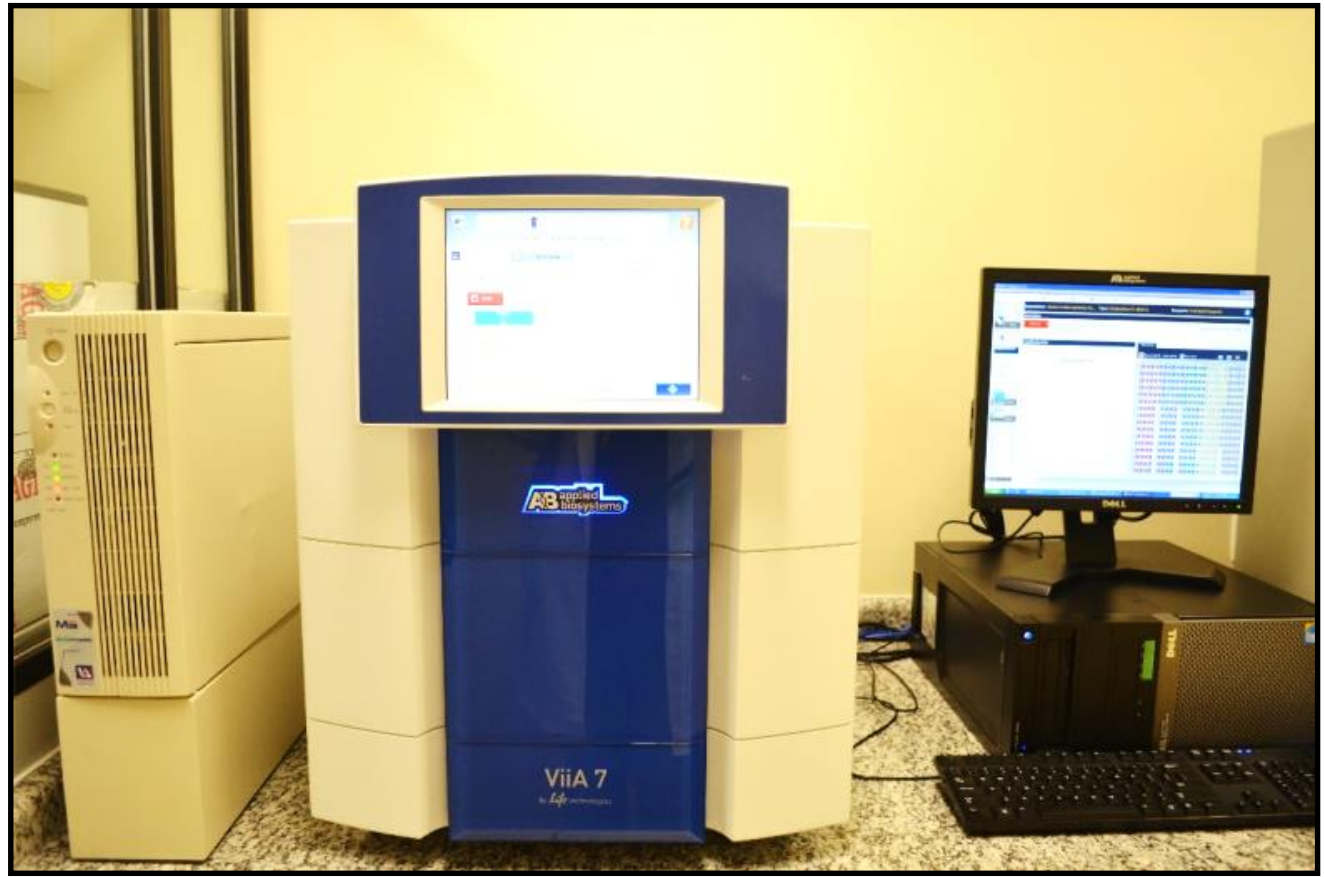

Figura 10 - Sistema de Real-Time RT-PCR ViiATM7 (Applied Biosystems).

\subsection{ENSAIO DE MINERALIZAÇÃO}

Para avaliar a capacidade de mineralização, células HOAL e MC3T3-E1 foram submetidas ao estímulo osteogênico e a deposição de cálcio foi avaliada por meio da coloração com vermelho de alizarina. Para tanto, as células HOAL e MC3T3E1 foram plaqueadas na densidade de $4 \times 10^{4}$ em placas de 12 poços. Após a aderência, as mesmas foram cultivadas com meio DMEM e MEM, respectivamente, $10 \%$ SFB, suplementado com ácido ascórbico $(50 \mu \mathrm{g} / \mathrm{mL})$ e beta-glicerofosfato (10 $\mathrm{mM}$ ), substâncias que induzem a diferenciação osteogênica das células. A mineralização foi avaliada por coloração com Alizarina Red S (Sigma®). Após 14, 21 e 28 dias de cultivo (Figura 11 A, B e C, respectivamente), as células HOAL e MC3T3E1 tiveram os sobrenadantes descartados e foram lavadas com PBS 1X seguida da fixação com formaldeído $4 \%$ por 5 minutos em temperatura ambiente (TA). As células foram incubadas com solução de alizarina $2 \% \mathrm{pH} \mathrm{4,2} \mathrm{por} 10$ minutos em TA seguido de 3 lavagens com água ultra pura. As placas foram fotografadas utilizando a câmera El Logic 100 Imaging System e analisadas pelo programa Kodak, Molecular Imaging software v.4.5. 
A análise quantitativa da coloração foi avaliada pelo método colorimétrico segundo Petri et al. (2010) (Figura 11D). Após as placas estarem totalmente secas, foram adicionados $280 \mu \mathrm{l}$ de ácido acético a $10 \%$ diretamente em cada poço corado com vermelho de alizarina. A placa foi submetida à agitação por 30 minutos à TA. O conteúdo de cada poço foi transferido para tubos tipo eppendorf, que foram aquecidos a $85^{\circ} \mathrm{C}$ por 10 minutos e depois mantidos em gelo por 5 minutos. Os tubos foram centrifugados a $20.000 \mathrm{~g}$ por 15 minutos e $100 \mu \mathrm{l}$ do sobrenadante de cada tubo foi transferido para poços de placas com 96 poços. Posteriormente, adicionou-se $40 \mu \mathrm{l}$ de hidróxido de amônia a $10 \%$ em cada poço para neutralização do ácido. A absorbância foi medida em espectofotômetro a $405 \mathrm{~nm}$, sendo a formação de matriz mineralizada expressa como densidade óptica (D.O.). Quando apropriado, foram realizados os ensaios de mineralização com aplicação da fototerapia.

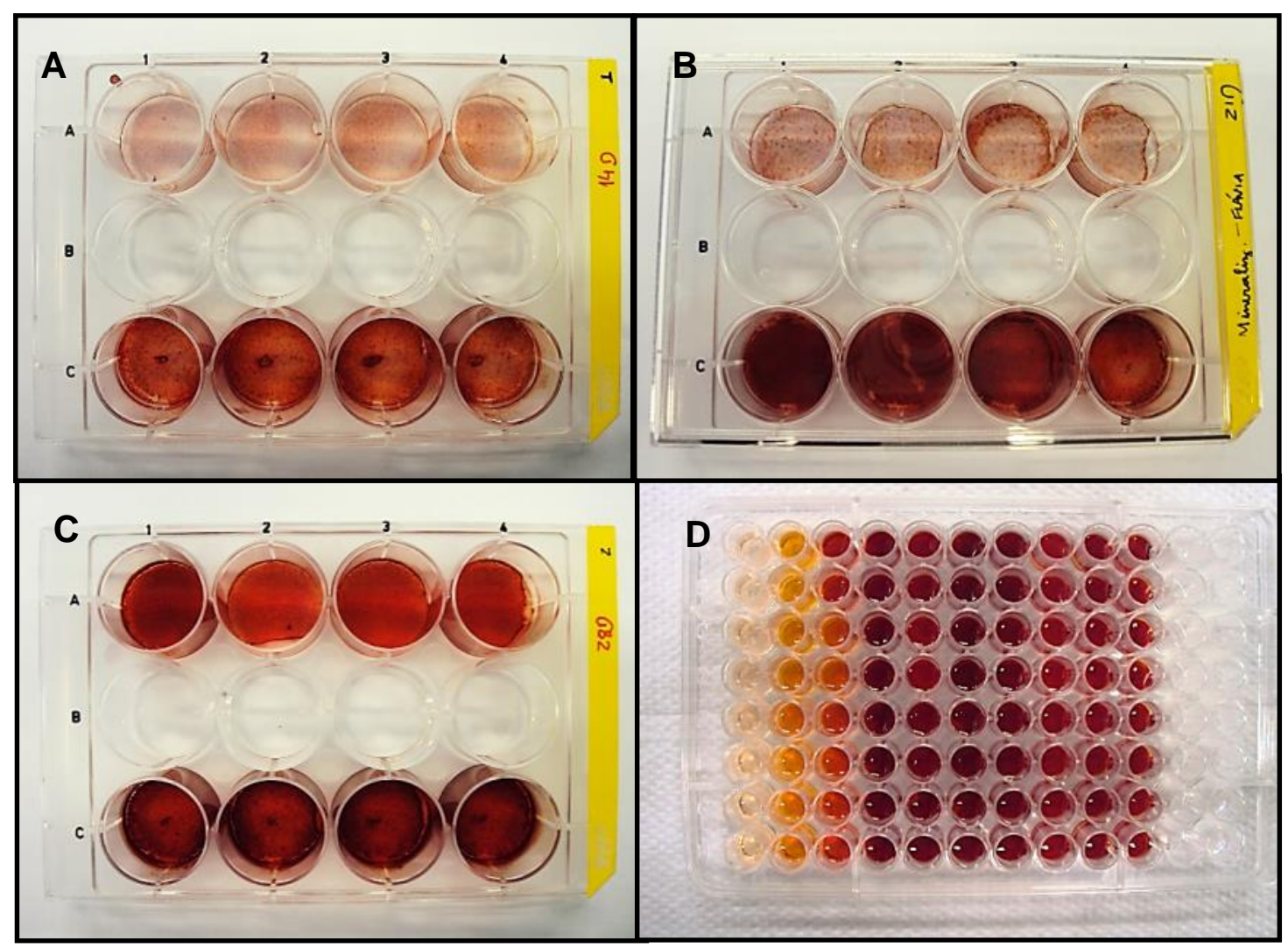

Figura 11 - Deposição de cálcio pelas células HOAL (linha A da placa) e MC3T3-E1 (linha C da placa) pelo corante vermelho de alizarina, nos períodos de 14 dias (A), 21 dias (B) e 28 dias (C). (D) Quantificação colorimétrica. 


\subsection{ANÁLISE ESTATÍSTICA}

Os resultados foram analisados utilizando os programas Statistica 5.1 (Statsoft) e GraphPad Prism 4. Os grupos experimentais foram submetidos à análise de variância ANOVA One-way, Two-way e Three-way (quando apropriado) seguido pelo teste de Tukey. A significância foi dada quando $p<0,05$. Todas as amostras passaram pelo teste de normalidade de acordo com o método de Kolmogorov e Smirnov, onde o valor de $p$ foi $>0.10$. 


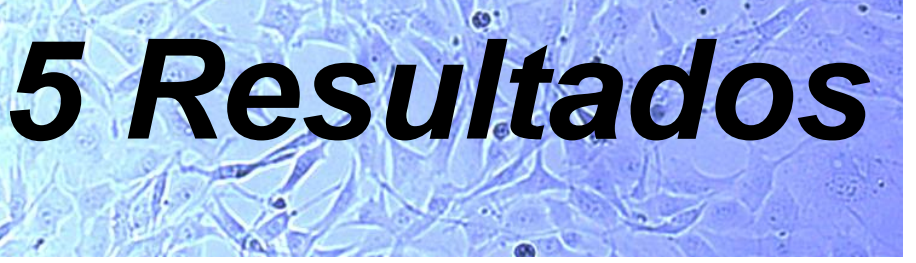





\section{RESULTADOS}

\subsection{ANÁLISE DA VIABILIDADE CELULAR}

Os resultados serão descritos separadamente dependendo se as fototerapias foram realizadas em uma única aplicação (após adesão celular) ou dupla (com intervalo de 6 horas após a primeira irradiação) conforme a seguir, sendo descritos ao final, a comparação entre os dois tipos de irradiação. A análise estatística foi representada por letras nos gráficos, onde letras diferentes significam diferenças somente em relação ao controle. A descrição completa da estatística dos ensaios de MTT e CV com outros tipos de comparações encontra-se nos anexos 2 ao 15.

\subsubsection{Redução do MTT}

A ANOVA a 3 critérios mostrou diferença significativa entre os grupos ( $F=$ 41,08993); $(p<0,0001)$, entre os períodos $(F=2488,72) ;(p<0,0001)$ e entre os dois tipos de aplicação $(F=493,6363) ;(p<0,0001)$ revelando significativa interação entre os três critérios $(F=12,7906) ;(p<0,0001)$ (Figura 12).

\section{Aplicação única:}

Quando comparado com células controle não irradiadas, o LED (na dose de $10 \mathrm{~J} / \mathrm{cm}^{2}$ ) aumentou a proliferação após 24 horas. No período de $48 \mathrm{~h}$ observou-se um aumento da proliferação nos grupos submetidos à irradiação com laser vermelho (todas as doses), laser infravermelho 20 e $50 \mathrm{~J} / \mathrm{cm}^{2}$ e LED apenas na dose de 10 $\mathrm{J} / \mathrm{cm}^{2}$. Após 72 horas, apenas o grupo infravermelho $50 \mathrm{~J} / \mathrm{cm}^{2}$ apresentou maior viabilidade.

Dentro da mesma terapia, observamos que o LED $10 \mathrm{~J} / \mathrm{cm}^{2}$ aumentou significativamente a viabilidade em relação às doses de 20 e $50 \mathrm{~J} / \mathrm{cm}^{2}$ após 24 horas. No período de 48 horas, observamos que o infravermelho 20 e $50 \mathrm{~J} / \mathrm{cm}^{2}$ foram mais efetivo que o infra em sua menor dose. O LED na dose de $10 \mathrm{~J} / \mathrm{cm}^{2}$ teve um efeito estimulatório positivo em relação às doses de 20 e $50 \mathrm{~J} / \mathrm{cm}^{2}$.

Com relação a uma mesma dose, comparamos o efeito diferencial das fototerapias. Quanto às irradiações na dose de $10 \mathrm{~J} / \mathrm{cm}^{2}$, observamos que o LED aumentou significativamente a viabilidade em relação ao laser vermelho nos períodos de 24 e 48 horas e em relação ao laser infravermelho (48 horas). No período de 72 horas, na dose de $50 \mathrm{~J} / \mathrm{cm}^{2}$, o laser vermelho foi mais efetivo que o LED. 


\section{Aplicação dupla:}

Em relação ao grupo controle, a fototerapia com LED (nas doses de $20 \mathrm{e}$ $50 \mathrm{~J} / \mathrm{cm}^{2}$ ) aumentou significativamente a viabilidade celular pós 24 horas da estimulação. No período de 48 horas, o laser vermelho e o LED em todas as doses avaliadas também induziram o aumento da viabilidade. No período de 72 horas, observamos que todas as fototerapias e em todas as doses (exceto LED $50 \mathrm{~J} / \mathrm{cm}^{2}$ ) foi eficiente em aumentar a viabilidade quando comparado com as células não estimuladas.

Quando diferentes doses da mesma fototerapia foram comparativamente analisadas, observamos que o LED nas doses de 10 e $20 \mathrm{~J} / \mathrm{cm}^{2}$ teve um efeito positivo na proliferação em relação à maior dose $\left(50 \mathrm{~J} / \mathrm{cm}^{2}\right)$ após 72 horas.

Com relação às diferenças observadas na comparação entre as diferentes fototerapias na mesma dose, observamos que o LED na dose de $10 \mathrm{~J} / \mathrm{cm}^{2}$ potencializou o efeito positivo na viabilidade em relação ao laser vermelho e infravermelho, ambos na dose de $10 \mathrm{~J} / \mathrm{cm}^{2}$ com 48 horas.

\section{Aplicação única x aplicação dupla:}

Com relação aos dois tipos de aplicação foi observado aumento da viabilidade celular com duas aplicações em todos os períodos, quando comparado com aplicação única. Com 24 horas, o infravermelho $\left(50 \mathrm{~J} / \mathrm{cm}^{2}\right)$ foi mais efetivo após 2 aplicações. No período de 48 horas todos os grupos experimentais apresentaram maior viabilidade com 2 irradiações, comparando mesmo grupo, na mesma dose. Não foi observado diferenças apenas nos grupos infra (10, 20 e $\left.50 \mathrm{~J} / \mathrm{cm}^{2}\right)$ e LED $\left(50 \mathrm{~J} / \mathrm{cm}^{2}\right)$ $(p>0,05)$ com 72 horas.

\subsubsection{Cristal Violeta}

A Anova a 3 critérios mostrou diferença significativa entre os grupos ( $\mathrm{F}=$ 18,37727); $(p<0,0001)$, entre os períodos $(F=4410,939)$; $(p<0,0001)$ e entre os dois tipos de aplicação $(F=5,718036) ;(p<0,0001)$ revelando significativa interação entre os três critérios ( $F=5,681163) ;(p<0,0001)$ (Figura 13). 


\section{Aplicação única:}

Quando comparado com o grupo controle, o infravermelho, na dose de 50 $\mathrm{J} / \mathrm{cm}^{2}$, aumentou a viabilidade após 24 horas. No período de 48 horas, não houve diferença estatística entre os grupos. Com 72 horas, o laser vermelho, em todas as doses, o infravermelho na dose de $50 \mathrm{~J} / \mathrm{cm}^{2}$ e O LED (doses de 20 e $50 \mathrm{~J} / \mathrm{cm}^{2}$ ) apresentaram maior viabilidade.

Dentro da mesma fototerapia, foi observado aumento da viabilidade no grupo infravermelho, em todas as doses nos períodos de 24 e 48 horas. Com 72 horas, houve diferenças apenas no LED, em todas as doses.

Comparando o efeito diferencial da fototerapia na mesma dose, observamos que as irradiações na dose de 10,20 e $50 \mathrm{~J} / \mathrm{cm}^{2}$ aumentaram a viabilidade nos períodos de 48 e 72 horas.

\section{Aplicação dupla:}

Quando comparado com células não irradiadas, o laser vermelho (50 $\left.\mathrm{J} / \mathrm{cm}^{2}\right)$ e o infra $\left(20 \mathrm{~J} / \mathrm{cm}^{2}\right)$ apresentaram aumento da viabilidade com 24 horas. No período de 48 horas, apenas os grupos com a dose de $20 \mathrm{~J} / \mathrm{cm}^{2}$ não apresentaram diferenças significantes $(p>0,05)$. Todos os grupos tiveram maior viabilidade no período de 72 horas, exceto o infravermelho e LED, nas doses de $20 \mathrm{~J} / \mathrm{cm}^{2}$.

Com relação à mesma fototerapia, no período de 24 horas, a dose de 50 $\mathrm{J} / \mathrm{cm}^{2}$ do laser vermelho foi mais efetiva que a de $10 \mathrm{~J} / \mathrm{cm}^{2}$. O infravermelho de 20 $\mathrm{J} / \mathrm{cm}^{2}$ apresentou maior aumento de viabilidade quando comparado com a dose de 10 $\mathrm{J} / \mathrm{cm}^{2}$ e quanto ao LED, as doses 10 e $50 \mathrm{~J} / \mathrm{cm}^{2}$ foram mais efetivas que a dose de 20 $\mathrm{J} / \mathrm{cm}^{2}$. Com 48 horas, as doses de 10 e $50 \mathrm{~J} / \mathrm{cm}^{2}$ tiveram maior viabilidade do que a dose de $20 \mathrm{~J} / \mathrm{cm}^{2}$ no grupo laser vermelho. Com 72 horas, o infra de $10 \mathrm{~J} / \mathrm{cm}^{2}$ apresentou um efeito estimulatório positivo em relação à dose de $20 \mathrm{~J} / \mathrm{cm}^{2}$. $O$ grupo LED na dose de $10 \mathrm{~J} / \mathrm{cm}^{2}$ foi mais efetivo que as doses de 20 e $50 \mathrm{~J} / \mathrm{cm}^{2}$.

Quando da mesma dose, os três tipos de fototerapia apresentaram diferenças na dose de $20 \mathrm{~J} / \mathrm{cm}^{2}$. Observamos que o LED $20 \mathrm{~J} / \mathrm{cm}^{2}$ aumentou significativamente a viabilidade em relação ao infravermelho $20 \mathrm{~J} / \mathrm{cm}^{2}$ com 24 horas. No período de 48 horas observou-se diferença estatística $(p<0,05)$ nos grupos laser 
68

vermelho e LED, na dose de $20 \mathrm{~J} / \mathrm{cm}^{2}$. Com 72 horas, o laser vermelho apresentou maior viabilidade que o infravermelho e LED na dose de $20 \mathrm{~J} / \mathrm{cm}^{2}$.

\section{Aplicação única $x$ aplicação dupla:}

Foram observadas diferenças significantes em todos os períodos quando comparamos o tipo de aplicação com mesma fototerapia, na mesma dose. O laser vermelho, na dose de $50 \mathrm{~J} / \mathrm{cm}^{2}$, e o infravermelho $\left(20 \mathrm{~J} / \mathrm{cm}^{2}\right)$ apresentaram maior viabilidade com duas aplicações no período de 24 horas. Com 48 horas houve aumento significativo apenas no LED $\left(20 \mathrm{~J} / \mathrm{cm}^{2}\right)$ no grupo de aplicação dupla. No período de 72 horas, observou-se um efeito positivo nos grupos infravermelho (dose de 20 e $50 \mathrm{~J} / \mathrm{cm}^{2}$ ), e LED (10 e $20 \mathrm{~J} / \mathrm{cm}^{2}$ ) os quais apresentaram maior viabilidade com 2 aplicações. 
MTT

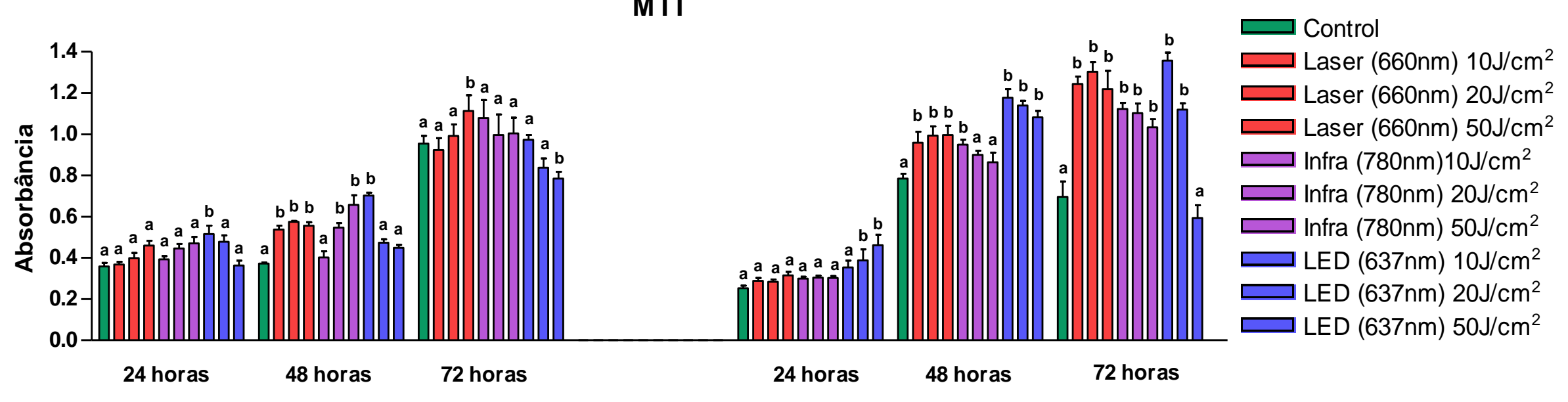

1 aplicação

2 aplicações

Figura 12 - Efeito da LLLT na viabilidade de osteoblastos humanos (HOAL) avaliado por redução do MTT nos períodos de 24, 48 e 72 horas. Os gráficos mostram a irradiação realizada em 1 aplicação (A) ou 2 aplicações (B) com irradiação pontual nas doses de 10, 20 ou $50 \mathrm{~J} / \mathrm{cm}^{2}$. Os resultados representam a média \pm SEM dos valores de absorbância. Letras diferentes indicam diferenças estatísticas $(p<0,05)$ em relação ao grupo controle. As demais comparações são apresentadas nos Anexos 2 a 8. 


\section{Cristal Violeta}

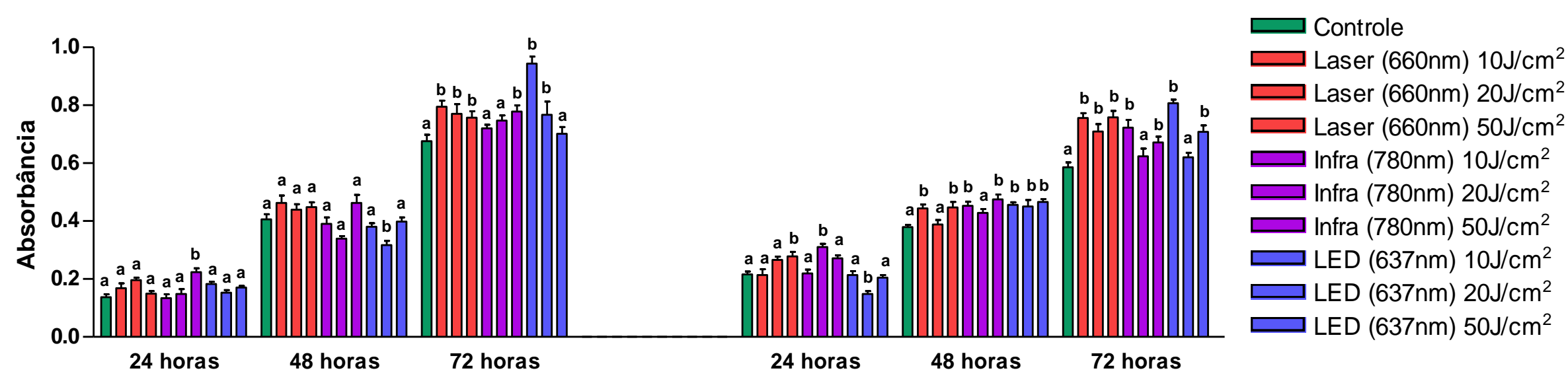

1 aplicação

2 aplicações

Figura 13 - Efeito da LLLT na viabilidade de osteoblastos humanos (HOAL) avaliado por cristal violeta nos períodos de 24,48 e 72 horas. Os gráficos mostram a irradiação realizada em 1 aplicação (A) ou 2 aplicações (B) com irradiação pontual nas doses de 10, 20 ou $50 \mathrm{~J} / \mathrm{cm}^{2}$. Os resultados representam a média \pm SEM dos valores de absorbância. Letras diferentes indicam diferenças estatísticas $(p<0,05)$ em relação ao grupo controle. As demais comparações estão apresentadas nos Anexos 9 a 15. 


\subsection{EFEITO DOS DIFERENTES ESPECTROS NA PROLIFERAÇÃO CELULAR}

Uma vez que o ensaio de MTT e CV apresentam limitações quanto à avaliação da proliferação celular, optou-se por confirmar e/ou complementar os resultados anteriores por citometria de fluxo utilizando o composto fluorescente CFSE (carboxyfluorescein diacetate, succinimidyl Ester). O CFSE se difunde passivamente pelas células e é transferido às células-filhas, de forma que a cada divisão a intensidade de fluorescência é dividida pela metade. A figura 14 mostra o perfil das células HOAL com 0 (imediatamente posterior a marcação com CFSE) e 72 horas (tempo de análise da proliferação). No momento 0 , a intensidade de fluorescência é da ordem de $10^{3}$, e após 72 horas, esta é da ordem de $10^{1}$ demonstrando que houve extensa proliferação celular nesse período. Os diferentes espectros foram aplicados às células em aplicação dupla (com intervalo de 6 horas entre uma e outra) e a proliferação foi avaliada após 72 horas da última irradiação. Os resultados da triplicata (Figura 16) mostram que a irradiação com laser vermelho $10 \mathrm{~J} / \mathrm{cm}^{2}$ promoveu aumento significativo $(p<0,05)$ de $7 \%$ de proliferação celular em relação ao controle. Embora as demais fototerapias também tenham induzido um aumento na intensidade da fluorescência observado pelo discreto desvio à esquerda nos histogramas (Figura 15), estas se mostram não significativas. 


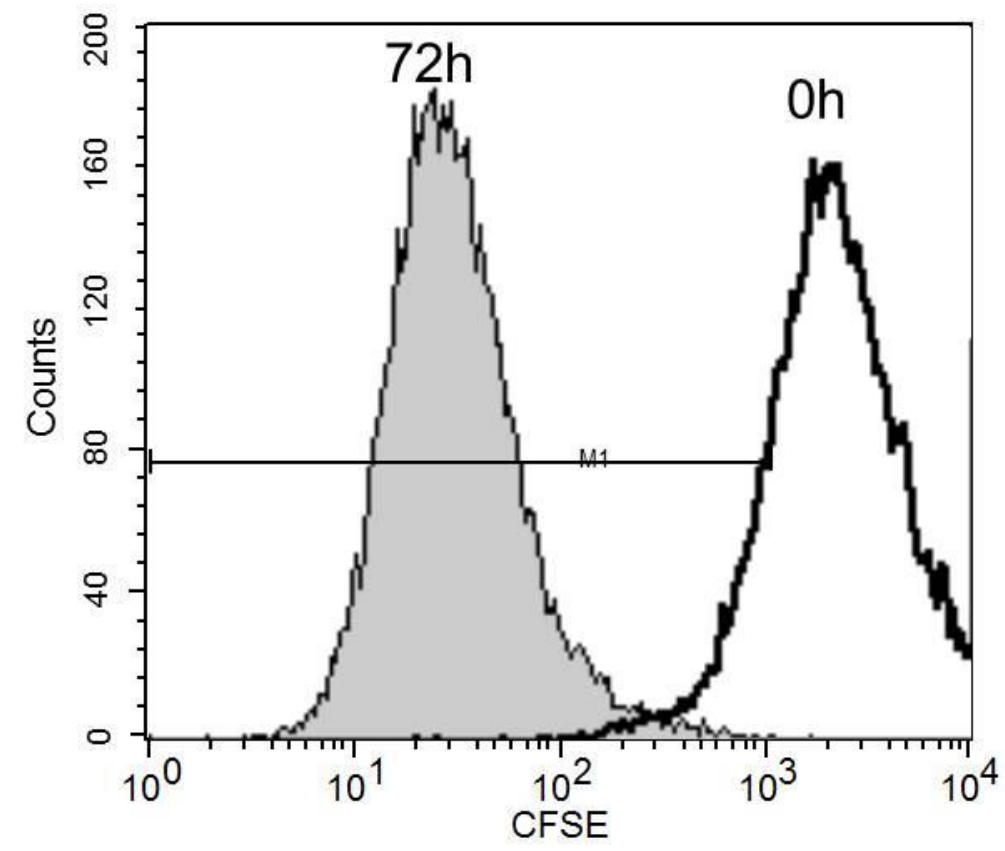

Figura 14 - Histograma representativo da proliferação das células HOAL. As células foram marcadas com $20 \mu \mathrm{M}$ do composto CFSE $(10 \mu \mathrm{M})$ e imediatamente as mesmas foram adquiridas (período 0) (não preenchido) e após 72 horas a $37^{\circ} \mathrm{C} / 5 \% \mathrm{CO}_{2}$ (preenchido em cinza). O posicionamento do marcador M1 (que representam a proliferação celular) foi dado a partir da intensidade de fluorescência das células no momento inicial, sendo igual a103. 

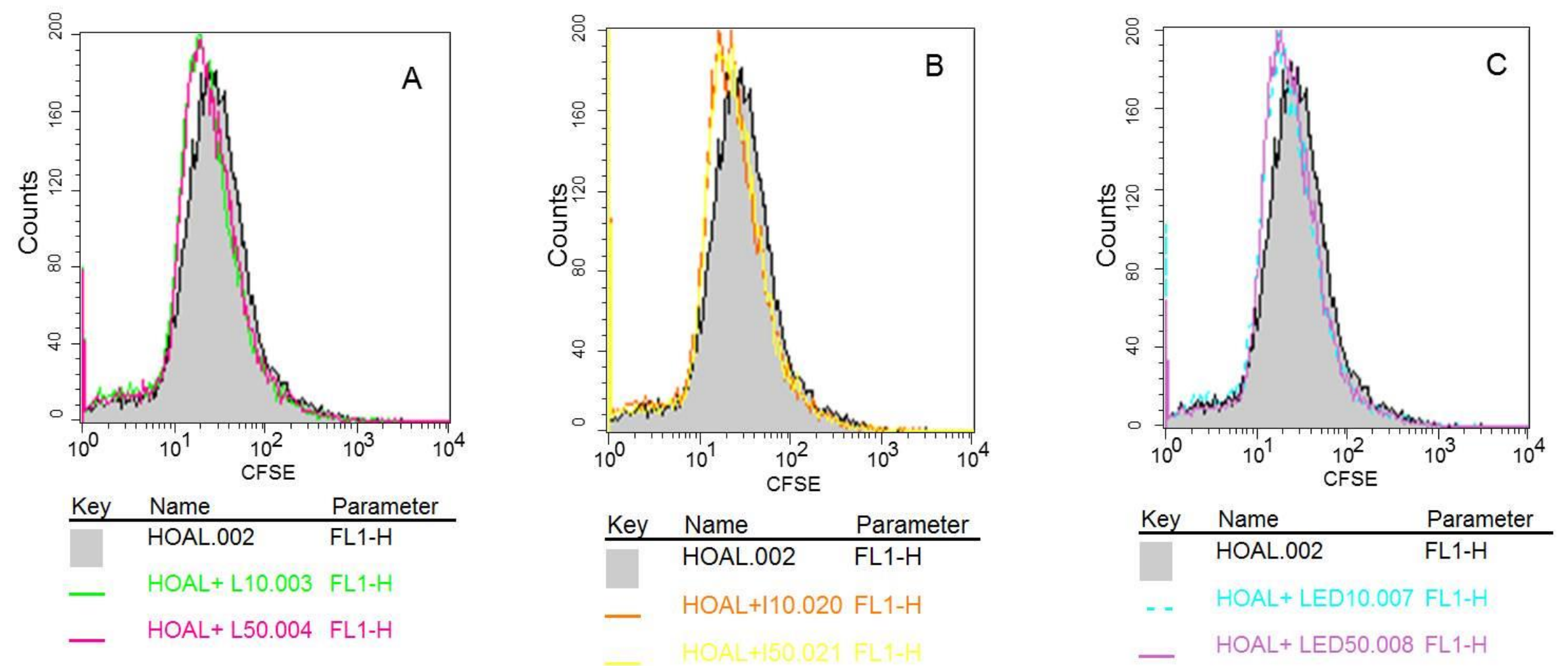

Figura 15 - Histogramas do efeito da fototerapia na proliferação das células HOAL realizados por citometria de fluxo no período de 72 horas. (A) Comparações entre o controle (cinza) e laser vermelho nas doses de 10 (verde) e $50 \mathrm{~J} / \mathrm{cm}^{2}$ (rosa). (B) Comparações entre os grupos controle (cinza) e laser infravermelho nas doses de 10 (laranja) e $50 \mathrm{~J} / \mathrm{cm}^{2}$ (amarelo). (C) Comparações entre o controle (cinza) e LED nas doses de 10 (azul) e $50 \mathrm{~J} / \mathrm{cm}^{2}$ (roxo). O posicionamento do marcador M1 foi dado a partir da intensidade de fluorescência $=10^{3}$. 


\section{CFSE}

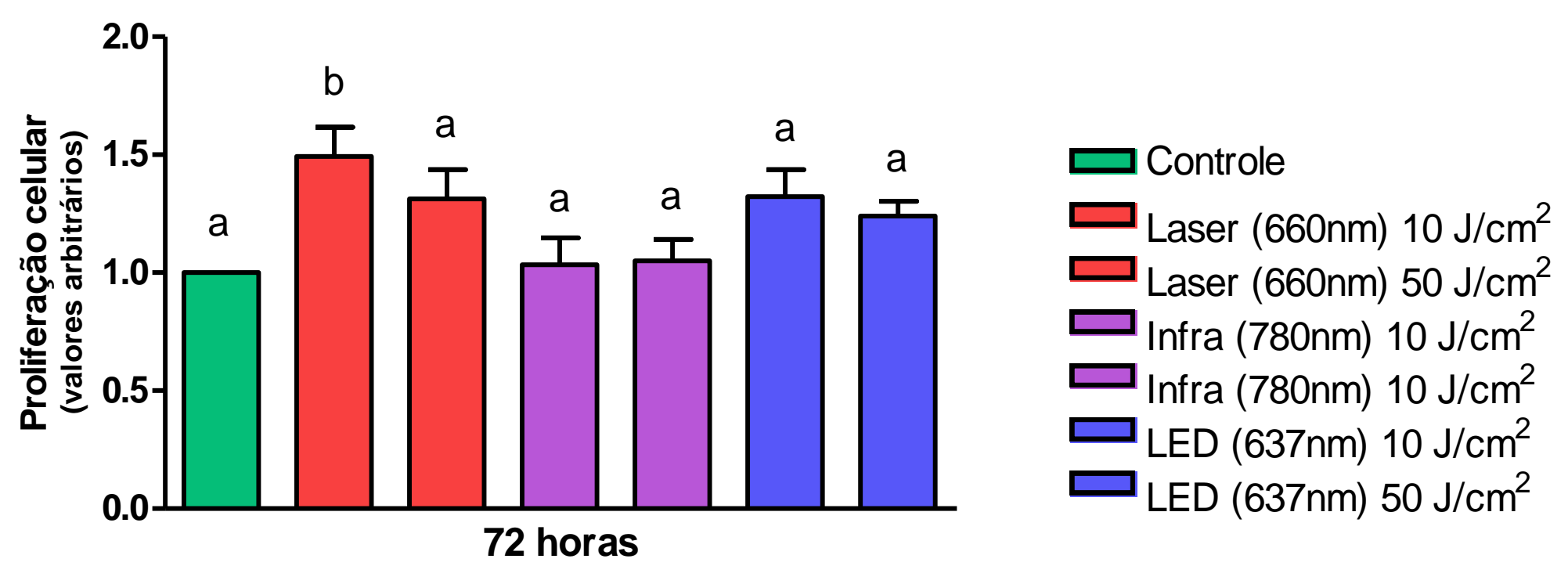

Figura 16 - Efeito dos diferentes espectros na proliferação dos osteoblastos humanos HOAL no período de 72 horas. Os resultados da triplicata representam a média \pm SEM dos valores relativos da densitometria, adotando o grupo controle como sendo $=1$. Letras diferentes indicam diferenças estatísticas $(p<0,05)$ em relação ao grupo controle. 


\subsection{ANÁLISE DA ATIVAÇÃO DA PROTEÍNA INTRACELULAR ERK}

Uma vez tenha sido mostrado que as diferentes fototerapias aumentam a viabilidade e/ou proliferação celular, a seguir avaliamos se a proteína intracelular ERK foi ativada durante a proliferação celular induzida pela irradiação. Esta foi avaliada pela semi-quantificação da fosforilação por meio da técnica de western blotting, usando anticorpo específico após $10 \mathrm{~min}$ da irradiação pontual com as diferentes fototerapias. A fosforilação de ERK foi dada pela razão da proteína ERK total não-fosforilada. O Blotting de 3 experimentos independentes mostrando a marcação da ERK1/2 fosforilada ( $p$-ERK) nos diferentes grupos experimentais estão representados na figura 17A. A análise densitométrica da pERK1/2/ERK $1 / 2$ total demonstra que a irradiação das células HOAL com laser vermelho e infravermelho, na dose de $10 \mathrm{~J} / \mathrm{cm}^{2}$, aumentou significativamente a fosforilação da ERK1/2 em relação grupo controle (Figura 17B). As demais doses bem como outros espectros aumentaram, embora de maneira não significativa, a ativação de ERK1/2. Esses resultados sugerem que a ativação de ERK pode estar envolvida no aumento da proliferação celular induzido pelos laseres vermelho e infravermelho (mostrado anteriormente nos ensaios de MTT e de citometria de fluxo). 
A

$\operatorname{EXP} 1$

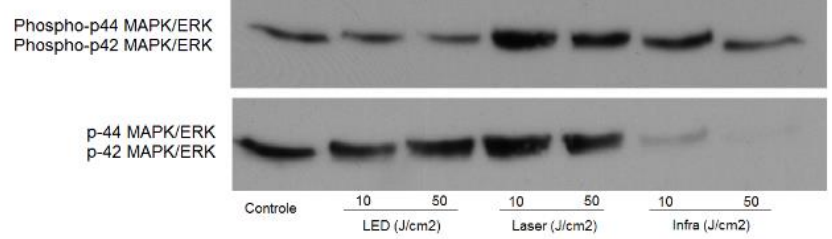

B

p-ERK

EXP 2

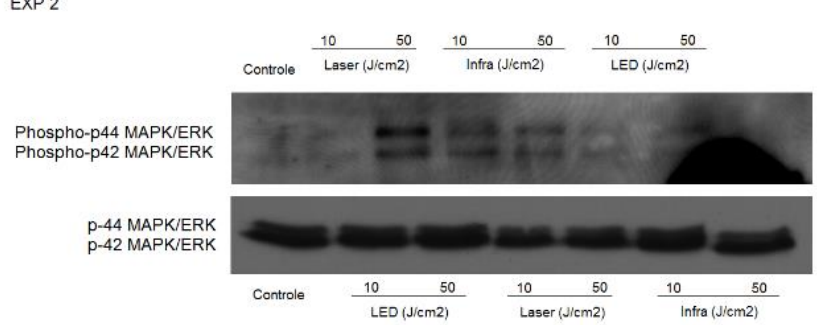

EXP 3
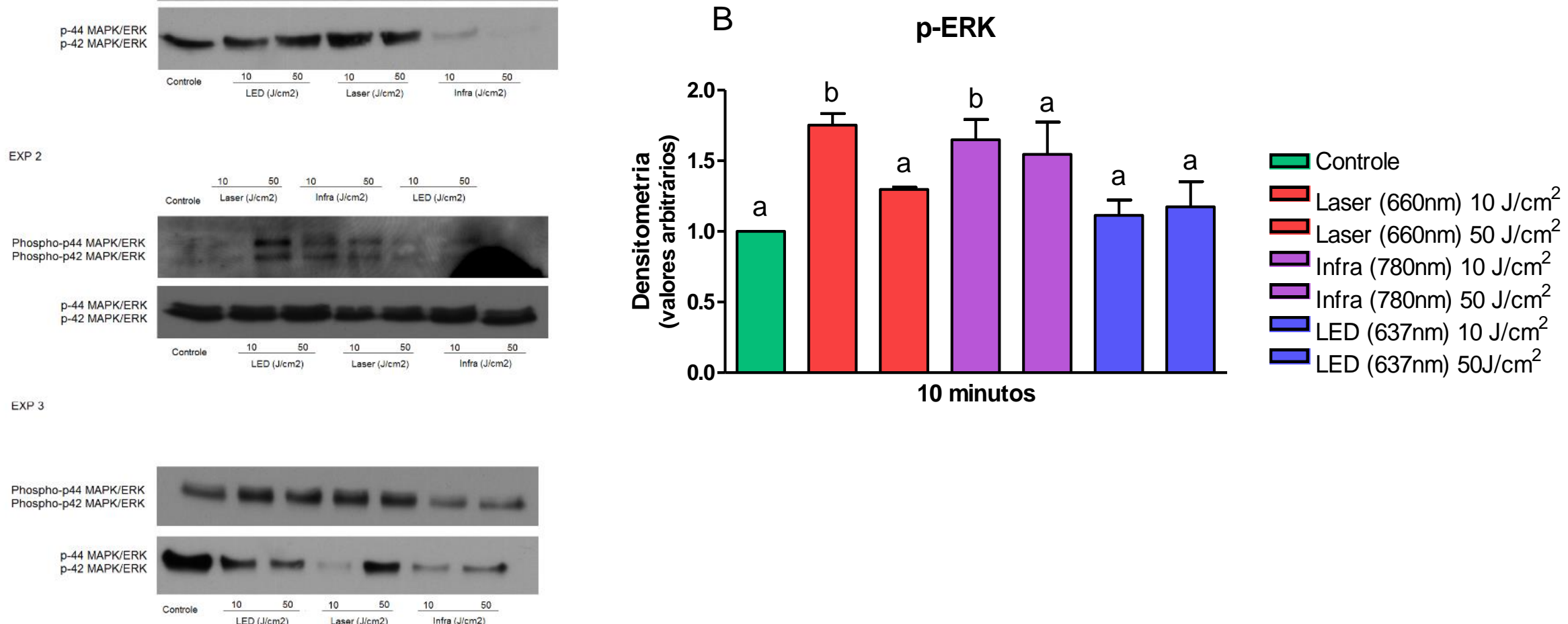

Figura 17 - Ativação da ERK em células HOAL após diferentes fototerapias. (A) Figura representativa das bandas dos grupos controle, laser vermelho 10 e 50 $\mathrm{J} / \mathrm{cm}^{2}$, infravermelho 10 e $50 \mathrm{~J} / \mathrm{cm}^{2}$, LED 10 e $50 \mathrm{~J} / \mathrm{cm}^{2} ; \mathrm{n}=3$. (B) Gráfico da análise densitométrica. Números arbitrários foram utilizados no qual o grupo controle foi adotado como sendo igual a 1 e os valores dos grupos tratados são relativos ao controle. Letras diferentes significam diferenças em relação ao controle. 


\subsection{EFEITO DA INIBIÇÃO DE ERK NA PROLIFERAÇÃO INDUZIDA PELOS DIFERENTES ESPECTROS}

A seguir, avaliamos se a ativação de ERK1/2 participa da indução das fototerapias sobre a proliferação das células HOAL. Para tanto, as células foram sequencialmente pré-tratadas com o inibidor farmacológico de ERK, seguido da estimulação com as diferentes fototerapias (aplicação dupla). Diferente dos histogramas mostrados na Figura 18, a inibição de ERK previamente à aplicação dos laseres e LED em ambas doses testadas mostraram que não houve diferença estatística na proliferação quando comparado com as células tratadas com o inibidor não-irradiadas. Assim na presença do inibidor de ERK, todas as fototerapias foram semelhantes ao controle mostrando que a inibição de ERK impediu o efeito positivo do laser na indução da proliferação celular (Figura 19). 

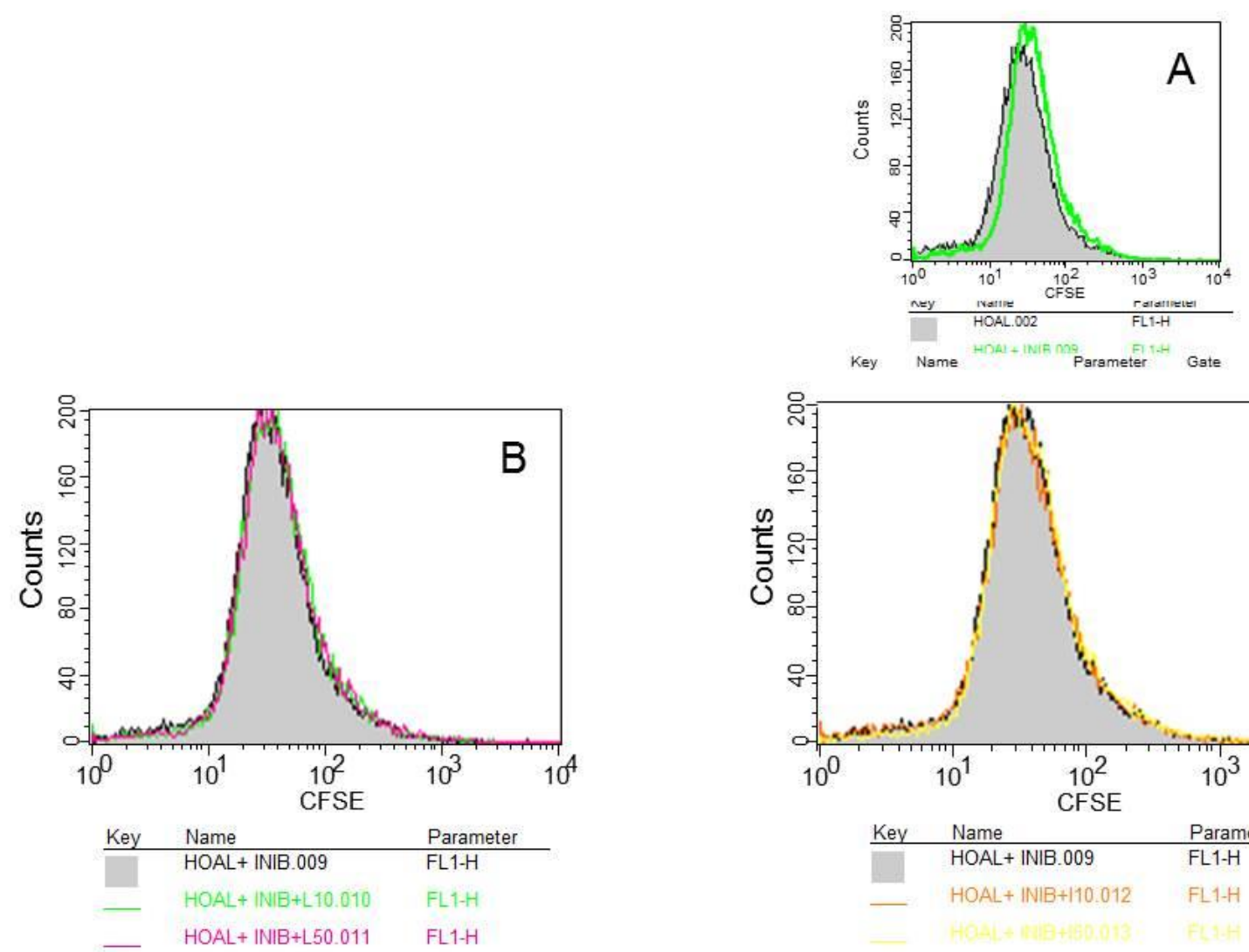

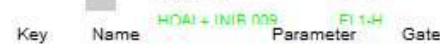
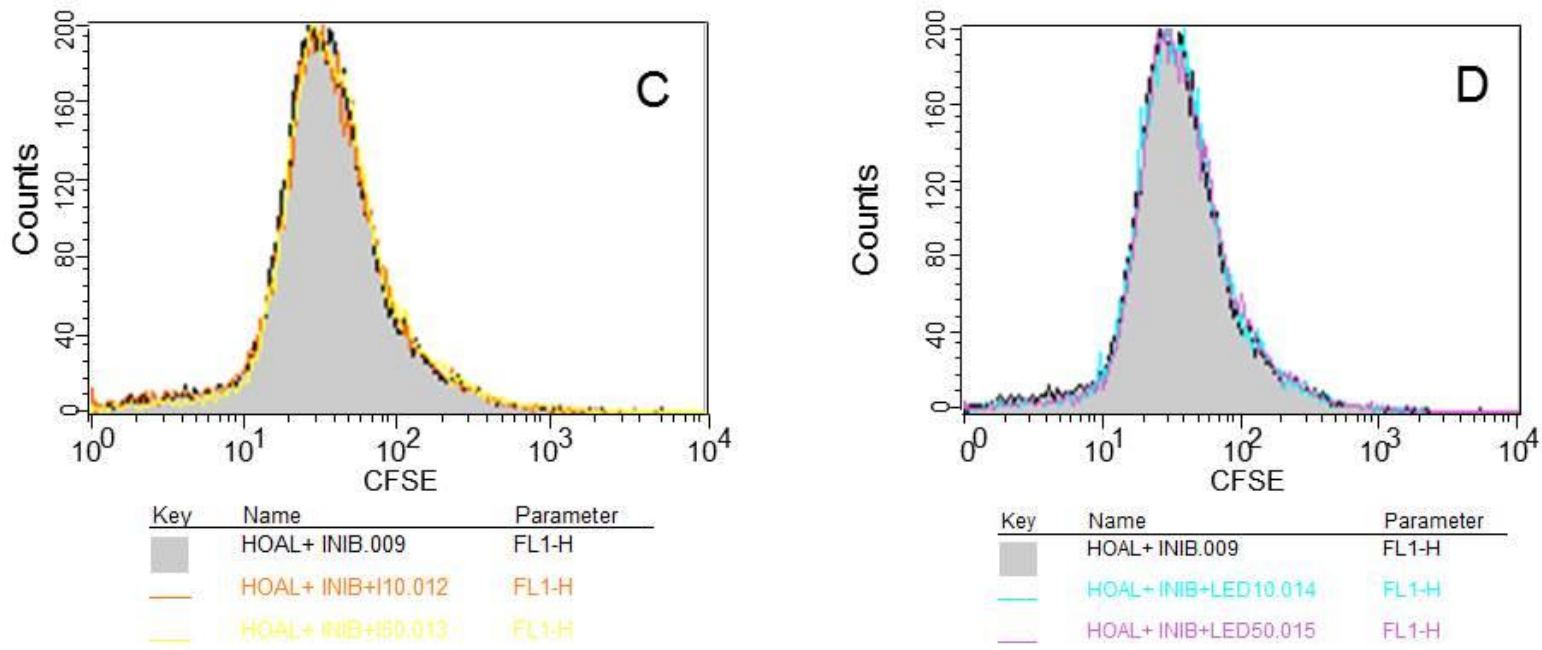

Figura 18 - Histogramas do efeito da fototerapia na proliferação das células HOAL na presença do inibidor de ERK PD98059 no período de 72 horas. (A) Células HOAL na ausência (cinza) ou presença (verde) do inibidor. (B) Comparações entre o controle (cinza) e laser vermelho nas doses de 10 (verde) e 50 $\mathrm{J} / \mathrm{cm}^{2}$ (rosa). (C) Comparações entre os grupos controle (cinza) e infravermelho nas doses de 10 (laranja) e $50 \mathrm{~J} / \mathrm{cm}^{2}$ (amarelo). (D) Comparações entre o controle (cinza) e LED nas doses de 10 (azul) e $50 \mathrm{~J} / \mathrm{cm}^{2}$ (roxo). O posicionamento do marcador M1 foi dado a partir da intensidade de fluorescência $=10^{3}$. 


\section{CFSE + Inibidor de ERK}

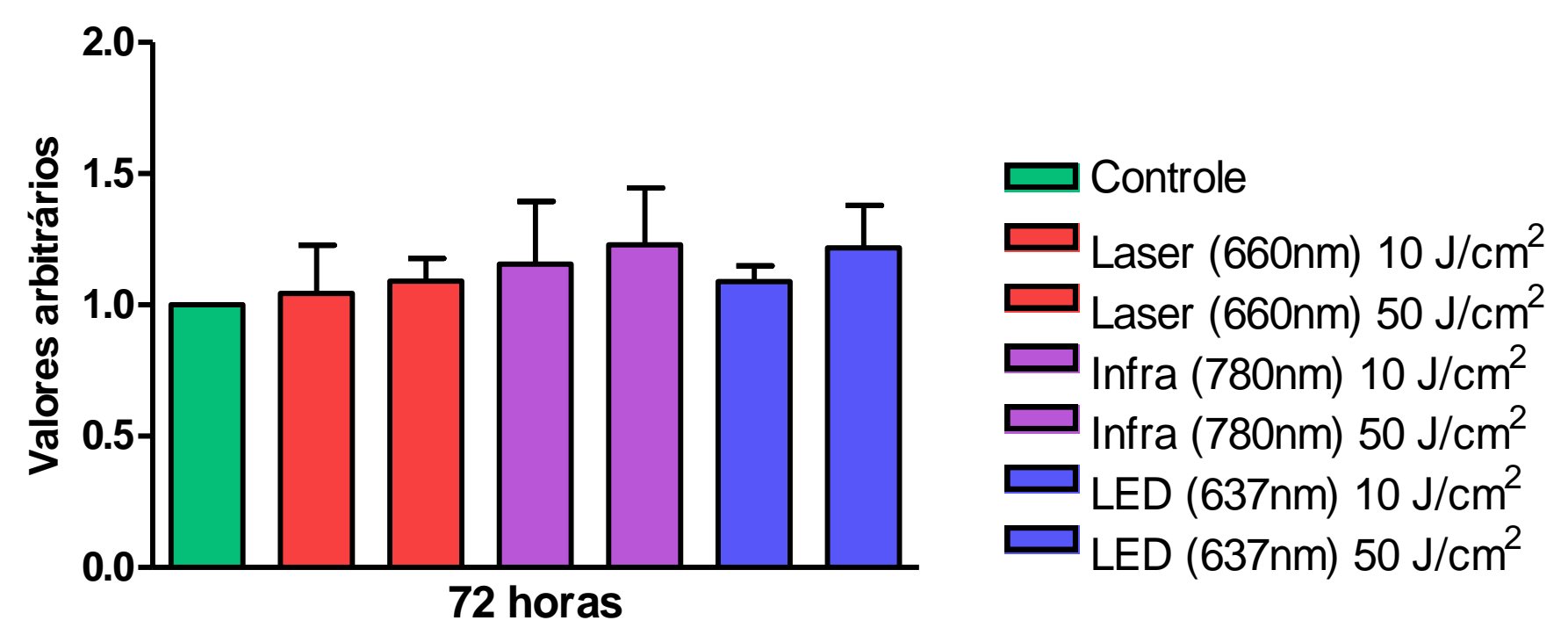

Figura 19 - Efeito da inibição de ERK na proliferação das células HOAL induzida pelos diferentes espectros no período de 72 horas. Os resultados representam a média \pm SEM dos valores relativos da densitometria, adotando o grupo controle como sendo $=1$. 


\subsection{ATIVIDADE DA ALP: HOAL X MC3T3-E1}

Inicialmente, com o objetivo de avaliar o potencial osteogênico das células HOAL; realizamos a análise da atividade da ALP produzidas por essas células, por ser um marcador importante da diferenciação osteogênica. Para fins comparativos, a mesma foi avaliada em células MC3T3-E1, ambas submetidas ou não ao estímulo osteogênico. O perfil da atividade da ALP se mostrou bastante semelhante para ambas células (Figura 20). Não observou-se nenhum efeito aditivo da atividade da ALP frente ao estímulo osteogênico. Além disso, embora a atividade não tenha variado significativamente em relação aos períodos avaliados para ambas, observamos que no 21ำ dia, há um ligeiro aumento na atividade para as MC3T3-E1 e diminuição para a HOAL, enquanto no $28^{\circ}$ dia, esse perfil é invertido. Isso pode sugerir que as células HOAL apresentam um grande potencial osteogênico, porém com um retardo de 7 dias, em relação às células MC3T3-E1. Adicionalmente, pelo fato de a atividade de ALP da HOAL não ter apresentado diferenças após indução in vitro da osteogênese, como acontece com os pré-osteoblastos MC3T3-E1, essas células parecem estar num grau de diferenciação já avançado e totalmente comprometido com a linhagem osteogênica. 
Atividade de ALP

HOAL x MC3T3-E1
Meio

Meio osteogênico

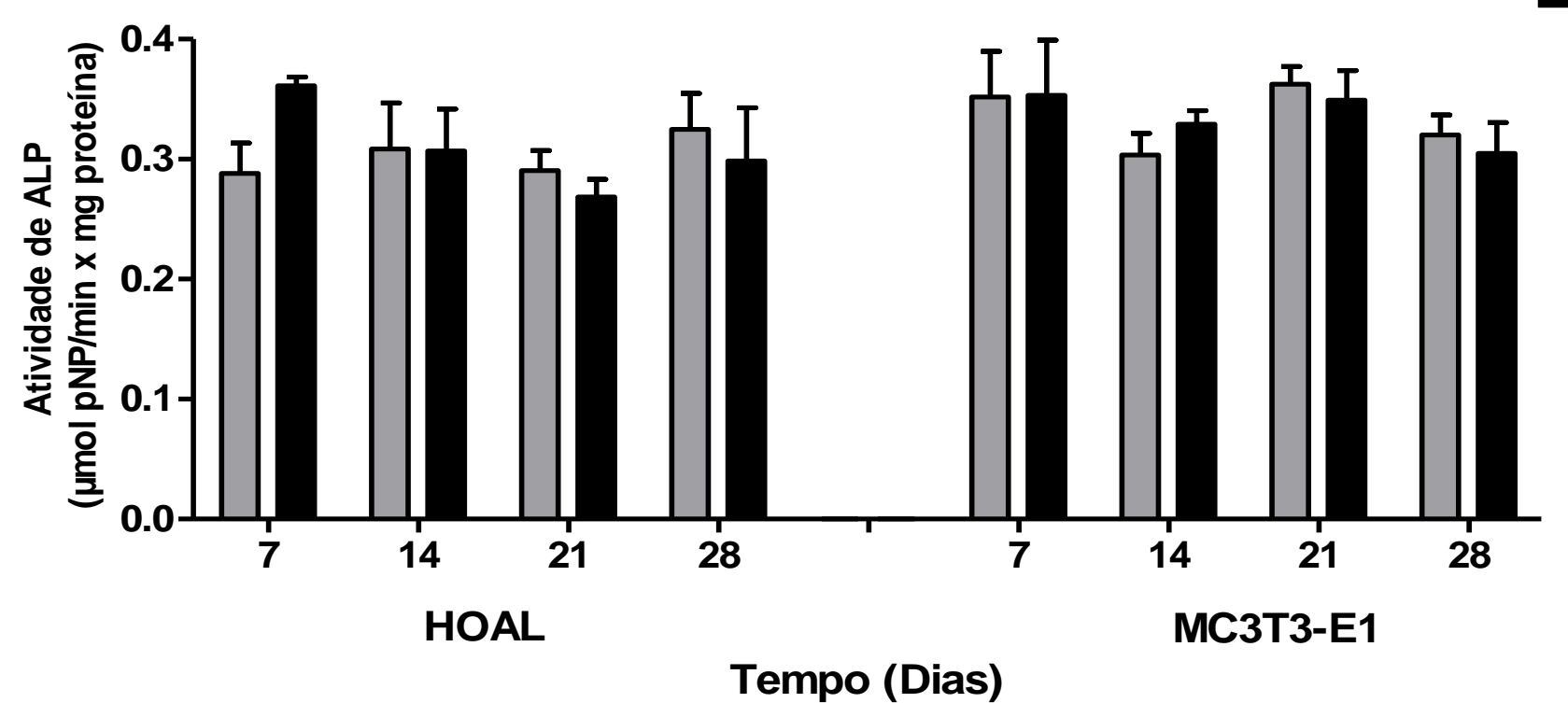

Figura 20 - Atividade de ALP em HOAL e MC3T3-E1 nos períodos de 7, 14, 21 e 28 dias de cultivo. As células foram cultivadas em DMEM/10\% SFB ou DMEM/10\% SFB osteogênico (acrescido de $50 \mu \mathrm{g} / \mathrm{mL}$ ácido ascórbico e $10 \mathrm{mM}$ de $\beta$-glicerofosfato) para as células HOAL e MEM/10\%SFB ou MEM/10\% SFB osteogênico para as células MC3T3-E1. Os resultados mostram a média da atividade enzimática em nmol de p-NP/minuto pela quantidade de proteína total em mg. Não houve diferença estatística $(p>0,05)$ 


\subsection{EFEITO DAS DIFERENTES FOTOTERAPIAS NA ATIVIDADE DA ALP}

Com o objetivo de avaliar o efeito dos laseres e LED na osteogênese das células HOAL; realizamos a análise da atividade da ALP produzidas por essas células, por ser um marcador importante da diferenciação osteogênica. A Anova a 2 critérios detectou diferença significativa entre os grupos ( $F=8,228442) ;(p<0,0001)$ e entre os períodos $(F=151,2067) ;(p<0,0001)$, revelando significativa interação entre os dois critérios $(F=2,258674) ;(p<0,004286133)$.

Quando comparado com o controle, observou-se inibição significativa da atividade da ALP nas células irradiadas com LED em ambas intensidades no $14^{\circ}$ dia. Entretanto, não foram observadas diferenças entre os demais grupos e períodos em relação ao controle. A atividade de ALP nas células HOAL que não foram irradiadas apresentou um pico no $14^{\circ}$ dia sendo reduzida significativamente nos períodos posteriores, não sendo observada diferença significativa entre os períodos de 21 e 28 dias. A cinética da ALP nos demais grupos experimentais apresentou um perfil bastante semelhante ao grupo controle. Nota-se que o grupo LED nas doses de $10 \mathrm{e}$ $50 \mathrm{~J} / \mathrm{cm}^{2}$ já apresentou inibição, porém não significativa, da ALP no $7^{\circ}$ dia em relação aos demais grupos, e embora tenhamos observado uma tendência de aumento no 14ํㅜำ dia em relação ao $7^{\circ}$ dia, essa diferença foi menos aparente do que nos demais grupos e talvez seja o motivo de termos encontrado inibição significativa no $14^{\circ}$ dia em relação ao controle (Figura 21). 


\section{Atividade de ALP}

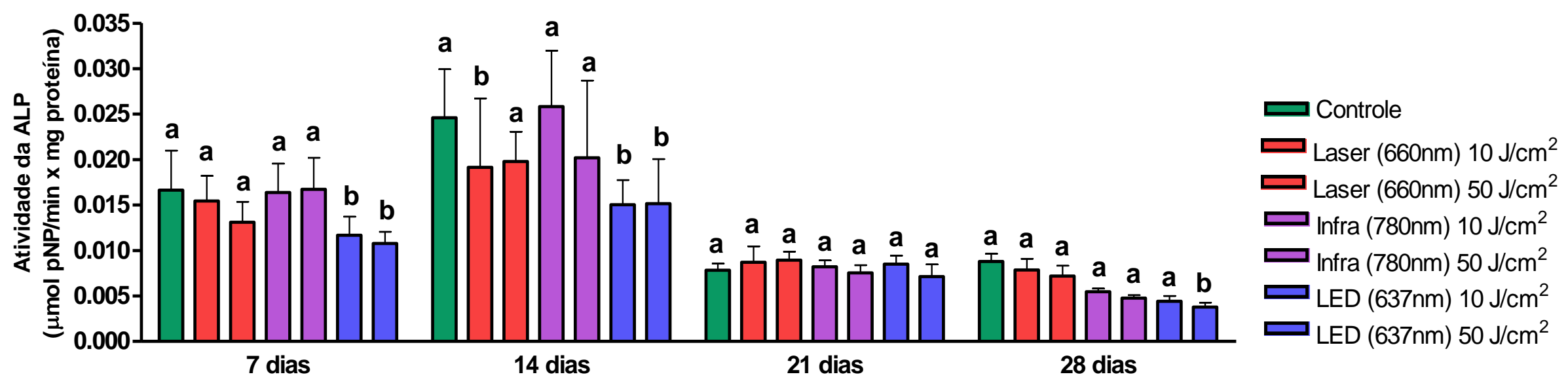

Figura 21 - Efeito dos diferentes tipos de laser e LED na atividade de fosfatase alcalina. Os resultados mostram a média e o desvio padrão da atividade enzimática dado em $\mu$ mol de p-NP/minuto pela quantidade de proteína total em mg. Letras diferentes significam diferenças em relação ao controle (Anexos 16 a 18). 


\subsection{ANÁLISE DO RT-PCR EM TEMPO REAL}

\subsubsection{Efeito dos diferentes espectros na expressão gênica do Colágeno I (COL1A1)}

O ensaio de RT-PCR em tempo real mostrou que o gene colágeno I foi modulado pelos diferentes tipos de laser (Figura 22A). Em geral a expressão relativa do COL1A1 apresentou oscilações de acordo com os períodos apresentados, tendo sua expressão diminuída no período de 21 dias. Com 07 dias, os níveis de expressão gênica apresentaram-se de forma linear, não havendo diferenças significativas em relação ao controle. No período de 14 dias, o LED $50 \mathrm{~J} / \mathrm{cm}^{2}$ modulou positivamente a expressão de colágeno $\mathrm{I}$, porém os diferentes espectros (laser vermelho e infravermelho) nas diferentes doses inibiu a expressão desse gene. Após 21 dias, o LED em ambas doses, aumentou de forma significativa a expressão desse gene quando comparada ao controle. No período de 28 dias, o laser vermelho na dose de $50 \mathrm{~J} / \mathrm{cm}^{2}$ inibiu a expressão de COL1A1.

\subsubsection{Efeito dos diferentes espectros na expressão gênica do SPARC}

O perfil geral da expressão de SPARC nos 4 períodos se mostrou semelhante ao perfil do $\operatorname{COL} 1 \mathrm{~A} 1$, observando uma diminuição da expressão no $21^{\circ}$ dia (Figura 22B). Com 07 dias, os grupos laser vermelho e LED, nas doses de $10 \mathrm{e}$ $50 \mathrm{~J} / \mathrm{cm}^{2}$ respectivamente, estimulou um aumento da expressão desse gene $(p<0,05)$. No 14ำ não houve diferenças estatísticas entre os grupos $(p>0,05)$. $O$ aumento da expressão de SPARC foi observado com 21 dias, nos grupos laser vermelho $10 \mathrm{~J} / \mathrm{cm}^{2}$ e LED 10 e $50 \mathrm{~J} / \mathrm{cm}^{2}$ em relação ao controle, porém, nesse tempo todos os grupos foram menos expressivos quando comparados aos demais períodos. Com 28 dias foi observado um aumento da expressão gênica nos grupos infravermelho, em ambas doses e no LED $10 \mathrm{~J} / \mathrm{cm}^{2}$ com relação ao controle. 


\section{A}

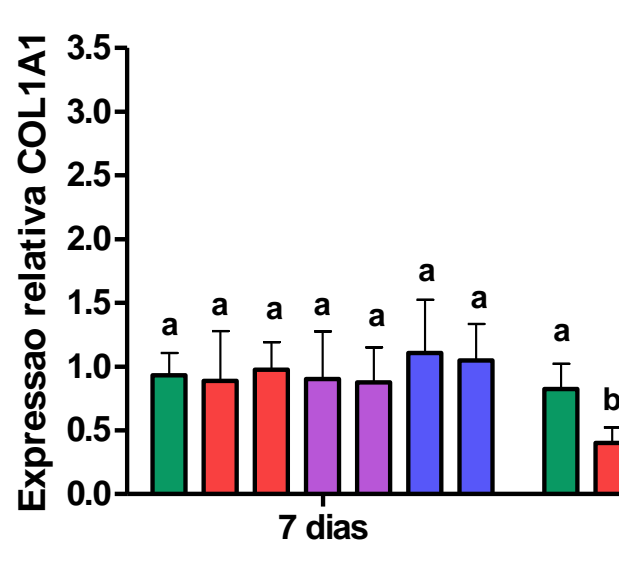

COL $1 \mathrm{~A} 1$

B

SPARC

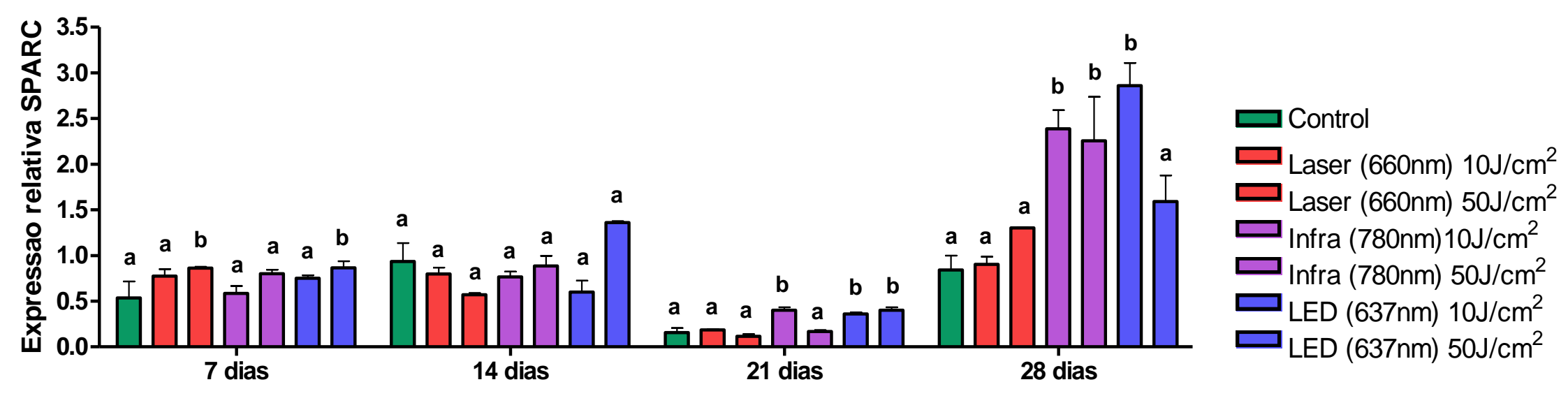

Figura 22 - Efeito dos diferentes espectros na expressão gênica de COL1A1 (A) e SPARC (B) em osteoblastos humanos. Letras diferentes representam diferenças estatísticas em relação ao grupo controle (Anexos 19 a 24). 


\subsection{CARACTERIZAÇÃO DO POTENCIAL DE MINERALIZAÇÃO DAS CÉLULAS} HOAL

A deposição de cálcio em placas coradas com vermelho de alizarina de experimento representativo é mostrada na figura 23 A, B e C. A análise quantitativa da coloração demonstra que a mineralização das células MC3T3-E1 apresentam significativamente maior deposição de cálcio no $14^{\circ}$ e $21^{\circ}$ dias comparado com as células HOAL, sendo o pico no $21^{\circ}$ dia seguido de discreto declínio no $28^{\circ}$ dia. Já as células HOAL apresentam o pico no 28 dia com níveis semelhantes aos da MC3T3E1 (Figura 24). Esses resultados mostram que as células HOAL apresentam capacidade de mineralização comparado aos pré-osteoblastos, porém o pico da mineralização ocorre no $28^{\circ}$ dia de cultura e não no $21^{\circ}$ dia. Em conjunto com os dados da ALP, mostramos que essa célula humana já está em processo de diferenciação osteogênica e é capaz de sintetizar matriz óssea proteica com potencial mineralizador.

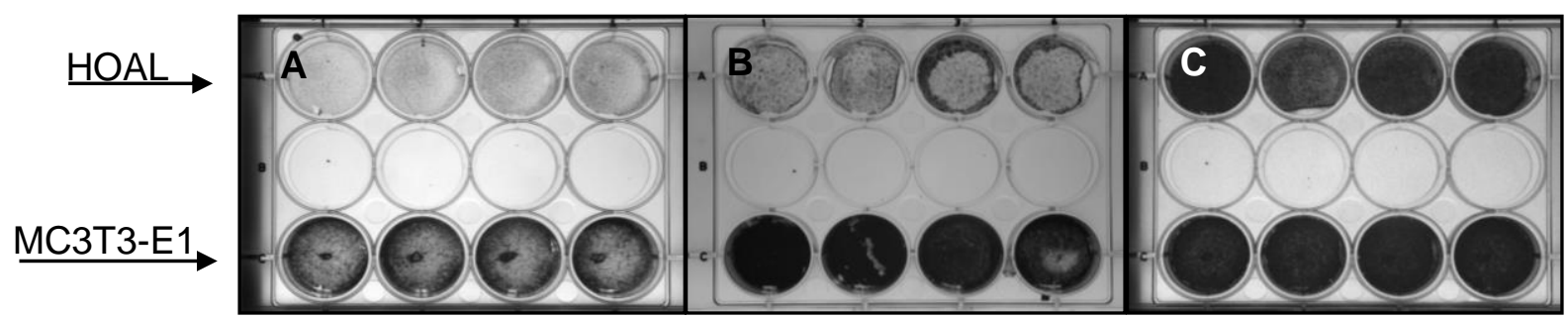

Figura 23 - Deposição de cálcio pelas células HOAL (superior) e MC3T3-E1 (inferior) pelo corante vermelho de alizarina vermelha, nos períodos de 14 dias (A), 21 dias (B) e 28 dias (C). $n=4$. 


\section{Deposição de Cálcio}

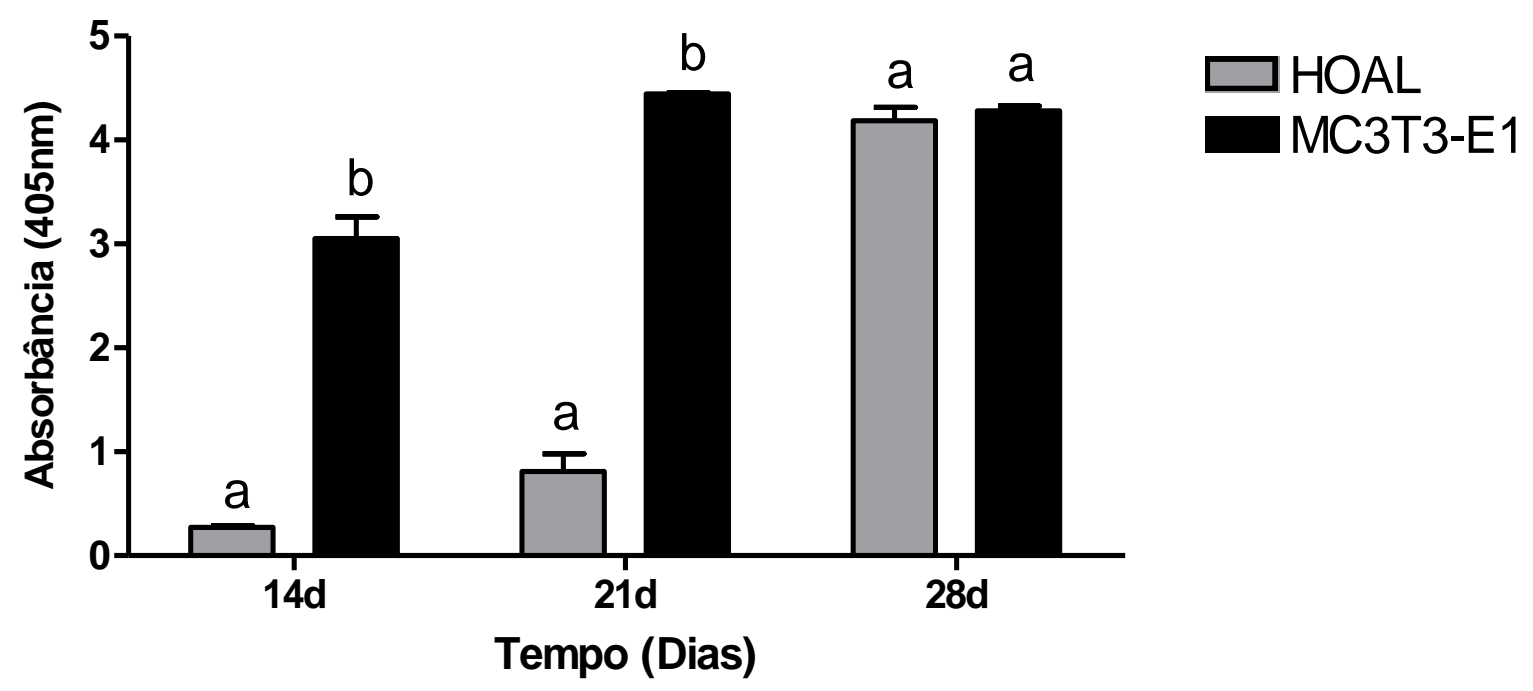

Figura 24 - Análise quantitativa da coloração com vermelho de alizarina nas células HOAL e MC3T3E1 nos períodos de 14, 21 e 28 dias. Letras diferentes indicam diferenças estatísticas em relação à mineralização de ambas linhagens dentro de um mesmo período.

\subsection{EFEITO DOS DIFERENTES ESPECTROS NA MINERALIZAÇÃO}

A ANOVA a 2 critérios mostrou diferença significativa entre os grupos ( $\mathrm{F}=$ 8,997007); $(p<0,0001)$ e entre os períodos $(F=829,4574)$; $(p<0,0001)$, revelando significativa interação entre os dois critérios ( $F=9,388209)$; $(p<0,0001)$.

Quando comparado com o controle, o grupo laser vermelho nas doses de $50 \mathrm{~J} / \mathrm{cm}^{2}$ e $10 \mathrm{~J} / \mathrm{cm}^{2}$ apresentaram aumento da mineralização nos períodos de 21 e 28 dias respectivamente, porém, não foram observados diferenças em relação aos demais grupos. Com relação ao mesmo tipo de laser, em doses diferentes, observouse que a dose de $10 \mathrm{~J} / \mathrm{cm}^{2}$ foi mais efetiva que a de $50 \mathrm{~J} / \mathrm{cm}^{2}$ em promover a mineralização com laser vermelho e o infravermelho $10 \mathrm{~J} / \mathrm{cm}^{2}$ apresentou aumento de mineralização em relação ao infravermelho $50 / \mathrm{cm}^{2}$ com 28 dias. Na dose de $50 \mathrm{~J} / \mathrm{cm}^{2}$, o infravermelho apresentou maior deposição de cálcio que o laser vermelho no período de 7 dias, e com 21 dias, o laser foi mais efetivo que o laser infravermelho (Figura 25). A descrição completa está representada nos anexos 25 a 27. 


\section{Deposição de Cálcio}

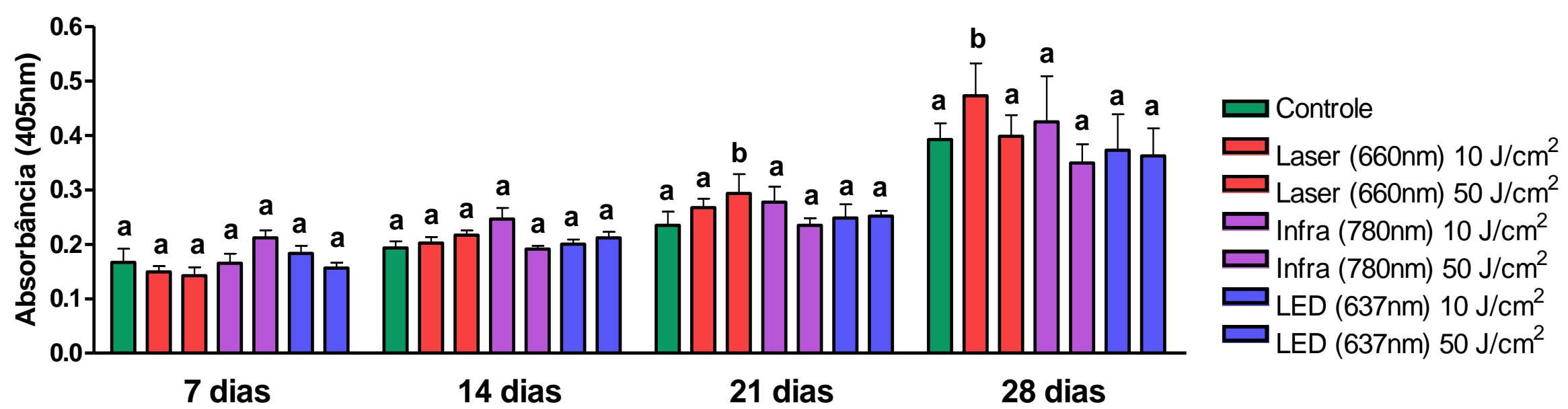

Figura 25 - Efeito dos diferentes espectros na análise quantitativa da deposição de cálcio por meio da coloração com vermelho de alizarina nas células HOAL nos períodos de 07, 14, 21 e 28 dias. Letras diferentes representam diferenças em relação ao controle em um mesmo período. 


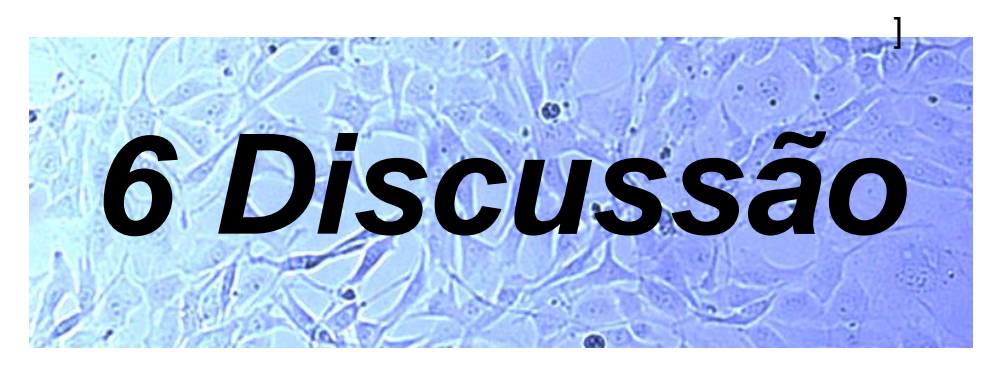





\section{DISCUSSÃO}

O laser de baixa potência é uma importante ferramenta terapêutica na área odontológica e médica (POSTEN et al., 2005; PINHEIRO, 2009). No entanto, os mecanismos biológicos relacionados aos efeitos bio-estimulantes do laser não foram completamente elucidados. Vários estudos têm sido realizados para ampliar a compreensão dos efeitos da irradiação com laser no nível celular, e sugerem que a terapia com LLLT modula os processos metabólicos de vários tipos celulares (MESTER et al., 1985; KAMALI et al., 2007; KHADRA et al., 2005; KHADRA et al. 2005; SCHWARTZ-FILHO et al., 2011), inclusive em células osteogênicas, aumentando sua proliferação (GRASSI et al., 2011).

Este trabalho avaliou o efeito de diferentes fototerapias de baixa potência, o laser vermelho, infravermelho e diodo emissor de luz na viabilidade e proliferação de osteoblastos humanos. Em relação à viabilidade, as fototerapias em diferentes doses aumentaram significativamente a viabilidade das células HOAL, demonstrado por meio do ensaio de Redução do MTT e cristal violeta. Embora esses ensaios sejam um método indireto para avaliar a proliferação celular, eles não são totalmente apropriados para a avaliação direta do aumento do número de células, portanto, nossos resultados sugerem que as diferentes fototerapias aumentam a proliferação celular, fenômeno inicial do processo da diferenciação osteogênica. Além disso, os resultados demonstram que o regime de aplicação é importante em exacerbar o efeito estimulatório das fototerapias sobre a proliferação das células osteogênicas.

Nesse sentido, mostramos que, comparado à apenas uma aplicação, duas aplicações foram mais eficientes em aumentar a viabilidade celular. Essa resposta é evidenciada uma vez que todas as fototerapias testadas, nas doses de 10, 20 ou 50 $\mathrm{J} / \mathrm{cm}^{2}$, aumentaram significativamente a viabilidade celular nos períodos de 24 , 48 e 72 horas. Resultados anteriores do nosso grupo mostraram que as doses de 1,9 e $3,8 \mathrm{~J} / \mathrm{cm}^{2}$ aumentaram a viabilidade de pré-osteoblastos de linhagem (MC3T3-E1), porém em intensidades inferiores àquelas observadas nesse trabalho (OLIVEIRA et al., 2013). Embora esses dados tenham sido obtidos em tipos celulares diferentes, podemos sugerir que a dose da irradiação é um fator importante em determinar os efeitos estimulatório e/ou inibitório. De fato, mostramos no ensaio de MTT que o LED na dose de $50 \mathrm{~J} / \mathrm{cm}^{2}$ tanto no regime de uma aplicação quanto no de aplicação dupla, 
com 72 horas e, no ensaio cristal violeta, o LED $20 \mathrm{~J} / \mathrm{cm}^{2}$ nos períodos de 48 e 24 horas, com 1 ou 2 aplicações respectivamente inibiram significativamente a viabilidade das células HOAL quando comparado com dose inferior $\left(10 \mathrm{~J} / \mathrm{cm}^{2}\right)$.

Para complementar os resultados de viabilidade celular, optou-se por analisar a proliferação por citometria de fluxo utilizando o corante nuclear CFSE. Quando células marcadas com CFSE sofrem mitose, o corante se distribui igualmente entre as células filhas, as quais passam a apresentar metade da fluorescência da célula mãe. Assim, a diminuição da intensidade de fluorescência das células é proporcional à sua proliferação (ALVES, 2011). Com relação a proliferação das células HOAL, nosso trabalho mostrou que as todas as células apresentaram $100 \%$ de proliferação após 72 horas, porém, na análise do efeito das fototerapias foi observado discreto aumento do laser $50 \mathrm{~J} / \mathrm{cm}^{2}$ e do LED em ambas doses embora não se mostraram significativas. Apenas o laser vermelho $10 \mathrm{~J} / \mathrm{cm}^{2}$ apresentou aumento de $7 \%$ na proliferação em relação ao controle.

Vários estudos envolvendo LLLT mostram que eles promovem a aceleração dos processos de cicatrização por seu efeito bioestimulador sobre diferentes tipos celulares (NOGUEIRA et al., 2009). Os mecanismos de ação do laser que promovem a cicatrização e redução da inflamação e da dor, em nível celular e molecular, ainda não foram completamente elucidados, mas algumas hipóteses têm sido levantadas. Em 1989, Karu defendia que a energia do laser seria absorvida nas mitocôndrias por citocromos, provocando a transmissão de elétrons e levando a um aumento da síntese proteica e ativação da produção de energia (ATP) promovendo o efeito cicatricial (VOLPATO, 2009).

Com o objetivo de avaliar o mecanismo intracelular induzido pelas fototerapias, avaliamos se as mesmas ativam a proteína quinase ERK $1 / 2$, pertencente à família das MAPquinases, envolvida em processos de proliferação celular, diferenciação e apoptose (KIYOSAKI et al., 2010). A sinalização da ERK ativada pela LLLT ocorre em períodos curtos. Os autores supracitados avaliaram a fosforilação da ERK com 5, 10, 20, 30 e 60 minutos, e observaram maior expressão nos períodos de 10 a 30 minutos após estimulação com LLLT.

Mostramos que houve um aumento significativo da expressão de ERK fosforilada nas células tratadas com laser vermelho e infravermelho na dose de 
$10 \mathrm{~J} / \mathrm{cm}^{2}$ após 10 minutos de estimulação. A escolha do tempo foi baseada no trabalho de Kiyosaki et al. (2010). Portanto, a ativação desta via de sinalização pode ser um dos mecanismos intracelulares envolvidos no aumento da proliferação das células HOAL induzido pelas fototerapias. Para a comprovação dessa hipótese, os osteoblastos humanos foram tratados com o inibidor de ERK. Assim, na sua presença, todas as fototerapias foram semelhantes ao controle mostrando que a inibição de ERK impediu o efeito positivo do laser na indução da proliferação celular, contudo mais estudos são necessários para elucidar os efeitos dos diferentes espectros na ativação dessa proteína.

O efeito dos laseres na diferenciação de células osteogênicas também tem sido avaliado. Em osteoblastos humanos e células da calvária de ratos o laser de baixa intensidade pulsado aumentou a síntese de proteínas da matriz óssea (XU et al., 2009).

A remodelação óssea é refletida por uma atividade complexa de marcadores tanto de formação quanto de reabsorção óssea. Sabe-se que os marcadores de formação óssea refletem a atividade osteoblástica em diferentes estágios de diferenciação. Entre eles, a fosfatase alcalina específica do osso, produzida por osteoblastos, é essencial para a mineralização óssea, onde a sua síntese maior coincide com a produção de matriz orgânica rica em colágeno (STEIN \& LIAN, 1993).

A compreensão do papel da ALP na mineralização é baseada em estudos de expressão gênica durante a diferenciação osteoblástica. No tecido ósseo, a ALP é expressa precocemente no desenvolvimento sendo observada na superfície da célula e em vesículas de matriz. Durante o desenvolvimento, outros genes como a osteocalcina são altamente regulados e consequentemente a expressão da ALP diminui. Portanto, é notável que sua atividade é maior nas fases iniciais do processo de formação óssea. O mecanismo pela qual a expressão da ALP é regulada é bastante complexo, no qual várias vias de sinalização estão envolvidas, cujos detalhes estão emergindo (GOLUB et al., 2007; BOESZE-BATTAGLIA, 2007).

Para conhecer o potencial de diferenciação das células primárias HOAL foi realizado o ensaio da atividade de ALP comparativamente às células imortalizadas de linhagem murina MC3T3-E1, onde foi mostrado que a atividade de fosfatase alcalina 
de ambas linhagens na presença ou ausência de meio osteogênico apresentaram valores semelhantes em todos os períodos mostrando que essas células estão comprometidas com a diferenciação.

Martinasso e colaboradores (2007) mostraram que o laser de baixa intensidade aumenta a proliferação e mineralização de osteoblastos humanos vista pelo aumento da quantidade de proteínas essenciais para a formação da matriz óssea. Com relação aos efeitos da fototerapia, estudos do nosso grupo mostraram que o laser vermelho e infravermelho, nas doses de $90 \mathrm{~J} / \mathrm{cm}^{2}$ e $150 \mathrm{~J} / \mathrm{cm}^{2}$, nos períodos de 3, 4, 7 e 14 dias, não aumentam a produção da ALP em células osteogênicas da linhagem MC3T3-E1, quando comparado ao grupo controle (PACHECO et al., 2013). Porém em doses menores $\left(1,9 \mathrm{~J} / \mathrm{cm}^{2}\right.$ e $\left.3,8 \mathrm{~J} / \mathrm{cm}^{2}\right)$ a mesma LLLT modula a proliferação e diferenciação das células MC3T3-E1 aumentando a proliferação e a atividade da ALP, nos períodos de 24, 48 e 72 horas (OLIVEIRA et al., 2013). Este trabalho mostrou que o perfil da ALP nas células HOAL corrobora outros da literatura em outros tipos de células osteoblásticas, mostrando seu aumento nos períodos iniciais da diferenciação, com declínio em períodos posteriores caracterizados pela deposição de matriz óssea e mineralização quando em meio osteogênico. As fototerapias com os laseres de baixa intensidade em geral, mostraram resultados semelhantes ao controle. Porém, a irradiação com LED inibiu a atividade de ALP, exceto no período de 21 dias, onde os valores não apresentaram diferença do controle.

Poucos trabalhos estudaram o efeito da LLLT e LED na expressão de colágeno I (COL1A1). Assim, nosso trabalho avaliou a expressão de COL1A, no qual foi observado sua modulação pelos diferentes tipos de laser. O colágeno tipo I é o principal tipo de colágeno expresso nos ossos (NICOLAl et al., 2004) e consiste em duas cadeias de polipeptídeos, a a1 (I) e a $\alpha 2$ (I), que se unem na proteína funcional colágeno. As subunidades a1 (I) e a a2 (I) são codificadas como COL1A1 e COL1A2, respectivamente, e apresenta diferentes sequências de aminoácidos primários (MIAO et al., 2002 e XU et al., 2003). Dentre outros fenômenos, o colágeno tipo I está envolvido na produção de matriz extracelular em osteoblastos (SILVA et al., 2011). Em geral, a expressão de COL1A1 apresentou algumas oscilações após tratamento com os diferentes espectros, e o grupo LED, em ambas doses, se mostrou mais 
efetivo em aumentar a expressão desse gene. Nos períodos iniciais, de 07 e 14 dias, os níveis de expressão se mantiveram semelhantes, não havendo muitas diferenças entre a fototerapia e o controle, exceto pelo laser vermelho $10 \mathrm{~J} / \mathrm{cm}^{2}$ e infravermelho $50 \mathrm{~J} / \mathrm{cm}^{2}$ os quais causaram uma diminuição na expressão do COL1A1. No $21^{\circ}$ dia houve uma redução considerável nos níveis de expressão. Isso poderia ser explicado de acordo com a literatura, que o colágeno I é mais expresso nos períodos iniciais do processo de mineralização e depois sua expressão diminui (DA SILVA et al., 2012). Porém, quando avaliamos o período de 28 dias, os níveis de COL1A1 subiram quando comparado com 21 dias.

Apresentamos aqui algumas hipóteses que poderiam tentar explicar esse fenomeno. A queda dos níveis de expressão no período de 21 dias, aconteceu por algum problema técnico no processamento da amostra, em alguma das etapas como na extração do RNAm ou na transcrição reversa, ou até mesmo por algum problema em algum dos reagentes utilizados, culminando nesse efeito, ou os resultados obtidos demonstram algum efeito modulador negativo, porém não esperados de acordo com os achados da literatura.

A expressão gênica da SPARC também foi avaliada. A SPARC, também conhecida como osteonectina e BM-40, é a proteína não colagênica mais abundante da matriz óssea (KUWATA et al., 1985; TERMINE et al., 1984 , ROBEY et al., 2006). Essa glicoproteína modula as demais proteínas da matriz extracelular em muitos processos fisiológicos, (BREKKEN \& SAGE 2001; YAN \& SAGE 1999) e funciona como uma molécula de adesão, além de ser moduladora da atividade de citocinas e fatores de crescimento. A SPARC é espacialmente e temporalmente regulada durante o desenvolvimento e é altamente expressa nos tecidos em remodelação (CHLENSKI \& COHN, 2010; JORGENSEN et al., 2009).

O perfil geral da expressão de SPARC nos 4 períodos se mostrou semelhante aos resultados do COL1A1. O LED em ambas doses, em geral, aumentou a expressão de SPARC. O grupo infravermelho no $28^{\circ}$ dia também apresentou aumento expressivo desse gene. Porém, com 21 dias todos os grupos foram menos expressivos quando comparados aos demais períodos, assim como o perfil do COL1A1. Dessa forma, é necessário a repetição do experimento para compreendermos melhor esse efeito. 
Estudos in vitro utilizando LLLT em modelos osteogênicos, sugere que a laserterapia tem um efeito estimulador aumentando a proliferação de células (STEIN et al., 2005; STEIN \& LIAN, 1993) inibindo a diferenciação de osteoclastos por meio da regulação de RANKL e OPG em osteoblastos (XU et al., 2009), e também podem alterar a atividade mitocondrial (PIRES OLIVEIRA et al., 2008), bem como induzir o processo de mineralização (FUKUHARA et al., 2006; SCHWARTZ-FILHO et al., 2011).

Com relação ao potencial de mineralização dessas células, observamos que as células de linhagem de camundongo (MC3T3-E1) apresentaram maior deposição de cálcio na matriz extracelular nos períodos de 14 e 21 dias quando comparadas aos osteoblastos humanos, que apresentou seu pico de mineralização no $28^{\circ}$ dia. A aplicação da fototerapia com laser vermelho e infravermelho promoveu um aumento de deposição de cálcio na matriz extracelular quando comparados com o controle nos períodos de 21 e 28 dias. Observa-se que o efeito em aumentar a mineralização das diferentes fototerapias ocorreu de maneira dependente do tempo avaliado, ou seja, do número de vezes em que as células foram expostas a irradiação. Além disso, o aumento da mineralização induzido pelos diferentes espectros não foi dependente do aumento da atividade da ALP como poderia se esperar. Nossa hipótese é a de que outros fatores como por exemplo, moléculas orgânicas, ou moléculas sinalizadoras possam ser o alvo dos diferentes laseres na promoção da mineralização. Em resumo, a fototerapia com o laser de baixa intensidade e diodo emissor de luz, nesse regime de aplicação, modula o metabolismo dos osteoblastos humanos, aumentado sua viabilidade e diferenciação, porém, é necessário mais estudos para elucidar seus complexos mecanismos. 


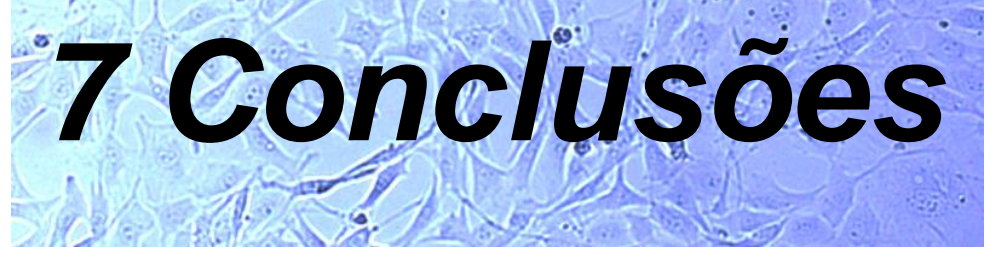





\section{CONCLUSÕES}

Baseado nos resultados obtidos, em geral, a LLLT e LED não causou danos aos osteoblastos humanos, apresentando em grande parte um efeito estimulatório positivo nas células, aumentando a viabilidade e ativando a fosforilação da ERK. Diante disso, podemos concluir que em períodos mais curtos, a fototerapia apresentou diferenças mais expressivas quando comparada aos períodos mais longos, de mineralização, em relação ao controle, no regime de aplicação adotado. Desta forma, a irradiação com o laser de baixa intensidade e com o diodo emissor de luz modulou o metabolismo dos osteoblastos humanos, mostrando ser uma ferramenta útil na área da saúde. 


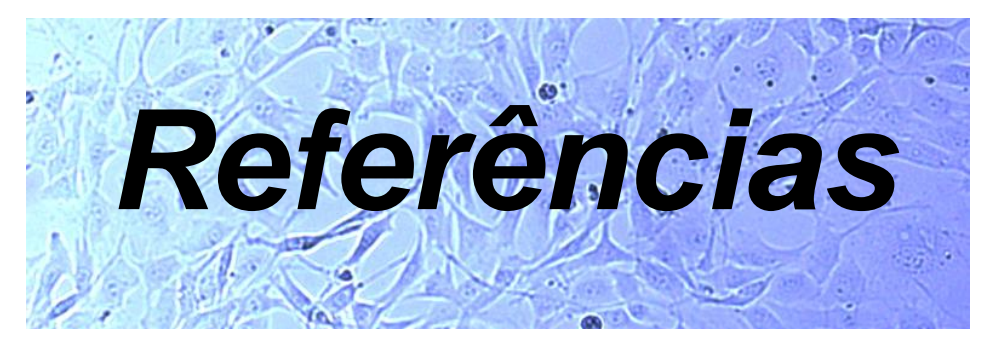





\section{REFERÊNCIAS}

Agas D, Sabbieti MG, Marchetti L, Xiao L, Hurley MM. FGF-2 enhances Runx-2/ Smads nuclear localization in BMP-2 canonical signaling in osteoblastos. J Cell Physiol. 2013;228(11):2149-58.

Aleksic V, Aoki A, Iwasaki K, Takasaki AA, Wang CY, Abiko Y, et al. Low-level Er:YAG laser irradiation enhances osteoblast proliferation through activation of MAPK/ERK. Lasers Med Sci. 2010;25(4):559-69.

Almeida-Lopes L, Rigau J, Zângaro RA, Guidugli-Neto J, Jaeger MMM. Comparison of the low level laser therapy effects on cultured human gingival fibroblasts proliferation using different irradiance and same fluence. Lasers Surg Med. 2001;29:179-184.

Alves VBF. Potencial terapêutico do transplante xenogênico de células estromais mesenquimais multipotentes na doença inflamatória intestinal [dissertação]. Uberaba (MG): Universidade Federal do Triângulo Mineiro; 2011.

Anderson GJ, Frazer DM, McLaren GD. Iron absorption and metabolismo. Curr Opin Gastroenterol. 2009;25:129-35.

Ash P, Loutit JF, Townsend KMS. Osteoclasts derived from haematopoietic stem cells. Nature. 1980;283:669-70.

Azevedo LH, Eduardo FP, Moreira MS, Eduardo CP, Marques MM. Influence of different power densities of LILT on cultured human fibroblast growth: a pilot study. Lasers Med Sci. 2006;21:86-89.

Babapour R, Glassberg E, Lask GP. Low-energy laser systems. Clin Dermatol. 1995;13(1):87-90.

Balooch G, Balooch M, Nalla R, Schilling S, Filvaroff EH, Marshall GW, et al. TGF-beta regulates the mechanical properties and composition of bone matrix. Proc Natl Acad Sci USA. 2005;102(52):18813-8.

Bianco P, Riminucci M, Bonucci E, Termine JD, Robey PG. Bone sialoprotein (BSP) secretion and osteoblast differentiation: relationship to bromodeoxyuridine 
incorporation, alcaline phosphate, and matrix deposition. J Histochem Cytochem. 1993;41(2):183-91.

Bouvet-Gerbettaz S, Merigo E, Rocca JP, Carle GF, Rochet N. Effects of low-level laser therapy on proliferation and differentiation of murine bone marrow cells into osteoblasts and osteoclasts. Lasers Surg Med. 2009;41:291-297.

Caetano-Lopes J, Canhão H, Fonseca JE. Osteoblasts and bone formation. Acta Reumatol Port. 2007;32(2):103-10.

Canalis E, Economides AN, Gazzerro E. Bone morphogenetic proteins, their antagonists, and the skeleton. Endocr Rev. 2003;24:218-35.

Canhão H, Fonseca JE, Queiroz MV. Epidemiologia da osteoporose. Mecanismos de remodelação óssea e fatores protetores do osso. Acta Reumatol Port. 2005;30:225240.

Cankaya AB, Erdem MA, Erdem AP, Erguven M, Aybar B, Kasapoglu C, et al. Evaluation of light-emitting diode (LED-660 nm) application over primary osteoblast like cells on titanium surfaces: an in vitro study. Int J Med Sci. 2011;8(7):584-93.

Carroll L, Humphreys TR. Laser-tissues interactions.Clin Dermatol. 2006;24:2-7.

Chang YS, Hwang JH, Kwon HN, Choi CW, Koy SY, Park WS, et al. In vitro and in vivo efficacy of new blue light emitting diode phototherapy compared to conventional halogen quartz phototherapy for neonatal jaundice. J Korean Med Sci. 2005;20:61-4.

Chen D, Zhao M, Mundy GR. Bone morphogenenetic proteins. Growth Factors. 2004;22:233-41.

Chlenski A, Cohn SL. Modulation of matrix remodeling by SPARC in neoplastic progression. Semin Cell Dev Biol. 2010;21:55-65.

Cobb CM. Laser in periodontics: A review of the literature. J Periodontol. 2006;77:54564. 
Corazza AV, Jorge J, Kurachi C, Bagnato VS. Photobiomodulation on the angiogenesis of skin wounds in rats using different light sources. Photomed Laser Surg. 2007;25(2):102-6.

Corti L, Chiarion-Sileni V, Aversa S, Ponzoni A, D'Arcais R, Pagnutti S, et al. Treatment of chemotherapy-induced oral mucositis with light-emitting diode. Photomed Laser Surg. 2006;24:207-13.

Dale L, Jones CM. BMP signalling in early Xenopus development. Bioessays. 1999;21:751-60.

Damante CA. Efeito da terapia com laser em baixa intensidade (LILT) na expressão de fatores de crescimento da família FGF por fibroblastos gengivais humanos [tese]. São Paulo (SP): Universidade de São Paulo; 2007.

Da Silva AP, Petri AD, Crippa GE, Stuani AS, Rosa AL, Stuani MB. Effect of low-level laser therapy after rapid maxillary expansion on proliferation and differentiation of osteoblastic cells. Lasers Med Sci. 2012;27(4):777-83.

Datta HK, Ng WF, Walker JA, Tuck SP, Varanasi SS. The cell biology of bone metabolism. J Clin Pathol. 2008;61(5):577-87.

Davis LA, Zur Nieden NI. Mesodermal fate decisions of a stem cell: the Wnt switch. Cell Mol Life Sci. 2008;65(17):2658-74.

De Paula Eduardo C, Moreira De Freitas P, Esteves-Oliveira M, Corréa Aranha AC, Müler Ramalho K, Simões A, et al. Laser phototherapy in the treatment of periodontal disease. Lasers Med Sci. 2010;25:781-92.

Di Lullo GA, Sweeney SM, Korkko L, San Antonio JD. Mapping the ligand-binding sites and disease-associated mutations on the most abundant protein in the human type I collagen. J Biol Chem. 2002;277(6):4223-31.

Ducy P, Zhang R, Geoffroy V, Ridall AL, Karsenty G. Osf2/Cbfa1: a transcriptional activator of osteoblast differentiation. Cell. 1997;89(5):747-54. 
Eduardo FP, Mehnert DU, Monezi TA, Zezell DM, Schubert MM, Eduardo CP, et al. Cultured epithelial cells response to phototherapy with low intensity laser. Lasers Surg Med. 2007;39:365-72.

Eells JT, Wong-Riley MT, Verhoeve J, Henry M, Buchman EV, Kane MP, et al. Mitochondial signal transduction in acelerated wound and retinal healing by nearinfrared light therapy. Mitochondrion. 2004;4:559-67.

Fávaro-Pípi E, Ribeiro DA, Ribeiro JU, Bossini P, Oliveira P, Parizotto NA, et al. Lowlevel laser therapy induces differential expression of osteogenic genes during bone repair in rats. Photomed Laser Surg. 2011;29(5):311-7.

Feng X, McDonald JM. Disorders of Bone Remodeling. Annu Ver Pathol Mech Dis. $2011 ; 6: 121-45$.

Fujihara NA, Hiraki KR, Marques MM. Irradiation at $780 \mathrm{~nm}$ increases proliferation rate of osteoblasts independently of dexamethasone presence. Lasers Surg Med. 2006;38:332-6.

Fujimoto K, Kiyosaki T, Mitsui N, Mayahara K, Omasa S, Suzuki N, et al. Low intensity laser irradiation stimulates mineralization via increased BMPs in MC3T3-E1 cells. Lasers Surg Med. 2010;42(6):519-26.

Fukuhara E, Goto T, Matayoshi T, Kobayashi S, Takahashi T. Optimal low-energy laser irradiation causes temporal G2/M arrest on rat calvarial osteoblasts. Calcif. Tissue Int. 2006;79(6):443-50.

Gay CV, Ito MB, Schraer H. Carbonic anhydrase activity in isolated osteoclasts. Metab Bone Dis Rel Res. 1983;5:33-9.

Ge C, Xiao G, Jiang D, Franceschi RT. Critical role of the extracelular signal-regulated kinases-MAPK pathways in osteoblast differentiation and skeletal development. J Cell Biol. 2007;176(5):709-18.

Golub EE, Boesze-Battaglia K. The role of alkaline phosphatase in mineralization. Curr Opin Orthop. 2007;18:444-8. 
Gori F, Hofbauer LC, Dunstan CR, Spelaberg TC, Khosla S, Riggs BL. The expression of osteoprotegerin and RANK ligand and the suporto $f$ osteoclast formation by stromalosteoblast lineage cells in developmentally regulated. Endocrinology. 2000;141:476876.

Granjeiro JM, Oliveira RC, Bustos-Valenzuela JC, Sogayar MC, Taga R. Bone morphogenetic proteins: from structure to clinical use. Braz J Med Biol Res. 2005;38(10).

Grassi FR, Ciccolella F, D'Apolito G, Papa F, Luso A, Salzo AE, et al. Effect of lowlevel laser irradiation on osteoblast proliferation and bone formation. J. Biol. Regul. Homeost. Agents. 2011;25(4):603-14.

Greenblatt MB, Shim JH, Zou W, Sitara D, Schweitzer M, Hu D, et al. The p38 pathway is essential for skeletogenesis and bone homeostasis in mice. J Clin Invest. 2010;120(7):2457-73.

Greenblatt MB, Shim JH, Glimcher LH. Mitogen-activated protein kinase pathways in osteoblasts. Annu Rev Cell Dev Biol. 2013;29:63-79.

Hammond JB, Kruger NJ. The bradford method for protein quantitation. Methods Mol Biol. 1988;3:25-32.

Henriques ACG, Cazal C, Castro JF. Ação da laserterapia no processo de proliferação e diferenciação celular: Revisão da literatura. Rev Col Bras Cir. 2010;37(4).

Ibbotson KJ, Roodman CD, McManus LM, Mundy GR. Identification and characterization of ostecclast-like cells and their progenitors in cultures of feline marrow mononuclear cells. J Cell Biol. 1984;99:471-80.

Junqueira LC, Carneiro J.Histologia Básica. Ed.11. Guanabara Koogan, Rio de Janeiro. 2006.

Jorgensen LH, Petersson SJ, Sellathurai J, Andersen DC, Thayssen S, Sant DJ, et al. Secreted protein acidic and rich in cysteine (SPARC) in human skeletal muscle. J Histochem Cytochem. 2009;57:29-39. 
Kamali F, Bayat M, Torkaman G, Ebrahimi E, Salavati M. The therapeutic effect of lowlevel laser on repair of osteochondral defects in rabbit knee. J. Photochem. Photobiol. B. 2007;88(1):11-5.

Karu TI. Photobiology of low-power laser effects. Health Phys. 1989;56:691-704.

Karu T, Pyatibrat L, Kalendo G. Irradiation with He-Ne laser increases ATP level in cells cultivated in vitro. J Photochem Photobiol B. 1995;27(3):219-23.

Karu T. Primary and secondary mechanisms of action of visible to near-IR radiation on cells. J Photochem Photobiol B. 1999;49:1-17.

Karu TI, Pyatibrat LV, Afanasyeva NI. A novel mitochindrial signaling pathway activeted by visible-to-near infrared radiation. Photochem Photobiol. 2004;80:336-72.

Karu TI, Pyatibrat LV, Kplyakov SF, Afanasyeva NI. Absorption measurements of a cell monolayer relevant to phototherapy: reduction of cytochrome $\mathrm{c}$ oxidase under near IR radiation. J Photochem Photobiol B. 2005;81(2):98-106.

Kato Y, Boskey A, Spevak L, Dallas M, Hori M, Bonewald LF. Establishment of an osteoid preosteocyte-like cell MLO-A5 that spontaneously mineralizes in culture. J Bone Miner Res. 2001;16:1622-33.

Kavukcuoglu NB, Denhardt DT, Guezelsu N, Mann AB. Osteopontin deficiency and aging on nanomechanics of mouse bone. J Biomed Meter Res A. 2007;83(1):136-44.

Khadra M, Kasem N, Lyngstadaas SP, Haanaes HR, Mustafa K. Laser therapy accelerates initial attachment and subsequente behaviour of human oral fibroblasts cultured on titanium implant material. A scanning electron microscope and histomorphometric analysis. Clin. Oral Implants Res. 2005;16(2):168-75.

Khadra M, L Lyngstadaas SP, Haanaes HR, Mustafa K. Effect of laser therapy on attachment, proliferation and differentiation of human osteoblast-like cells cultured on titanium implant material. Biomaterials. 2005;26(17):3503-9. 
Khosla S, Westendorf JJ, Mödder Ul. Concise rewiew: Insights from nomal bone remodeling stem cell-based therapies for bone repair. Stem Cells. 2010;28(12):21248.

Kim HK, Kim JH, Abbas AA, Kim DO, Park SJ, Chung JY, et al. Red light of 647 nm enhances osteogenic differentiation in mesenchymal stem cells. Lasers Med Sci. 2009;24(2):214-22.

Kim SJ, Moon SU, Kang SG, Park YG. Effects of low-level laser therapy after Corticision on tooth movement and paradental remodeling. Lasers Surg Med. 2009;41(7):524-33.

Kishimoto Y, Kurita N, Shimokado K, Maruyama N, Ishigami A. Ascorbic acid enhances the expression. Of type 1 and type 4 collagen and SVCT2 in cultured human skin fibroblastos. Biochem Biophys Res Commun. 2013;430(2):579-84.

Kiyosaki T, Mitsui N, Suzuki N, Shimizu N. Low-level laser therapy stimulates mineralization via increased Runx2 expression and ERK phosphorylation in osteoblasts. Photomed Laser Surg. 2010;28:S167-S72.

Knothe Tate ML, Adamson JR, Tami AE, Bauer TW. The osteocyte. Int J Biochem Cell Biol. 2004;36:1-8.

Kohn AD, Moon RT. Wnt and calcium signaling: beta-catenin-independent pathways. Cell Calcium. 2005;38(3-4):439-46.

Kolch W. Meaningful relationships: regulation of the Ras/Raf/MEK/ERK pathway by protein interactions. Biochem J. 2000;351:289-305.

Komori T, Yagi H, Nomura S, Yamaguchi A, Sasaki K, Deguchi K, et al. Taegeted disruption of Cbfa1 results in a complete lack of bone formation owing to maturational arrest of osteoblasts. Cell. 1997;89(5):755-64.

Kong YY, Yoshida H, Sarosi I, Tan HL, Timms E, Capparelli C, et al. OPGL is a key regulator of osteoclastogenesis, lymphocyte development and lymph-node organogenesis. Nature. 1999;397(6717):315-23. 
Kreisler M, Christoffers AB, Al-Haj H, Willershausen B, d'Hoedt B. Low level 809-nm diode laser induced in vitro stimulation of the proliferation of human gingival fibroblasts. Lasers Surg Med. 2002;30:365-69.

Kreisler M, Christoffers AB, Willershausen B, d'Hoedt B. Low-level 809nm GaAlAs laser irradiation increases the proliferation rate of human laryngeal carcinoma cells in vitro. Lasers Med Sci. 2003;18:100-3.

Kueng W, Silber E, Eppenberger U. Quantification of cells cultured on 96-well plates. Anal Biochem. 1989;182(1):16-9.

Kuwata F, Yao KL, Sodek J, Ives S, Pulleyblank D. Identification of pre-osteonectin produced by cell-free translation of fetal porcine calvarial mRNA. J Biol Chem. 1985; 260:6993-8.

Lacey DL, Timms E, Tan HL, Kelley MJ, Dunstan CR, Burgess T, et al. Osteoprotegerin ligand is a cytokine that regulates osteoclast differentiation and activation. Cell. 1998;93(2):165-76.

Li Y, Ge C, Franceschi RT. Differentiation-dependent association of phosphorylated extracellular signal-regulated kinase with the chromatin of osteoblast-related genes. J Bone Miner Res. 2010;25(1):154-63.

Li M, Liu J, Zhang C. Evolutionary history of the vertebrate mitogen activated protein kinases Family. PLoS One. 2011;6(10):e26999.

Lian JB, Javed A, Zaidi SK, Lengner C, Montecino M, van Wijnen AJ, et al. Regulatory controls for osteoblast growth and differentiation role of Runx/Cbfa/AML factors. Crit Rev Eukaryot Gene Expr. 2004;14(1-2):1-41.

Lin GL, Hankenson KD. Integration of BMP, Wnt, and notch signaling pathways in osteoblast differentiation. J Cell Biochem. 2011;112(12):3491-501.

Loevschall $\mathrm{H}$, Arenholt-Bindslev D. Effect of low-level diode laser irradiation of human oral mucosa fibroblasts in vitro. Lasers Surg Med. 1994;14:347-54. 
Mackie EJ. Osteoblasts: novel roles in orchestration of skeletal architecture. Int $\mathrm{J}$ Biolchem Cell Biol. 2004;35:1301- 5.

Manolagas SC. Birth and death of bone cells: basic regulatory mechanisms and implications for the parthogenesis and treatment of osteoporosis. Endocr Rev. 2000;21:115-37.

Marie PJ. Transcription factors controlling osteoblastogenesis. Arch Biochem Biophys. 2008;473(2):98-105.

Marques MM, Pereira NA, Fujihara NA, Nogueira FN, Eduardo CP. Effect of low-power laser irradiation on protein synthesis and ultrastructure of human gingival fibroblasts. Lasers Surg Med. 2004;34:260-5.

Matsushita T, Chan YY, Kawanami A, Balmes G, Landreth GE, Murakami S. Extracellular signal-regulated kinase 1 (ERK1) and ERK2 play essential roles in osteoblast differentiation and in supporting osteoclastogenesis. Mol Cell Biol. 2009;29(21):5843-57.

Martinasso G, Mozzati M, Pol R, Canuto RA, Muzio G. Effect of superpulsed laser irradiation on bone formation in human osteoblast-like cell line. Minerva Stomatol. 2007;56:27-30.

Merli LA, Santos T, Genovese WJ, Faloppa F. Effect of low-intensity laser irradiation on the process of bone repair. Photomed Laser Surg. 2005;23(2):212-5.

Mester E, Mester A, Mester A. The biomedical effects of laser application. Lasers Surg Med. 1985;5:31-9.

Miao Q, Xu M, Liu BC, You BR, Kang N. In vivo and in vitro study on the effect of excessive fluoride on type I collagen of rats. J. Hyg. Res. 2002;31(3):145-7.

Mochida Y, Parisuthiman D, Pornprasertsuk-Damrongsri S, Atsawasuwan P, Sricholpech M, Boskey AL, et al. Decorin modulates collagen matrix assembly and mineralization. Matrix Biol. 2009;28(1):44-52. 
Morrison DK, Davis RJ. Regulation of MAP kinase signaling modules by scaffold proteins n mammals. Annu Rev Cell Dev Biol. 2003;19:91-118.

Mosmann T. Rapid colorimetric assay for cellular growth and survival: application to proliferation and cytotoxicity assays. J Immunol. 1983;65:55-63.

Mundlos S, Olsen BR. Heritable diseases of the skeleton. Part I: Molecular insights into skeletal development-transcription factors and signaling pathways. FASEB J. 1997;11(2):125-32.

Nicolai M, Michael H, Cyrilla M, Rainer H. Expression of collagen type I and type II in consecutive stages of human osteoarthritis. Histochem. Cell Biol. 2004;122(3):229-37.

Nissan J, Assif D, Gross MD, Yaffe A, Binderman I. Effect of low intensity laser irradiation on surgically created bony defects in rats. J Oral Rehabil. 2006;33(8):619924.

Nogueira GT, Ferrari RAM, Martins MD, Bussadori SK, Silva TD, Fernandes KPS. Efeito da laserterapia de baixa potência sobre o tecido ósseo: Revisão de literatura. ConScientiae Saude. 2009;671-6.

Oliveira FA, Matos AA, Matsuda SS, Buzalaf MAR, Machado MAAM, Damante CA, et al. Low- level laser therapy modulates proliferation, alkaline phosphatase and matrix metalloproteinase-2 activities of osteoblasts. Lasers Med Sci. (Manuscrito enviado em 2013).

Olszta MJ, Cheng X, Jee SS. Bone structure and formation: a new perspective. Mater Sci Eng Rev. 2007;58:77-116.

Otto F, Thornell AP, Crompton T, Denzel A, Gilmour KC, Rosewell IR, et al. Cbfa1, a candidate gene for cleidocranial dysplasia syndrome, is essential for osteoblast differentiation and bone development. Cell. 1997;89(5):765-71.

Ozawa $Y$, Shimizu N, Mishima H, Kariya G, Yamaguchi M, Takiguchi H, et al. Stimulatory effects of lowpower laser irradiation on bone formation in vitro. In: Altshuler GB, Blankenau RJ, Wigdor HA, eds. Advanced laser dentistry Proc SPIE 1984, Washington, DC: International Society for Optical Engineering,p. 281-288; 1995. 
Ozawa Y, Shimizu N, Kariya G, Abiko Y. Low-energy laser irradiation stimulates bone nodule formation at early stages of cell culture in rat calvarial cells. Bone. 1998;22(4):347-54.

Pacheco PS, Oliveira FA, Oliveira RC, Sant'Ana ACP, Rezende MLR, Greghi SLA, Damante CA. Laser Phototherapy at High Energy Densities Do Not Stimulate PreOsteoblast Growth and Differentiation, Photomed. and Laser Surg. 2013; 31(5):225-9.

Parfitt AM, Villanueva AR, Foldes J, Rao DS. Relations between histologic índices of bone formation: implications for the pathogenesis of spinal osteoporosis. J Bone Miner Res. 1995;10(3):466-73.

Parfitt AM. Skeletal heterogeneity and the purposes of bone remodeling: Implications for the understanding of osteoporosis. In: Marcus M, Feldman D, Nelson DA, Rosen CJ, eds. Osteoporosis. San Diego: Elsevier Academic Press; 2008, p.71-89.

Pastore D, Greco M, Passarela S. Specific helium-neon laser sensitivity of the purified cytocrome C oxidase. Int J Radiat Biol.2000;76: 863-70.

Pearson GJ, Schuckert KH. The role of lasers in dentistry: Present and future. Dental Update. 2003;30:70-6.

Pejcic A, Kojovic D, Kesic L, Obradovic R. The effects of low level laser irradiation on gingival inflammation. Photomed Laser Surg. 2010;28:69-74.

Peng $\mathrm{F}, \mathrm{Wu} \mathrm{H}$, Zheng Y, Xu X, Yu J. The effect of noncoherent red light irradiation on proliferation and osteogenic differentiation of bone marrow mesenchymal stem cells. Lasers Med Sci. 2012;27(3):645-53.

Pereira AN, Eduardo CP, Matson E, Marques MM. Effect of low-power laser irradiation on cell growth and procollagen synthesis of cultured fibroblasts. Lasers Surg Med. 2002;31:263-7.

Petri AD. Efeitos da radiação laser de baixa Intensidade em células osteoblásticas humanas cultivadas sobre titânio [dissertação]. Ribeirão Preto (SP): Universidade de São Paulo; 2008. 
Pinheiro AL. Advances and perspectives on tissue repair and healing. Photomed. Laser Surg. 2009; 27(6):833-6.

Pires Oliveira DA, de Oliveira RF, Zangaro RA, Soares CP. Evaluation of low-level laser therapy of osteoblastic cells. Photomed Laser Surg. 2008;26:401-4.

Posten W, Wrone DA, Dover JS, Arndt KA, Silapunt S, Alam M. Low-level laser therapy for wound healing: mechanism and efficacy. Dermatol. Surg. 2005; 31(3):334-40.

Poundarik A, Karim L, Gundberg C, Vashishth D. The role of osteocalcin in bone fracture. Proceedings of the 55th Meeting of the Orthopaedic Research Society, Las Vegas, USA, February, 22- 25, 2009 [abstract 724].

Pyo SJ, Song WW, Kim IR, Park BS, Kim CH, Shin SH, et al. Low-level laser therapy induces the expressions of BMP-2, osteocalcin, and TGF- $\beta 1$ in hypoxic-cultured human osteoblasts. Lasers Med Sci. 2013;28:543-50.

Qiu SR, Wierzbicki A, Orme CA, Cody AM, Hoyer JR, Nancollas GH, et al. Molecular modulation of calcium oxalate crystallization by osteopontin and citrate. Proc Natl Acad Sci USA. 2004;101(7):1811-5.

Ratz JL. Laser physics. Clin Dermatol. 1995;13(1):11-20.

Reddi $\mathrm{AH}$, Reddi A. Bone morphogenetic proteins (BMPs): from morphogens to metabologens. Cytokine Growth Factor Rev. 2009;20:341-2.

Renno AC, McDonnell PA, Crovace MC, Zanotto ED, Laakso L. Effect of 830nm laser phototherapy on osteoblasts grown in vitro on Biosilicate scaffolds. Photomed Laser Surg. 2009;28:131-3.

Ribeiro MS, Zezell DM. Laser de baixa intensidade. In: Gutknecht N, Eduardo CP. A odontologia e o laser: atuação do laser na especialidade odontológica. São Paulo: Quintessence; 2004. cap. 5, p. 217-40.

Ribeiro DA, Matsumoto MA. Low-level laser therapy improves bone repair in rats treated with anti-inflammatory drugs. J Oral Rehabil. 2008;35(12):925-33. 
Robey PG, Boskey AL, Lian JB, Goldring SR. Extracellular matrix and biomineralization of bone. Primer. 2006;6:12-9.

Rosen V, Wozne JM. Bone morphogenetic proteins. In: Belizikian J, Raisz LG, Rodan G, editors. Principles of bone biology 2nd edition. San Diego: Academic Press. 2002;p.919-28.

Sacono NT, Costa CAS, Bagnato VS, Abreu-e-Lima FCB. Light-emitting diode therapy in chemotherapy-induced mucositis. Lasers Surg Med. 2008;40:625-33.

Sakurai Y, Yamaguchi M, Abiko Y. Inhibitory effect of low level laser irradiation on LPSstimulated prostaglandin E2 production and cyclooxygenase-2 in human gingival fibroblasts. Europ J Oral Sci. 2000;108:29-34.

Scheven BAA, Visser JWM, Nijweide PJ. In vitro osteoclast generation from diferente bone marrow fractions, including a highly enriched haematopoietic stem cell population. Nature. 1986;321:79-81.

Schindeler A, Little DG. Ras-MAPK signaling in osteogenic differentiaton:friend or foe? J Bone Miner Res. 2006;21(9):1331-8.

Schwartz-Filho HO, Reimer AC, Marcantonio C, Marcantonio EJr, Marcantonio RA. Effects of low level laser therapy $(685 \mathrm{~nm})$ at diferente doses in osteogenic cell cultures. Lasers Med Sci. 2011; 26(4):539-43.

Seeman E, Delmas PD. Bone quality: the material and structural basis of bone strength and fragility. N Engl J Med. 2006;354:2250-61.

Shimizu N, Mayahara K, Kiyosaki T, Yamaguchi A, Ozawa Y, Abiko Y. Low-intensity laser irradiation stimulates bone nodule formation via insulin-like growth factor-I expression in rat calvarial cells. Lasers Surg Med. 2007;39:551-9.

Skinner SM, Gage JP, Wilce PA, Shaw RM. A preliminary study of the effects of laser radiation on collagen metabolism in cell culture. Aust Dent J. 1996;41:188-92. 
Soudry M, Franquin JC, Porreau-Schneider N, Martin PM. Effect of a helium-neon laser on cellular growth: an in vitro study of human gingival fibroblasts. J Biol Buccale. 1988;16:129-35.

Sroga GE, Karim L, Colón W, Vashishth D. Biochemical Characterization of Major Bone-Matrix Proteins Using Nanoscale-Size Bone Samples and Proteomics Methodology. Mol Cell Proteomics. 2011.

Stains JP, Watkins MP, Grimston SK, Hebet C, Civiteli R. Molecular mechanosms of osteoblast/ osteocyte regulation by connexin 43. Calcif Tissue Int. 2013.

Stein GS, Lian JB. Molecular mechanisms mediating proliferation/ differentiation interrelationships during progressive development of the osteoblast phenotype, Endocrin Rev. 1993;14:424-42.

Stein A, Benayahu D, Maltz L, Oron U. Low-level laser irradiation promotes proliferation and differentiation of human osteoblasts in vitro. Photomed Laser Surg. 2005;23(2):161-6.

Tam G. Low power laser therapy and analgesic action. J Clin Laser Med Surg. 1999;17:29-33.

Termine JD, Robey PG, Fisher LW, Shimokawa H, Drum MA, Conn KM, Hawkins GR, Cruz JB, Thompson KG. Osteonectin, bone proteoglycan, and phosphophoryn defects in a form of bovine osteogenesis imperfecta. Proc Natl Acad Sci USA. 1984; 81:22137.

Tridente A, De Luca D. Efficacy of light-emitting diode versus other light sources for treatment of neonatal hyperbilirubinemia: a systematic review and meta-analysis. Acta Paediatr. 2012;101(5):458-65.

Tunér J, Hode L. Laser therapy in dentistry and medicine. Edsbruk: Prima Books; 1996.

Volpato LER. Avaliação do uso do laser de baixa intensidade e do light-emitting diode (LED) no comportamento de fibroblastos e na redução da incidência da mucosite bucal em crianças sob tratamento quimioterápico [tese]. Bauru (SP): Faculdade de Odontologia de Bauru, Universidade de São Paulo; 2009. 
Vreman HJ, Wong RJ, Stevenson DK, Route RK, Reader SD, Fejer MM, et al. Light emitting diodes: a novel light source for phototherapy. Pediatr Res. 1998;44:804-9.

Vrijens K, Lin W, Cui J, Farmer D, Low J, Pronier E, et al. Identification of small molecule activators of BMP signaling. PLoS One. 2013;8(3):e59045.

Xu ZL, Liu BC, Miao Q, et al. Effects of excessive fluoride on the expression. of type I collagen mRNA and fiber characteristics in rat bone. J. Environ. Health. 2003; 20(4):204-7.

Xu M, Deng T, Mo F, Deng B, Lam W, Deng P, et al. Low-intensity pulsed laser irradiation affects RANKL and OPG mRNA expression in rat calvarial cells. Photomed Laser Surg. 2009;27(2):309-15.

Walsh LJ. The current status of low level laser therapy in dentistry. Part 1: Soft tissue applications. Aust Dent J. 1997;42:247-5.

Watabe T, Miyazono K. Roles of TGF-beta Family signaling in stem cell renewal and differentiation. Cell Res. 2009;19:103-15.

Watrous DA, Andrews BS. The metabolismo and immunology of bone. Semin Arthritis Rheum. 1989;19(1):45-65.

Weins MA, Hudson DM, Kim L, Scott M, Wu JJ, Eyre DR. Location of 3-hydroxyproline residues in collagen types I,II,III and $\mathrm{V} / \mathrm{XI}$ implies a role in fibril supramolecular assembly. J Biol Chem. 2010;285(4):2580-90.

Welch AJ, Torres JH, Cheong WF. Laser physics and laser-tissue interaction. Texas Heart Institute Journal. 1989;16:141-9.

Whelan HT, Buchmann EV, Whelan NT, Turner SG, Cevenin V, Stinson H, et al. NASA light emitting diode medical applications from deep space to deep sea space. Tech Appl Int Forum. 2001;552: 35-45.

Winterle JS, Einarsdóttir O. Photoreactions of cytochrome C oxidase. Photochem Photobiol. 2006;82(3):711-9. 
Yamaguchi A. Regulation of differentiation pathway of skeletal mesenchymal cells in cell lines by transforming growth fator-beta superfamily. Semin Cell Biol. 1995;6(3):165-73.

Yan Q, Sage EH. SPARC, a matricellular glycoprotein with importante biological functions. J Histochem Cytochem. 1999;47:1495-1506.

Young MF, Kerr JM, Ibaraki K, Heegaard AM, Robey PG. Structure, expression, and regulation of the major noncollagenous matrix proteins of bone. Clin Orthop Relat Res. 1992;281:275-94.

Zambuzzi WF, Yano CL, Cavagis AD, Peppelenbosch MP, Granjeiro JM, Ferreira CV. Ascorbate-induced osteoblast differentiation recruits distinct MMP-inhibitors: RECK and TIMP-2. Mol Cell Biochem. 2009;322:143-50.

Zou W, Greenblatt MB, Shim JH, Kant S, Zhai B, Lotinun S, et al. MLK3 regulates bone development downstream of the faciogenital dysplasia protein FGD1 in mice. J Clin Invest. 2011;121(11):4383-92.

Zouani OF, Rami L, Lei Y, Durrieu MC. Insights into the osteoblast precursor differentiation towards mature osteoblasts induced by continuous BMP-2 signaling. Biology Open. 2013;2:872-81. 


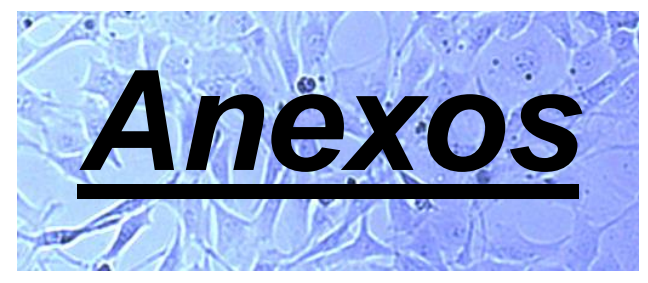





\section{Anexo 1: Carta de aprovação do Comitê de Ética em Pesquisa}

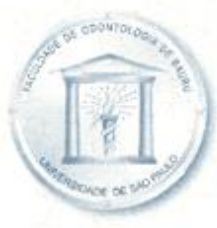

Processo no 095/2011

Bauru, 5 de setembro de 2011

\section{Universidade de São Paulo \\ Faculdade de Odontologia de Bauru}

Al. Dr. Octávio Pinheiro Brisolla, 9-75 - Bauru-SP - CEP 17012-901 - C.P. 73 PABX (0XX14)3235-8000 - FAX (0XX14)3223-4679

Comitê de Ética em Pesquisa (14)3235-8356

mferrari@fob.usp.br

Senhor Professor,

Informamos que após o envio da documentação solicitada, o projeto de pesquisa encaminhado a este Comitê de Ética em Pesquisa Efeito dos laseres de baixa intensidade na profiferação e diferenciação de osteoblastos humanos, a ser desenvolvido pela aluna Flávia Amadeu de Oliveira, sob sua orientação e co-orientação da Drâ Camila Peres Buzalaf e colaboração de Adriana Arruda Matos foi novamente analisado em reunião realizada no dia 31 de agosto de 2011.

O CEP-FOB/USP considerou o projeto APROVADO lembrando que a condição de aprovação da pesquisa propriamente dita exige o que segue:

- que sejam encaminhados ao CEP-FOB/USP relatórios anuais sobre o andamento da pesquisa (parciais e finais), conforme o cronograma apresentado;

que sejam notificados ao CEP-FOB/USP, com a devida justificativa, qualquer modificação na metodologia e/ou título e a inclusão ou exclusão de autores;

na apresentação do relatório final, incluir todos os TCLEs e/ou termos de doação de dentes devidamente assinados e rubricados.

Atenciosamente,

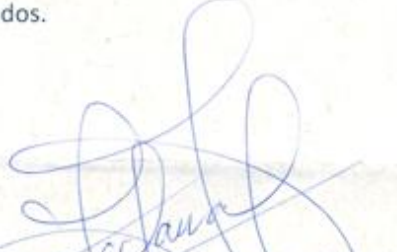

Prof. Dr flávio Augusto Cardoso de Faria

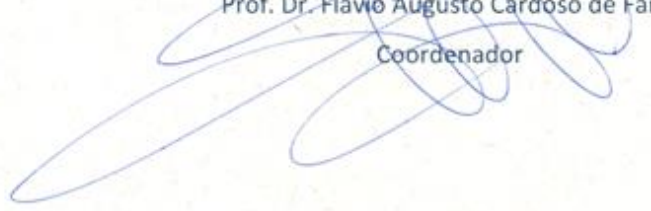

Prof. Dr. Rodrigo Cardoso de Oliveira

Docente do Departamento de Ciências Biológicas 
Anexo 2: Comparação entre os diferentes espectros em relação ao controle com uma aplicação em um mesmo período. Valores de absorbância (média e desvio-padrão) do teste de MTT nos períodos de 24, 48 e 72 horas.

\begin{tabular}{|c|c|c|c|}
\hline \multirow{2}{*}{ GRUPOS EXPERIMENTAIS } & \multicolumn{3}{|c|}{ TEMPO (HORAS) } \\
\hline & 24 & 48 & 72 \\
\hline \multirow{2}{*}{ Controle } & $0.358^{\mathrm{A}}$ & $0.372^{\mathrm{A}}$ & $0.955^{\mathrm{A}}$ \\
\hline & \pm 0.040 & \pm 0.014 & \pm 0.088 \\
\hline \multirow{2}{*}{ Laser $10 \mathrm{~J} / \mathrm{cm}^{2}$} & $0.367^{A}$ & $0.537^{\mathrm{B}}$ & $0.922^{A}$ \\
\hline & \pm 0.036 & \pm 0.051 & \pm 0.154 \\
\hline \multirow{2}{*}{ Laser $20 \mathrm{~J} / \mathrm{cm}^{2}$} & $0.398^{A}$ & $0.574^{\mathrm{B}}$ & $0.992^{A}$ \\
\hline & \pm 0.072 & \pm 0.015 & \pm 0.149 \\
\hline \multirow{2}{*}{ Laser $50 \mathrm{~J} / \mathrm{cm}^{2}$} & $0.459^{A}$ & $0.556^{\mathrm{B}}$ & $1.112^{\mathrm{B}}$ \\
\hline & \pm 0.065 & \pm 0.049 & \pm 0.202 \\
\hline \multirow{2}{*}{ Infra $10 \mathrm{~J} / \mathrm{cm}^{2}$} & $0.392^{A}$ & $0.402^{A}$ & $1.078^{A}$ \\
\hline & \pm 0.045 & \pm 0.081 & \pm 0.215 \\
\hline \multirow{2}{*}{ Infra $20 \mathrm{~J} / \mathrm{cm}^{2}$} & $0.445^{\mathrm{A}}$ & $0.547^{\text {B }}$ & $0.996^{A}$ \\
\hline & \pm 0.063 & \pm 0.060 & \pm 0.245 \\
\hline \multirow{2}{*}{ Infra $50 \mathrm{~J} / \mathrm{cm}^{2}$} & $0.470^{\mathrm{A}}$ & $0.656^{\mathrm{B}}$ & $1.003^{A}$ \\
\hline & \pm 0.089 & \pm 0.134 & \pm 0.202 \\
\hline \multirow{2}{*}{ LED $10 \mathrm{~J} / \mathrm{cm}^{2}$} & $0.515^{B}$ & $0.702^{B}$ & $0.972^{\mathrm{A}}$ \\
\hline & \pm 0.098 & \pm 0.035 & \pm 0.062 \\
\hline \multirow{2}{*}{ LED $20 \mathrm{~J} / \mathrm{cm}^{2}$} & $0.478^{A}$ & $0.473^{A}$ & $0.837^{\mathrm{A}}$ \\
\hline & \pm 0.076 & \pm 0.051 & \pm 0.119 \\
\hline \multirow{2}{*}{ LED $50 \mathrm{~J} / \mathrm{cm}^{2}$} & $0.363^{A}$ & $0.448^{A}$ & $0.785^{\mathrm{B}}$ \\
\hline & \pm 0.055 & \pm 0.042 & \pm 0.086 \\
\hline
\end{tabular}

Letras diferentes representam diferenças estatisticamente significantes. 
Anexo 3: Comparação entre o mesmo tipo de laser com doses diferentes com uma aplicação em um mesmo período. Valores de absorbância (média e desvio-padrão) do teste de MTT nos períodos de 24, 48 e 72 horas.

\begin{tabular}{|c|c|c|c|}
\hline \multirow{2}{*}{ GRUPOS EXPERIMENTAIS } & \multicolumn{3}{|c|}{ TEMPO (HORAS) } \\
\hline & 24 & 48 & 72 \\
\hline \multirow{2}{*}{ Laser $10 \mathrm{~J} / \mathrm{cm}^{2}$} & $0.367^{\mathrm{A}}$ & $0.537^{\mathrm{A}}$ & $0.922^{\mathrm{A}}$ \\
\hline & \pm 0.036 & \pm 0.051 & \pm 0.154 \\
\hline \multirow{2}{*}{ Laser $20 \mathrm{~J} / \mathrm{cm}^{2}$} & $0.398^{A}$ & $0.574^{A}$ & 0.992 A, B \\
\hline & \pm 0.072 & \pm 0.015 & \pm 0.149 \\
\hline \multirow{2}{*}{ Laser $50 \mathrm{~J} / \mathrm{cm}^{2}$} & $0.459^{A}$ & $0.556^{A}$ & $1.112^{B}$ \\
\hline & \pm 0.065 & \pm 0.049 & \pm 0.202 \\
\hline \multirow{2}{*}{ Infra $10 \mathrm{~J} / \mathrm{cm}^{2}$} & $0.392^{A}$ & $0.402^{A}$ & $1.078^{A}$ \\
\hline & \pm 0.045 & \pm 0.081 & \pm 0.215 \\
\hline \multirow{2}{*}{ Infra $20 \mathrm{~J} / \mathrm{cm}^{2}$} & $0.445^{\mathrm{A}}$ & $0.547^{\mathrm{B}}$ & $0.996^{A}$ \\
\hline & \pm 0.063 & \pm 0.060 & \pm 0.245 \\
\hline \multirow{2}{*}{ Infra $50 \mathrm{~J} / \mathrm{cm}^{2}$} & $0.470^{\mathrm{A}}$ & $0.656^{\mathrm{B}}$ & $1.003^{\mathrm{A}}$ \\
\hline & \pm 0.089 & \pm 0.134 & \pm 0.202 \\
\hline \multirow{2}{*}{ LED $10 \mathrm{~J} / \mathrm{cm}^{2}$} & $0.515^{\mathrm{A}}$ & $0.702^{A}$ & $0.972^{A}$ \\
\hline & \pm 0.098 & \pm 0.035 & \pm 0.062 \\
\hline \multirow{2}{*}{ LED $20 \mathrm{~J} / \mathrm{cm}^{2}$} & $0.478 \mathrm{~A}, \mathrm{~B}$ & $0.473^{B}$ & $0.837^{\mathrm{B}}$ \\
\hline & \pm 0.076 & \pm 0.051 & \pm 0.119 \\
\hline \multirow{2}{*}{ LED $50 \mathrm{~J} / \mathrm{cm}^{2}$} & $0.363^{\mathrm{B}}$ & $0.448^{B}$ & $0.785^{\mathrm{B}}$ \\
\hline & \pm 0.055 & \pm 0.042 & \pm 0.086 \\
\hline
\end{tabular}

Letras diferentes representam diferenças estatisticamente significantes. 
Anexo 4: Comparação entre os diferentes espectros na mesma dose com uma aplicação em um mesmo período. Valores de absorbância (média e desvio-padrão) do teste de MTT nos períodos de 24, 48 e 72 horas.

\begin{tabular}{|c|c|c|c|}
\hline \multirow{2}{*}{ GRUPOS EXPERIMENTAIS } & \multicolumn{3}{|c|}{ TEMPO (HORAS) } \\
\hline & 24 & 48 & 72 \\
\hline \multirow{2}{*}{ Laser $10 \mathrm{~J} / \mathrm{cm}^{2}$} & $0.367^{\mathrm{A}}$ & $0.537^{\mathrm{A}}$ & $0.922 \mathrm{~A}$ \\
\hline & \pm 0.036 & \pm 0.051 & \pm 0.154 \\
\hline \multirow{2}{*}{ Laser $20 \mathrm{~J} / \mathrm{cm}^{2}$} & $0.398^{A}$ & $0.574^{A}$ & 0.992 A \\
\hline & \pm 0.072 & \pm 0.015 & \pm 0.149 \\
\hline \multirow{2}{*}{ Laser $50 \mathrm{~J} / \mathrm{cm}^{2}$} & $0.459^{A}$ & $0.556 \mathrm{~A}, \mathrm{~B}$ & $1.112^{\mathrm{A}}$ \\
\hline & \pm 0.065 & \pm 0.049 & \pm 0.202 \\
\hline \multirow{2}{*}{ Infra $10 \mathrm{~J} / \mathrm{cm}^{2}$} & $0.392 \mathrm{~A}, \mathrm{~B}$ & $0.402^{B}$ & $1.078^{\mathrm{B}}$ \\
\hline & \pm 0.045 & \pm 0.081 & \pm 0.215 \\
\hline \multirow{2}{*}{ Infra $20 \mathrm{~J} / \mathrm{cm}^{2}$} & $0.445^{A}$ & $0.547^{A}$ & $0.996^{\mathrm{A}}$ \\
\hline & \pm 0.063 & \pm 0.060 & \pm 0.245 \\
\hline \multirow{2}{*}{ Infra $50 \mathrm{~J} / \mathrm{cm}^{2}$} & $0.470^{\mathrm{A}}$ & $0.656^{\mathrm{A}}$ & $1.003^{\mathrm{A}}$ \\
\hline & \pm 0.089 & \pm 0.134 & \pm 0.202 \\
\hline \multirow{2}{*}{ LED $10 \mathrm{~J} / \mathrm{cm}^{2}$} & $0.515^{\mathrm{B}}$ & $0.702^{c}$ & 0.972 A, B \\
\hline & \pm 0.098 & \pm 0.035 & \pm 0.062 \\
\hline \multirow{2}{*}{ LED $20 \mathrm{~J} / \mathrm{cm}^{2}$} & $0.478^{A}$ & $0.473^{A}$ & $0.837^{B}$ \\
\hline & \pm 0.076 & \pm 0.051 & \pm 0.119 \\
\hline \multirow{2}{*}{ LED $50 \mathrm{~J} / \mathrm{cm}^{2}$} & $0.363^{A}$ & $0.448^{B}$ & $0.785^{\mathrm{B}}$ \\
\hline & \pm 0.055 & \pm 0.042 & \pm 0.086 \\
\hline
\end{tabular}

Letras diferentes representam diferenças estatisticamente significantes. 


\section{Anexos}

Anexo 5: Comparação entre os diferentes espectros em relação ao controle com duas aplicações em um mesmo período. Valores de absorbância (média e desvio-padrão) do teste de MTT nos períodos de 24, 48 e 72 horas.

\begin{tabular}{|c|c|c|c|}
\hline \multirow{2}{*}{ GRUPOS EXPERIMENTAIS } & \multicolumn{3}{|c|}{ TEMPO (HORAS) } \\
\hline & 24 & 48 & 72 \\
\hline \multirow{2}{*}{ Controle } & $0.252^{A}$ & $0.784^{A}$ & $0.695^{A}$ \\
\hline & \pm 0.037 & \pm 0.069 & \pm 0.184 \\
\hline \multirow{2}{*}{ Laser $10 \mathrm{~J} / \mathrm{cm}^{2}$} & $0.288^{A}$ & $0.959^{B}$ & $1.244^{\mathrm{B}}$ \\
\hline & \pm 0.038 & \pm 0.146 & \pm 0.091 \\
\hline \multirow{2}{*}{ Laser $20 \mathrm{~J} / \mathrm{cm}^{2}$} & $0.283^{A}$ & $0.992^{B}$ & $1.303^{\mathrm{B}}$ \\
\hline & \pm 0.031 & \pm 0.126 & \pm 0.132 \\
\hline \multirow{2}{*}{ Laser $50 \mathrm{~J} / \mathrm{cm}^{2}$} & $0.315^{\mathrm{A}}$ & $0.996^{\mathrm{B}}$ & $1.218^{\mathrm{B}}$ \\
\hline & \pm 0.046 & \pm 0.128 & \pm 0.235 \\
\hline \multirow{2}{*}{ Infra $10 \mathrm{~J} / \mathrm{cm}^{2}$} & 0.299 A & $0.949^{\text {B }}$ & $1.121^{\mathrm{B}}$ \\
\hline & \pm 0.027 & \pm 0.063 & \pm 0.083 \\
\hline \multirow{2}{*}{ Infra $20 \mathrm{~J} / \mathrm{cm}^{2}$} & $0.303^{A}$ & $0.899^{A}$ & $1.101^{\mathrm{B}}$ \\
\hline & \pm 0.030 & \pm 0.054 & \pm 0.131 \\
\hline \multirow{2}{*}{ Infra $50 \mathrm{~J} / \mathrm{cm}^{2}$} & $0.302^{A}$ & $0.863^{A}$ & $1.033^{\mathrm{B}}$ \\
\hline & \pm 0.027 & \pm 0.126 & \pm 0.113 \\
\hline \multirow{2}{*}{ LED $10 \mathrm{~J} / \mathrm{cm}^{2}$} & $0.354 \mathrm{~A}$ & $1.176^{\mathrm{B}}$ & $1.356^{\mathrm{B}}$ \\
\hline & \pm 0.089 & \pm 0.112 & \pm 0.111 \\
\hline \multirow{2}{*}{ LED $20 \mathrm{~J} / \mathrm{cm}^{2}$} & $0.387^{B}$ & $1.140^{B}$ & $1.119^{\mathrm{B}}$ \\
\hline & \pm 0.141 & \pm 0.063 & \pm 0.088 \\
\hline \multirow{2}{*}{ LED $50 \mathrm{~J} / \mathrm{cm}^{2}$} & $0.461^{\text {B }}$ & $1.082^{B}$ & $0.593^{A}$ \\
\hline & \pm 0.125 & \pm 0.089 & \pm 0.152 \\
\hline
\end{tabular}


Anexo 6: Comparação entre o mesmo tipo de laser com doses diferentes com duas aplicações em um mesmo período. Valores de absorbância (média e desvio-padrão) do teste de MTT nos períodos de 24, 48 e 72 horas.

\begin{tabular}{|c|c|c|c|}
\hline \multirow{2}{*}{ GRUPOS EXPERIMENTAIS } & \multicolumn{3}{|c|}{ TEMPO (HORAS) } \\
\hline & 24 & 48 & 72 \\
\hline \multirow{2}{*}{ Laser $10 \mathrm{~J} / \mathrm{cm}^{2}$} & $0.288^{\mathrm{A}}$ & $0.959^{A}$ & $1.244^{\mathrm{A}}$ \\
\hline & \pm 0.038 & \pm 0.146 & \pm 0.091 \\
\hline \multirow{2}{*}{ Laser $20 \mathrm{~J} / \mathrm{cm}^{2}$} & 0.283 A & 0.992 A & $1.303^{A}$ \\
\hline & \pm 0.031 & \pm 0.126 & \pm 0.132 \\
\hline \multirow{2}{*}{ Laser $50 \mathrm{~J} / \mathrm{cm}^{2}$} & $0.315^{A}$ & $0.996^{A}$ & $1.218^{A}$ \\
\hline & \pm 0.046 & \pm 0.128 & \pm 0.235 \\
\hline \multirow{2}{*}{ Infra $10 \mathrm{~J} / \mathrm{cm}^{2}$} & $0.299^{A}$ & $0.949^{A}$ & $1.121^{\mathrm{A}}$ \\
\hline & \pm 0.027 & \pm 0.063 & \pm 0.083 \\
\hline \multirow{2}{*}{ Infra $20 \mathrm{~J} / \mathrm{cm}^{2}$} & $0.303^{A}$ & $0.899^{A}$ & $1.101^{A}$ \\
\hline & \pm 0.030 & \pm 0.054 & \pm 0.131 \\
\hline \multirow{2}{*}{ Infra $50 \mathrm{~J} / \mathrm{cm}^{2}$} & $0.302^{A}$ & $0.863^{A}$ & $1.033^{A}$ \\
\hline & \pm 0.027 & \pm 0.126 & \pm 0.113 \\
\hline \multirow{2}{*}{ LED $10 \mathrm{~J} / \mathrm{cm}^{2}$} & $0.354^{\mathrm{A}}$ & $1.176^{\mathrm{A}}$ & $1.356^{A}$ \\
\hline & \pm 0.089 & \pm 0.112 & \pm 0.111 \\
\hline \multirow{2}{*}{ LED $20 \mathrm{~J} / \mathrm{cm}^{2}$} & $0.387^{A}$ & $1.140^{\mathrm{A}}$ & $1.119^{B}$ \\
\hline & \pm 0.141 & \pm 0.063 & \pm 0.088 \\
\hline \multirow{2}{*}{ LED $50 \mathrm{~J} / \mathrm{cm}^{2}$} & $0.461^{A}$ & $1.082^{A}$ & $0.593^{C}$ \\
\hline & \pm 0.125 & \pm 0.089 & \pm 0.152 \\
\hline
\end{tabular}

Letras diferentes representam diferenças estatisticamente significantes. 
Anexo 7: Comparação entre os diferentes espectros na mesma dose com duas aplicações em um mesmo período. Valores de absorbância (média e desvio-padrão) do teste de MTT nos períodos de 24, 48 e 72 horas.

\begin{tabular}{|c|c|c|c|}
\hline \multirow{2}{*}{ GRUPOS EXPERIMENTAIS } & \multicolumn{3}{|c|}{ TEMPO (HORAS) } \\
\hline & 24 & 48 & 72 \\
\hline \multirow{2}{*}{ Laser $10 \mathrm{~J} / \mathrm{cm}^{2}$} & $0.288^{A}$ & $0.959^{\mathrm{A}}$ & $1.244 \mathrm{~A}, \mathrm{~B}$ \\
\hline & \pm 0.038 & \pm 0.146 & \pm 0.091 \\
\hline \multirow{2}{*}{ Laser $20 \mathrm{~J} / \mathrm{cm}^{2}$} & $0.283^{A}$ & 0.992 A & $1.303^{A}$ \\
\hline & \pm 0.031 & \pm 0.126 & \pm 0.132 \\
\hline \multirow{2}{*}{ Laser $50 \mathrm{~J} / \mathrm{cm}^{2}$} & $0.315^{A}$ & $0.996^{A}$ & $1.218^{A}$ \\
\hline & \pm 0.046 & \pm 0.128 & \pm 0.235 \\
\hline \multirow{2}{*}{ Infra $10 \mathrm{~J} / \mathrm{cm}^{2}$} & 0.299 A & $0.949^{A}$ & $1.121^{\mathrm{A}}$ \\
\hline & \pm 0.027 & \pm 0.063 & \pm 0.083 \\
\hline \multirow{2}{*}{ Infra $20 \mathrm{~J} / \mathrm{cm}^{2}$} & $0.303^{A}$ & $0.899^{A}$ & $1.101^{\mathrm{B}}$ \\
\hline & \pm 0.030 & \pm 0.054 & \pm 0.131 \\
\hline \multirow{2}{*}{ Infra $50 \mathrm{~J} / \mathrm{cm}^{2}$} & $0.302^{A}$ & $0.863^{\mathrm{B}}$ & $1.033^{\mathrm{B}}$ \\
\hline & \pm 0.027 & \pm 0.126 & \pm 0.113 \\
\hline \multirow{2}{*}{ LED $10 \mathrm{~J} / \mathrm{cm}^{2}$} & $0.354^{A}$ & $1.176^{\mathrm{B}}$ & $1.356^{\mathrm{B}}$ \\
\hline & \pm 0.089 & \pm 0.112 & \pm 0.111 \\
\hline \multirow{2}{*}{ LED $20 \mathrm{~J} / \mathrm{cm}^{2}$} & $0.387^{A}$ & $1.140^{\mathrm{B}}$ & $1.119^{B}$ \\
\hline & \pm 0.141 & \pm 0.063 & \pm 0.088 \\
\hline \multirow{2}{*}{ LED $50 \mathrm{~J} / \mathrm{cm}^{2}$} & $0.461^{\mathrm{B}}$ & $1.082^{A}$ & $0.593^{C}$ \\
\hline & \pm 0.125 & \pm 0.089 & \pm 0.152 \\
\hline
\end{tabular}

Letras diferentes representam diferenças estatisticamente significantes. 
Anexo 8: Comparação dos diferentes espectros com uma aplicação e duas aplicações em um mesmo período. Valores de absorbância (média e desvio-padrão) do teste de MTT nos períodos de 24, 48 e 72 horas.

\begin{tabular}{|c|c|c|c|c|c|c|}
\hline \multirow{3}{*}{$\begin{array}{c}\text { GRUPOS } \\
\text { EXPERIMENTAIS }\end{array}$} & \multicolumn{5}{|c|}{ TEMPO (HORAS) } & \multirow[b]{3}{*}{72} \\
\hline & \multicolumn{3}{|c|}{1 APLICAÇÃO } & \multicolumn{2}{|c|}{2 APLICAÇŌES } & \\
\hline & 24 & 48 & 72 & 24 & 48 & \\
\hline & $0.358^{A}$ & $0.372^{A}$ & $0.955^{\mathrm{A}}$ & $0.252^{A}$ & $0.784^{\mathrm{B}}$ & $0.695^{\mathrm{B}}$ \\
\hline Controle & \pm 0.040 & \pm 0.014 & \pm 0.088 & \pm 0.037 & \pm 0.069 & \pm 0.184 \\
\hline acer $10 \mathrm{~J} / \mathrm{cm}^{2}$ & $0.367 \mathrm{~A}$ & $0.537 \mathrm{~A}$ & $0.922 \mathrm{~A}$ & $0.288^{A}$ & 0.959 B & $1.244^{\mathrm{B}}$ \\
\hline Laser $10 \mathrm{~J} / \mathrm{cm}^{2}$ & \pm 0.036 & \pm 0.051 & \pm 0.154 & \pm 0.038 & \pm 0.146 & \pm 0.091 \\
\hline Laser $20 \mathrm{~J} / \mathrm{cm}^{2}$ & $0.398^{A}$ & $0.574^{A}$ & 0.992 A & $0.283^{A}$ & 0.992 B & $1.303^{\mathrm{B}}$ \\
\hline Laser $20 \mathrm{~J} / \mathrm{cm}^{2}$ & \pm 0.072 & \pm 0.015 & \pm 0.149 & \pm 0.031 & \pm 0.126 & \pm 0.132 \\
\hline & $0.459^{A}$ & $0.556^{A}$ & $1.112^{\mathrm{A}}$ & $0.315^{A}$ & $0.996^{\mathrm{B}}$ & $1.218^{\mathrm{B}}$ \\
\hline Laser $50 \mathrm{~J} / \mathrm{cm}^{2}$ & \pm 0.065 & \pm 0.049 & \pm 0.202 & \pm 0.046 & \pm 0.128 & \pm 0.235 \\
\hline Infra $10 \mathrm{~J} / \mathrm{cm}^{2}$ & $0.392^{A}$ & $0.402 \mathrm{~A}$ & $1.078^{\mathrm{A}}$ & 0.299 A & 0.949 B & $1.121^{\mathrm{A}}$ \\
\hline & \pm 0.045 & \pm 0.081 & \pm 0.215 & \pm 0.027 & \pm 0.063 & \pm 0.083 \\
\hline Infra $20 \mathrm{~J} / \mathrm{cm}^{2}$ & $0.445^{A}$ & $0.547^{A}$ & $0.996^{A}$ & $0.303^{A}$ & 0.899 В & $1.101^{\mathrm{A}}$ \\
\hline IIIIIa $200 / \mathrm{Cmin}^{-1}$ & \pm 0.063 & \pm 0.060 & \pm 0.245 & \pm 0.030 & \pm 0.054 & \pm 0.131 \\
\hline Infra $50 \mathrm{~J} / \mathrm{cm}^{2}$ & $0.470^{\mathrm{A}}$ & $0.656^{A}$ & $1.003^{A}$ & $0.302^{B}$ & $0.863^{\mathrm{B}}$ & $1.033^{\mathrm{A}}$ \\
\hline InIra so J/ $\mathrm{cm}^{-}$ & \pm 0.089 & \pm 0.134 & \pm 0.202 & \pm 0.027 & \pm 0.126 & \pm 0.113 \\
\hline LED $10 \mathrm{~J} / \mathrm{cm}^{2}$ & $0.515^{A}$ & $0.702^{A}$ & $0.972 \mathrm{~A}$ & $0.354^{\mathrm{A}}$ & $1.176^{\mathrm{B}}$ & $1.356^{\mathrm{B}}$ \\
\hline LED $10 \mathrm{~J} / \mathrm{cm}^{2}$ & \pm 0.098 & \pm 0.035 & \pm 0.062 & \pm 0.089 & \pm 0.112 & \pm 0.111 \\
\hline LED $20 \mathrm{~J} / \mathrm{cm}^{2}$ & $0.478^{\mathrm{A}}$ & $0.473^{A}$ & $0.837^{A}$ & $0.387^{A}$ & $1.140^{\mathrm{B}}$ & $1.119^{\mathrm{B}}$ \\
\hline LED $20 \mathrm{~J} / \mathrm{cm}^{2}$ & \pm 0.076 & \pm 0.051 & \pm 0.119 & \pm 0.141 & \pm 0.063 & \pm 0.088 \\
\hline LED $50 \mathrm{~J} / \mathrm{cm}^{2}$ & $0.363^{A}$ & $0.448^{A}$ & $0.785^{A}$ & $0.461^{\mathrm{A}}$ & 1.082 B & $0.593^{A}$ \\
\hline & \pm 0.055 & \pm 0.042 & \pm 0.086 & \pm 0.125 & \pm 0.089 & \pm 0.152 \\
\hline
\end{tabular}

Letras diferentes representam diferenças estatisticamente significantes. 
Anexo 9: Comparação entre os diferentes espectros em relação ao controle com uma aplicação em um mesmo período. Valores de absorbância (média e desvio-padrão) do teste de cristal violeta nos períodos de 24, 48 e 72 horas.

\begin{tabular}{|c|c|c|c|}
\hline \multirow{2}{*}{ GRUPOS EXPERIMENTAIS } & \multicolumn{3}{|c|}{ TEMPO (HORAS) } \\
\hline & 24 & 48 & 72 \\
\hline \multirow{2}{*}{ Controle } & $0.137^{\mathrm{A}}$ & $0.405^{\mathrm{A}}$ & $0.676^{\mathrm{A}}$ \\
\hline & \pm 0.027 & \pm 0.047 & \pm 0.051 \\
\hline \multirow{2}{*}{ Laser $10 \mathrm{~J} / \mathrm{cm}^{2}$} & $0.168^{A}$ & $0.463^{A}$ & $0.795^{\mathrm{B}}$ \\
\hline & \pm 0.046 & \pm 0.072 & \pm 0.061 \\
\hline \multirow{2}{*}{ Laser $20 \mathrm{~J} / \mathrm{cm}^{2}$} & $0.195^{A}$ & $0.439^{A}$ & $0.771^{\mathrm{B}}$ \\
\hline & \pm 0.025 & \pm 0.054 & \pm 0.092 \\
\hline \multirow{2}{*}{ Laser $50 \mathrm{~J} / \mathrm{cm}^{2}$} & $0.149^{A}$ & $0.448^{A}$ & $0.757^{\mathrm{B}}$ \\
\hline & \pm 0.025 & \pm 0.048 & \pm 0.061 \\
\hline \multirow{2}{*}{ Infra $10 \mathrm{~J} / \mathrm{cm}^{2}$} & $0.134^{\mathrm{A}}$ & $0.390^{A}$ & $0.721^{\mathrm{A}}$ \\
\hline & \pm 0.037 & \pm 0.061 & \pm 0.035 \\
\hline \multirow{2}{*}{ Infra $20 \mathrm{~J} / \mathrm{cm}^{2}$} & $0.148^{A}$ & $0.339^{A}$ & $0.747^{\mathrm{A}}$ \\
\hline & \pm 0.041 & \pm 0.025 & \pm 0.048 \\
\hline \multirow{2}{*}{ Infra $50 \mathrm{~J} / \mathrm{cm}^{2}$} & $0.224^{B}$ & $0.462^{\mathrm{A}}$ & $0.778^{\mathrm{B}}$ \\
\hline & \pm 0.038 & \pm 0.080 & \pm 0.059 \\
\hline \multirow{2}{*}{ LED $10 \mathrm{~J} / \mathrm{cm}^{2}$} & $0.183^{A}$ & $0.380^{\mathrm{A}}$ & $0.944^{\mathrm{B}}$ \\
\hline & \pm 0.020 & \pm 0.034 & \pm 0.068 \\
\hline \multirow{2}{*}{ LED $20 \mathrm{~J} / \mathrm{cm}^{2}$} & $0.152^{A}$ & $0.317^{B}$ & $0.767^{\mathrm{B}}$ \\
\hline & \pm 0.027 & \pm 0.041 & \pm 0.112 \\
\hline \multirow{2}{*}{ LED $50 \mathrm{~J} / \mathrm{cm}^{2}$} & $0.170^{\mathrm{A}}$ & $0.398^{A}$ & $0.701^{\mathrm{A}}$ \\
\hline & \pm 0.015 & \pm 0.041 & \pm 0.066 \\
\hline
\end{tabular}


Anexo 10: Comparação entre o mesmo tipo de laser com doses diferentes com uma aplicação em um mesmo período. Valores de absorbância (média e desvio-padrão) do teste de cristal violeta nos períodos de 24, 48 e 72 horas.

\begin{tabular}{|c|c|c|c|}
\hline \multirow{2}{*}{ GRUPOS EXPERIMENTAIS } & \multicolumn{3}{|c|}{ TEMPO (HORAS) } \\
\hline & 24 & 48 & 72 \\
\hline \multirow{2}{*}{ Laser $10 \mathrm{~J} / \mathrm{cm}^{2}$} & $0.168^{\mathrm{A}}$ & $0.463^{\mathrm{A}}$ & $0.795^{\mathrm{A}}$ \\
\hline & \pm 0.046 & \pm 0.072 & \pm 0.061 \\
\hline \multirow{2}{*}{ Laser $20 \mathrm{~J} / \mathrm{cm}^{2}$} & $0.195 \mathrm{~A}$ & $0.439 \mathrm{~A}$ & $0.771^{A}$ \\
\hline & \pm 0.025 & \pm 0.054 & \pm 0.092 \\
\hline \multirow{2}{*}{ Laser $50 \mathrm{~J} / \mathrm{cm}^{2}$} & $0.149^{A}$ & $0.448^{\mathrm{A}}$ & $0.757^{\mathrm{B}}$ \\
\hline & \pm 0.025 & \pm 0.048 & \pm 0.061 \\
\hline \multirow{2}{*}{ Infra $10 \mathrm{~J} / \mathrm{cm}^{2}$} & $0.134^{A}$ & $0.390^{A}$ & $0.721^{A}$ \\
\hline & \pm 0.037 & \pm 0.061 & \pm 0.035 \\
\hline \multirow{2}{*}{ Infra $20 \mathrm{~J} / \mathrm{cm}^{2}$} & $0.148^{A}$ & $0.339^{A}$ & $0.747^{\mathrm{A}}$ \\
\hline & \pm 0.041 & \pm 0.025 & \pm 0.048 \\
\hline \multirow{2}{*}{ Infra $50 \mathrm{~J} / \mathrm{cm}^{2}$} & $0.224^{\mathrm{B}}$ & $0.462^{B}$ & $0.778^{A}$ \\
\hline & \pm 0.038 & \pm 0.080 & \pm 0.059 \\
\hline \multirow{2}{*}{ LED $10 \mathrm{~J} / \mathrm{cm}^{2}$} & $0.183^{\mathrm{A}}$ & $0.380^{\mathrm{A}, \mathrm{B}}$ & $0.944^{A}$ \\
\hline & \pm 0.020 & \pm 0.034 & \pm 0.068 \\
\hline \multirow{2}{*}{ LED $20 \mathrm{~J} / \mathrm{cm}^{2}$} & $0.152^{A}$ & $0.317^{\mathrm{A}}$ & $0.767^{\mathrm{B}}$ \\
\hline & \pm 0.027 & \pm 0.041 & \pm 0.112 \\
\hline \multirow{2}{*}{ LED $50 \mathrm{~J} / \mathrm{cm}^{2}$} & $0.170^{\mathrm{A}}$ & $0.398^{B}$ & $0.701^{\mathrm{B}}$ \\
\hline & \pm 0.015 & \pm 0.041 & \pm 0.066 \\
\hline
\end{tabular}

Letras diferentes representam diferenças estatisticamente significantes. 
Anexo 11: Comparação entre os diferentes espectros na mesma dose com uma aplicação em um mesmo período. Valores de absorbância (média e desvio-padrão) do teste de cristal violeta nos períodos de 24, 48 e 72 horas.

\begin{tabular}{|c|c|c|c|}
\hline \multirow{2}{*}{ GRUPOS EXPERIMENTAIS } & \multicolumn{3}{|c|}{ TEMPO (HORAS) } \\
\hline & 24 & 48 & 72 \\
\hline \multirow{2}{*}{ Laser $10 \mathrm{~J} / \mathrm{cm}^{2}$} & $0.168^{\mathrm{A}}$ & $0.463^{\mathrm{A}}$ & $0.795^{\mathrm{A}}$ \\
\hline & \pm 0.046 & \pm 0.072 & \pm 0.061 \\
\hline \multirow{2}{*}{ Laser $20 \mathrm{~J} / \mathrm{cm}^{2}$} & $0.195^{\text {A }}$ & $0.439^{A}$ & $0.771^{A}$ \\
\hline & \pm 0.025 & \pm 0.054 & \pm 0.092 \\
\hline \multirow{2}{*}{ Laser $50 \mathrm{~J} / \mathrm{cm}^{2}$} & $0.149^{A}$ & $0.448^{A, B}$ & $0.757^{A, B}$ \\
\hline & \pm 0.025 & \pm 0.048 & \pm 0.061 \\
\hline \multirow{2}{*}{ Infra $10 \mathrm{~J} / \mathrm{cm}^{2}$} & $0.134^{A}$ & $0.390^{\mathrm{B}}$ & $0.721^{\mathrm{B}}$ \\
\hline & \pm 0.037 & \pm 0.061 & \pm 0.035 \\
\hline \multirow{2}{*}{ Infra $20 \mathrm{~J} / \mathrm{cm}^{2}$} & $0.148^{A}$ & $0.339^{B}$ & $0.747^{\mathrm{A}}$ \\
\hline & \pm 0.041 & \pm 0.025 & \pm 0.048 \\
\hline \multirow{2}{*}{ Infra $50 \mathrm{~J} / \mathrm{cm}^{2}$} & $0.224^{\mathrm{B}}$ & $0.462^{\mathrm{A}}$ & $0.778^{A}$ \\
\hline & \pm 0.038 & \pm 0.080 & \pm 0.059 \\
\hline \multirow{2}{*}{ LED $10 \mathrm{~J} / \mathrm{cm}^{2}$} & $0.183^{A}$ & $0.380^{B}$ & $0.944^{C}$ \\
\hline & \pm 0.020 & \pm 0.034 & \pm 0.068 \\
\hline \multirow{2}{*}{ LED $20 \mathrm{~J} / \mathrm{cm}^{2}$} & $0.152^{\mathrm{A}}$ & $0.317^{\mathrm{B}}$ & $0.767^{A}$ \\
\hline & \pm 0.027 & \pm 0.041 & \pm 0.112 \\
\hline \multirow{2}{*}{ LED $50 \mathrm{~J} / \mathrm{cm}^{2}$} & 0.170 A, B & $0.398^{B}$ & $0.701^{\mathrm{B}}$ \\
\hline & \pm 0.015 & \pm 0.041 & \pm 0.066 \\
\hline
\end{tabular}

Letras diferentes representam diferenças estatisticamente significantes. 
Anexo 12: Comparação entre os diferentes espectros em relação ao controle em um mesmo período com duas aplicações. Valores de absorbância (média e desvio-padrão) do teste de cristal violeta nos períodos de 24, 48 e 72 horas.

\begin{tabular}{|c|c|c|c|}
\hline \multirow{2}{*}{ GRUPOS EXPERIMENTAIS } & \multicolumn{3}{|c|}{ TEMPO (HORAS) } \\
\hline & 24 & 48 & 72 \\
\hline \multirow{2}{*}{ Controle } & $0.216^{A}$ & $0.379^{A}$ & $0.586^{\mathrm{A}}$ \\
\hline & \pm 0.029 & \pm 0.021 & \pm 0.047 \\
\hline \multirow{2}{*}{ Laser $10 \mathrm{~J} / \mathrm{cm}^{2}$} & $0.214^{\mathrm{A}}$ & $0.444^{\mathrm{B}}$ & $0.756^{\mathrm{B}}$ \\
\hline & \pm 0.055 & \pm 0.036 & \pm 0.046 \\
\hline \multirow{2}{*}{ Laser $20 \mathrm{~J} / \mathrm{cm}^{2}$} & $0.266^{A}$ & $0.388^{A}$ & $0.709^{B}$ \\
\hline & \pm 0.030 & \pm 0.044 & \pm 0.071 \\
\hline \multirow{2}{*}{ Laser $50 \mathrm{~J} / \mathrm{cm}^{2}$} & $0.278^{B}$ & $0.447^{\mathrm{B}}$ & $0.757^{\mathrm{B}}$ \\
\hline & \pm 0.043 & \pm 0.051 & \pm 0.065 \\
\hline \multirow{2}{*}{ Infra $10 \mathrm{~J} / \mathrm{cm}^{2}$} & $0.219^{A}$ & $0.452^{B}$ & $0.723^{\mathrm{B}}$ \\
\hline & \pm 0.036 & \pm 0.041 & \pm 0.073 \\
\hline \multirow{2}{*}{ Infra $20 \mathrm{~J} / \mathrm{cm}^{2}$} & $0.310^{B}$ & $0.428^{A}$ & $0.624^{\mathrm{A}}$ \\
\hline & \pm 0.032 & \pm 0.036 & \pm 0.074 \\
\hline \multirow{2}{*}{ Infra $50 \mathrm{~J} / \mathrm{cm}^{2}$} & $0.271^{A}$ & $0.474^{\mathrm{B}}$ & $0.671^{\mathrm{B}}$ \\
\hline & \pm 0.027 & \pm 0.048 & \pm 0.057 \\
\hline \multirow{2}{*}{ LED $10 \mathrm{~J} / \mathrm{cm}^{2}$} & $0.214^{A}$ & $0.455^{\mathrm{B}}$ & $0.806^{\mathrm{B}}$ \\
\hline & \pm 0.036 & \pm 0.027 & \pm 0.035 \\
\hline \multirow{2}{*}{ LED $20 \mathrm{~J} / \mathrm{cm}^{2}$} & $0.148^{\mathrm{B}}$ & $0.450^{B}$ & $0.620^{\mathrm{A}}$ \\
\hline & \pm 0.027 & \pm 0.061 & \pm 0.044 \\
\hline \multirow{2}{*}{ LED $50 \mathrm{~J} / \mathrm{cm}^{2}$} & $0.205^{A}$ & $0.466^{\mathrm{B}}$ & $0.708^{B}$ \\
\hline & \pm 0.023 & \pm 0.027 & \pm 0.063 \\
\hline
\end{tabular}


Anexo 13: Comparação entre o mesmo tipo de laser com doses diferentes com duas aplicações em um mesmo período. Valores de absorbância (média e desvio-padrão) do teste de cristal violeta nos períodos de 24, 48 e 72 horas.

\begin{tabular}{|c|c|c|c|}
\hline \multirow{2}{*}{ GRUPOS EXPERIMENTAIS } & \multicolumn{3}{|c|}{ TEMPO (HORAS) } \\
\hline & 24 & 48 & 72 \\
\hline \multirow{2}{*}{ Laser $10 \mathrm{~J} / \mathrm{cm}^{2}$} & $0.214^{\mathrm{A}}$ & $0.444^{\mathrm{A}}$ & $0.756^{A}$ \\
\hline & \pm 0.055 & \pm 0.036 & \pm 0.046 \\
\hline \multirow{2}{*}{ Laser $20 \mathrm{~J} / \mathrm{cm}^{2}$} & 0.266 A, B & $0.388^{B}$ & 0.709 A \\
\hline & \pm 0.030 & \pm 0.044 & \pm 0.071 \\
\hline \multirow{2}{*}{ Laser $50 \mathrm{~J} / \mathrm{cm}^{2}$} & $0.278^{B}$ & $0.447^{A}$ & $0.757 \mathrm{~A}$ \\
\hline & \pm 0.043 & \pm 0.051 & \pm 0.065 \\
\hline \multirow{2}{*}{ Infra $10 \mathrm{~J} / \mathrm{cm}^{2}$} & $0.219^{A}$ & $0.452^{A}$ & $0.723^{A}$ \\
\hline & \pm 0.036 & \pm 0.041 & \pm 0.073 \\
\hline \multirow{2}{*}{ Infra $20 \mathrm{~J} / \mathrm{cm}^{2}$} & $0.310^{\mathrm{B}}$ & $0.428^{A}$ & $0.624^{\mathrm{B}}$ \\
\hline & \pm 0.032 & \pm 0.036 & \pm 0.074 \\
\hline \multirow{2}{*}{ Infra $50 \mathrm{~J} / \mathrm{cm}^{2}$} & $0.271 \mathrm{~A}, \mathrm{~B}$ & $0.474^{A}$ & $0.671^{\mathrm{A}, \mathrm{B}}$ \\
\hline & \pm 0.027 & \pm 0.048 & \pm 0.057 \\
\hline \multirow{2}{*}{ LED $10 \mathrm{~J} / \mathrm{cm}^{2}$} & $0.214^{\mathrm{A}}$ & $0.455^{\mathrm{A}}$ & $0.806^{\mathrm{A}}$ \\
\hline & \pm 0.036 & \pm 0.027 & \pm 0.035 \\
\hline \multirow{2}{*}{ LED $20 \mathrm{~J} / \mathrm{cm}^{2}$} & $0.148^{B}$ & $0.450^{\mathrm{A}}$ & $0.620^{B}$ \\
\hline & \pm 0.027 & \pm 0.061 & \pm 0.044 \\
\hline \multirow{2}{*}{ LED $50 \mathrm{~J} / \mathrm{cm}^{2}$} & $0.205^{A}$ & $0.466^{A}$ & $0.708^{c}$ \\
\hline & \pm 0.023 & \pm 0.027 & \pm 0.063 \\
\hline
\end{tabular}

Letras diferentes representam diferenças estatisticamente significantes. 
Anexo 14: Comparação entre os diferentes espectros na mesma dose com duas aplicações em um mesmo período. Valores de absorbância (média e desvio-padrão) do teste de cristal violeta nos períodos de 24, 48 e 72 horas.

\begin{tabular}{|c|c|c|c|}
\hline \multirow{2}{*}{ GRUPOS EXPERIMENTAIS } & \multicolumn{3}{|c|}{ TEMPO (HORAS) } \\
\hline & 24 & 48 & 72 \\
\hline \multirow{2}{*}{ Laser $10 \mathrm{~J} / \mathrm{cm}^{2}$} & $0.214^{\mathrm{A}}$ & $0.444^{\mathrm{A}}$ & $0.756^{A, B}$ \\
\hline & \pm 0.055 & \pm 0.036 & \pm 0.046 \\
\hline \multirow{2}{*}{ Laser $20 \mathrm{~J} / \mathrm{cm}^{2}$} & $0.266^{A}$ & $0.388^{A}$ & $0.709^{A}$ \\
\hline & \pm 0.030 & \pm 0.044 & \pm 0.071 \\
\hline \multirow{2}{*}{ Laser $50 \mathrm{~J} / \mathrm{cm}^{2}$} & $0.278^{A}$ & $0.447^{\mathrm{A}}$ & $0.757^{A}$ \\
\hline & \pm 0.043 & \pm 0.051 & \pm 0.065 \\
\hline \multirow{2}{*}{ Infra $10 \mathrm{~J} / \mathrm{cm}^{2}$} & $0.219^{A}$ & $0.452^{A}$ & $0.723^{A}$ \\
\hline & \pm 0.036 & \pm 0.041 & \pm 0.073 \\
\hline \multirow{2}{*}{ Infra $20 \mathrm{~J} / \mathrm{cm}^{2}$} & $0.310^{A}$ & $0.428^{A, B}$ & $0.624^{\text {B }}$ \\
\hline & \pm 0.032 & \pm 0.036 & \pm 0.074 \\
\hline \multirow{2}{*}{ Infra $50 \mathrm{~J} / \mathrm{cm}^{2}$} & $0.271^{A}$ & $0.474^{A}$ & $0.671^{\mathrm{B}}$ \\
\hline & \pm 0.027 & \pm 0.048 & \pm 0.057 \\
\hline \multirow{2}{*}{ LED $10 \mathrm{~J} / \mathrm{cm}^{2}$} & $0.214^{\mathrm{A}}$ & $0.455^{A}$ & $0.806^{\mathrm{B}}$ \\
\hline & \pm 0.036 & \pm 0.027 & \pm 0.035 \\
\hline \multirow{2}{*}{ LED $20 \mathrm{~J} / \mathrm{cm}^{2}$} & $0.148^{B}$ & $0.450^{B}$ & $0.620^{B}$ \\
\hline & \pm 0.027 & \pm 0.061 & \pm 0.044 \\
\hline \multirow{2}{*}{ LED $50 \mathrm{~J} / \mathrm{cm}^{2}$} & $0.205^{B}$ & $0.466^{A}$ & 0.708 A, B \\
\hline & \pm 0.023 & \pm 0.027 & \pm 0.063 \\
\hline
\end{tabular}

Letras diferentes representam diferenças estatisticamente significantes. 
Anexo 15: Comparação dos diferentes espectros com uma aplicação e duas aplicações em um mesmo período. Valores de absorbância (média e desvio-padrão) do teste de cristal violeta nos períodos de 24, 48 e 72 horas.

\begin{tabular}{|c|c|c|c|c|c|c|}
\hline \multirow{3}{*}{$\begin{array}{c}\text { GRUPOS } \\
\text { EXPERIMENTAIS }\end{array}$} & \multicolumn{5}{|c|}{ TEMPO (HORAS) } & \multirow[b]{3}{*}{72} \\
\hline & \multicolumn{3}{|c|}{1 APLICAÇÃO } & \multicolumn{2}{|c|}{2 APLICAÇŌES } & \\
\hline & 24 & 48 & 72 & 24 & 48 & \\
\hline \multirow{2}{*}{ Controle } & $0.137^{A}$ & $0.405^{A}$ & $0.676^{A}$ & $0.216^{A}$ & $0.379^{A}$ & $0.586^{A}$ \\
\hline & \pm 0.027 & \pm 0.047 & \pm 0.051 & \pm 0.029 & \pm 0.021 & \pm 0.047 \\
\hline \multirow{2}{*}{ Laser $10 \mathrm{~J} / \mathrm{cm}^{2}$} & $0.168^{\mathrm{A}}$ & $0.463^{A}$ & $0.795^{A}$ & $0.214^{A}$ & $0.444^{\mathrm{A}}$ & $0.756^{A}$ \\
\hline & \pm 0.046 & \pm 0.072 & \pm 0.061 & \pm 0.055 & \pm 0.036 & \pm 0.046 \\
\hline \multirow{2}{*}{ Laser $20 \mathrm{~J} / \mathrm{cm}^{2}$} & $0.195^{A}$ & $0.439^{A}$ & $0.771^{A}$ & $0.266^{A}$ & $0.388^{A}$ & $0.709^{A}$ \\
\hline & \pm 0.025 & \pm 0.054 & \pm 0.092 & \pm 0.030 & \pm 0.044 & \pm 0.071 \\
\hline \multirow{2}{*}{ Laser $50 \mathrm{~J} / \mathrm{cm}^{2}$} & $0.149^{A}$ & $0.448^{A}$ & $0.757^{A}$ & $0.278^{\mathrm{B}}$ & $0.447^{A}$ & $0.757^{\mathrm{A}}$ \\
\hline & \pm 0.025 & \pm 0.048 & \pm 0.061 & \pm 0.043 & \pm 0.051 & \pm 0.065 \\
\hline \multirow{2}{*}{ Infra $10 \mathrm{~J} / \mathrm{cm}^{2}$} & $0.134^{A}$ & $0.390^{\mathrm{A}}$ & $0.721^{A}$ & $0.219^{A}$ & $0.452^{A}$ & $0.723^{A}$ \\
\hline & \pm 0.037 & \pm 0.061 & \pm 0.035 & \pm 0.036 & \pm 0.041 & \pm 0.073 \\
\hline \multirow{2}{*}{ Infra $20 \mathrm{~J} / \mathrm{cm}^{2}$} & $0.148^{\mathrm{A}}$ & $0.339^{A}$ & $0.747^{A}$ & $0.310^{\mathrm{B}}$ & $0.428^{A}$ & $0.624^{\mathrm{B}}$ \\
\hline & \pm 0.041 & \pm 0.025 & \pm 0.048 & \pm 0.032 & \pm 0.036 & \pm 0.074 \\
\hline \multirow{2}{*}{ Infra $50 \mathrm{~J} / \mathrm{cm}^{2}$} & $0.224^{A}$ & $0.462^{\mathrm{A}}$ & $0.778^{A}$ & $0.271^{A}$ & $0.474^{\mathrm{A}}$ & $0.671^{\mathrm{B}}$ \\
\hline & \pm 0.038 & \pm 0.080 & \pm 0.059 & \pm 0.027 & \pm 0.048 & \pm 0.057 \\
\hline \multirow{2}{*}{ LED $10 \mathrm{~J} / \mathrm{cm}^{2}$} & $0.183^{\mathrm{A}}$ & $0.380^{\mathrm{A}}$ & $0.944^{A}$ & $0.214^{A}$ & $0.455^{\mathrm{aA}}$ & $0.806^{\mathrm{B}}$ \\
\hline & \pm 0.020 & \pm 0.034 & \pm 0.068 & \pm 0.036 & \pm 0.027 & \pm 0.035 \\
\hline \multirow{2}{*}{ LED $20 \mathrm{~J} / \mathrm{cm}^{2}$} & $0.152^{A}$ & $0.317^{A}$ & $0.767^{A}$ & $0.148^{A}$ & $0.450^{\mathrm{B}}$ & $0.620^{\mathrm{B}}$ \\
\hline & \pm 0.027 & \pm 0.041 & \pm 0.112 & \pm 0.027 & \pm 0.061 & \pm 0.044 \\
\hline \multirow{2}{*}{ LED $50 \mathrm{~J} / \mathrm{cm}^{2}$} & $0.170^{\mathrm{A}}$ & $0.398^{A}$ & $0.701^{A}$ & $0.205^{A}$ & $0.466^{A}$ & $0.708^{A}$ \\
\hline & \pm 0.015 & \pm 0.041 & \pm 0.066 & \pm 0.023 & \pm 0.027 & \pm 0.063 \\
\hline
\end{tabular}

Letras diferentes representam diferenças estatisticamente significantes. 
Anexo 16: Comparação entre os diferentes espectros em relação ao controle em um mesmo período. Valores da atividade de fosfatase alcalina (média e desvio-padrão) nos períodos de 7, 14, 21 e 28 dias.

\begin{tabular}{|c|c|c|c|c|}
\hline \multirow{2}{*}{ GRUPOS EXPERIMENTAIS } & \multicolumn{3}{|c|}{ TEMPO (DIAS) } & \multirow[b]{2}{*}{28} \\
\hline & 7 & 14 & 21 & \\
\hline Controle & $0.016^{\mathrm{A}}$ & $0.024^{\mathrm{A}}$ & $0.007 \mathrm{~A}$ & $0.008^{A}$ \\
\hline \multirow{2}{*}{ Laser $10 \mathrm{~J} / \mathrm{cm}^{2}$} & $0.015^{A}$ & $0.019^{B}$ & $0.008^{A}$ & $0.007^{A}$ \\
\hline & \pm 0.002 & \pm 0.007 & \pm 0.001 & \pm 0.001 \\
\hline Laser $50 \mathrm{~J} / \mathrm{cm}^{2}$ & $0.013^{A}$ & $0.019^{A}$ & $0.008^{A}$ & $0.007^{A}$ \\
\hline Infra $10 \mathrm{~J} / \mathrm{cm}^{2}$ & \pm 0.003 & \pm 0.006 & \pm 0.001 & \pm 0.001 \\
\hline \multirow{2}{*}{ Infra $50 \mathrm{~J} / \mathrm{cm}^{2}$} & $0.016^{A}$ & $0.020^{A}$ & $0.007^{A}$ & $0.004^{\mathrm{A}}$ \\
\hline & \pm 0.003 & \pm 0.008 & \pm 0.001 & \pm 0.001 \\
\hline \multirow{2}{*}{ LED $10 \mathrm{~J} / \mathrm{cm}^{2}$} & $0.011^{\mathrm{B}}$ & $0.015^{B}$ & $0.008^{A}$ & $0.004^{A}$ \\
\hline & \pm 0.002 & \pm 0.002 & \pm 0.001 & \pm 0.001 \\
\hline
\end{tabular}

Letras diferentes representam diferenças estatisticamente significantes. 
Anexo 17: Comparação entre mesmo tipo de laser com doses diferentes em um mesmo período. Valores da atividade de fosfatase alcalina (média e desvio-padrão) nos períodos de 7, 14, 21 e 28 dias.

\begin{tabular}{|c|c|c|c|c|}
\hline \multirow{2}{*}{ GRUPOS EXPERIMENTAIS } & \multicolumn{3}{|c|}{ TEMPO (DIAS) } & \multirow[b]{2}{*}{28} \\
\hline & 7 & 14 & 21 & \\
\hline Laser $10 \mathrm{~J} / \mathrm{cm}^{2}$ & $0.015^{\mathrm{A}}$ & $0.019^{\mathrm{A}}$ & $0.008^{\mathrm{A}}$ & $0.007^{\mathrm{A}}$ \\
\hline \multirow{2}{*}{ Laser $50 \mathrm{~J} / \mathrm{cm}^{2}$} & $0.013^{A}$ & $0.019^{A}$ & $0.008^{A}$ & 0.007 A \\
\hline & \pm 0.002 & \pm 0.003 & \pm 0.001 & \pm 0.001 \\
\hline Infra $10 \mathrm{~J} / \mathrm{cm}^{2}$ & $0.016^{A}$ & $0.025^{A}$ & $0.008^{A}$ & $0.005^{A}$ \\
\hline Infra $50 \mathrm{~J} / \mathrm{cm}^{2}$ & \pm 0.003 & \pm 0.008 & \pm 0.001 & \pm 0.001 \\
\hline \multirow{2}{*}{ LED $10 \mathrm{~J} / \mathrm{cm}^{2}$} & $0.011^{\mathrm{A}}$ & $0.015^{A}$ & $0.008^{A}$ & $0.004^{A}$ \\
\hline & \pm 0.002 & \pm 0.002 & \pm 0.001 & \pm 0.001 \\
\hline \multirow{2}{*}{ LED $50 \mathrm{~J} / \mathrm{cm}^{2}$} & $0.010^{\mathrm{A}}$ & $0.015^{\mathrm{A}}$ & $0.007 \mathrm{~A}$ & $0.003^{A}$ \\
\hline & \pm 0.001 & \pm 0.004 & \pm 0.001 & \pm 0.001 \\
\hline
\end{tabular}

Letras diferentes representam diferenças estatisticamente significantes. 
Anexo 18: Comparação entre os diferentes espectros na mesma dose em um mesmo período. Valores da atividade de fosfatase alcalina (média e desvio-padrão) nos períodos de 7, 14, 21 e 28 dias.

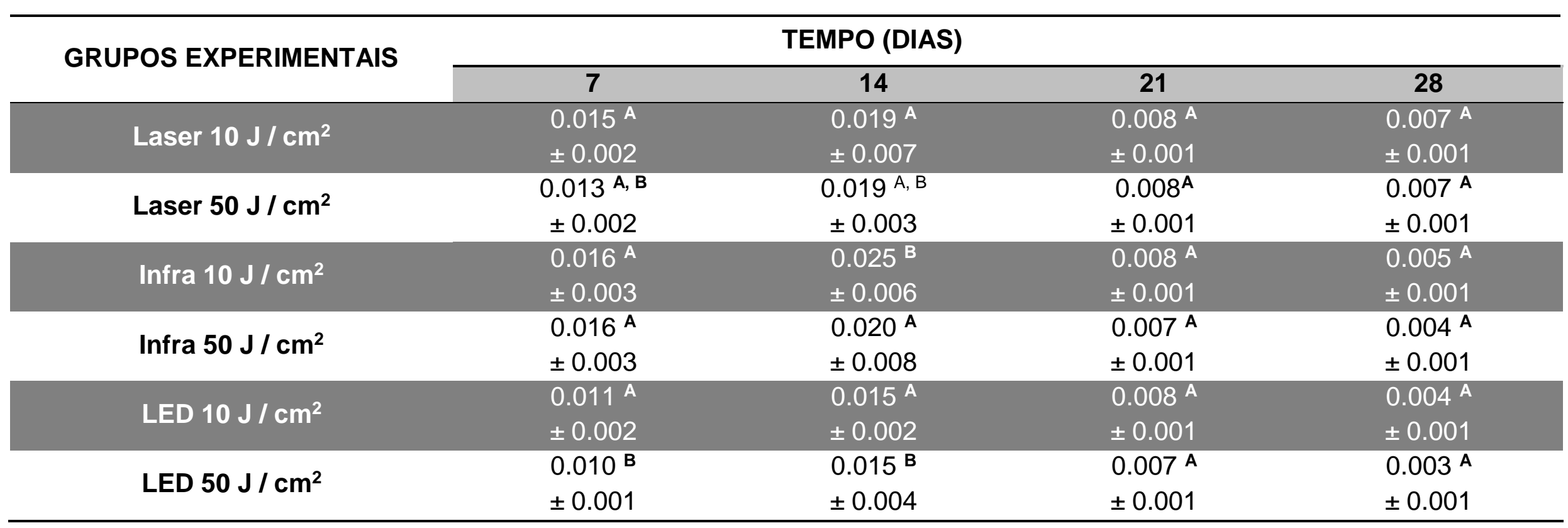

Letras diferentes representam diferenças estatisticamente significantes. 
Anexo 19: Comparação dos diferentes espectros em relação ao controle em um mesmo período. Valores de expressão gênica de COL 1A1 (média e desvio-padrão) nos períodos de 7, 14, 21 e 28 dias.

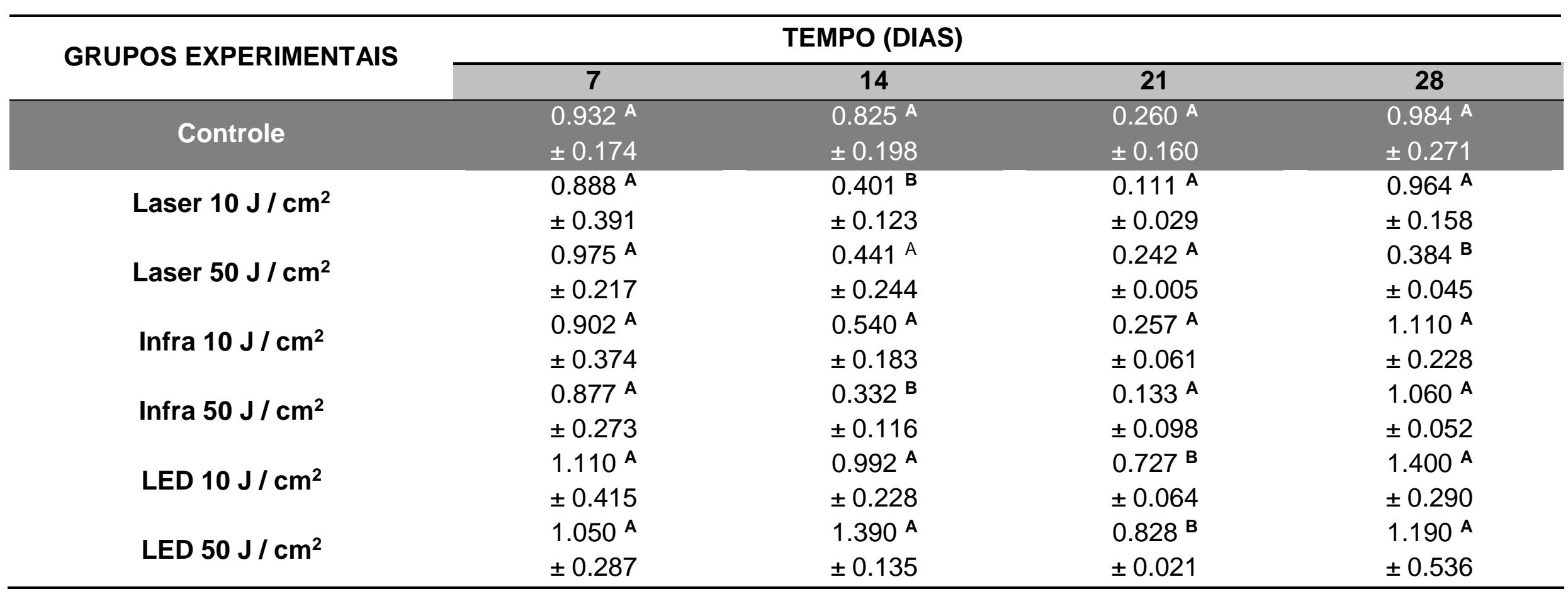

Letras diferentes representam diferenças estatisticamente significantes. 


\section{Anexos}

Anexo 20: Comparação entre o mesmo tipo de laser com doses diferentes em um mesmo período. Valores de expressão gênica de COL 1A1 (média e desvio-padrão) nos períodos de 7, 14, 21 e 28 dias.

\begin{tabular}{|c|c|c|c|c|}
\hline \multirow{2}{*}{ GRUPOS EXPERIMENTAIS } & \multicolumn{3}{|c|}{ TEMPO (DIAS) } & \multirow[b]{2}{*}{28} \\
\hline & 7 & 14 & 21 & \\
\hline Laser $10 \mathrm{~J} / \mathrm{cm}^{2}$ & $0.888^{A}$ & $0.401^{\mathrm{A}}$ & $0.111^{\mathrm{A}}$ & $0.964^{\mathrm{A}}$ \\
\hline \multirow{2}{*}{ Laser $50 \mathrm{~J} / \mathrm{cm}^{2}$} & 0.975 A & $0.441^{A}$ & $0.242 \mathrm{~A}$ & $0.384^{B}$ \\
\hline & \pm 0.217 & \pm 0.244 & \pm 0.005 & \pm 0.045 \\
\hline Infra $10 \mathrm{~J} / \mathrm{cm}^{2}$ & $0.902^{A}$ & $0.540^{A}$ & $0.257^{A}$ & $1.110^{\mathrm{A}}$ \\
\hline Infra $50 \mathrm{~J} / \mathrm{cm}^{2}$ & \pm 0.273 & \pm 0.116 & \pm 0.098 & \pm 0.052 \\
\hline \multirow{2}{*}{ LED $10 \mathrm{~J} / \mathrm{cm}^{2}$} & $1.110^{\mathrm{A}}$ & $0.992^{A}$ & $0.727^{A}$ & $1.400^{\mathrm{A}}$ \\
\hline & \pm 0.415 & \pm 0.228 & \pm 0.064 & \pm 0.290 \\
\hline \multirow{2}{*}{ LED $50 \mathrm{~J} / \mathrm{cm}^{2}$} & $1.050^{\mathrm{A}}$ & $1.390^{\mathrm{A}}$ & $0.828^{A}$ & $1.190^{\mathrm{A}}$ \\
\hline & \pm 0.287 & \pm 0.135 & \pm 0.021 & \pm 0.536 \\
\hline
\end{tabular}

Letras diferentes representam diferenças estatisticamente significantes. 
Anexo 21: Comparação entre os diferentes espectros na mesma dose em um mesmo período Valores de expressão gênica de COL 1A1 (média e desvio-padrão) nos períodos de 7, 14, 21 e 28 dias.

\begin{tabular}{|c|c|c|c|c|}
\hline \multirow{2}{*}{ GRUPOS EXPERIMENTAIS } & \multicolumn{3}{|c|}{ TEMPO (DIAS) } & \multirow[b]{2}{*}{28} \\
\hline & 7 & 14 & 21 & \\
\hline Laser $10 \mathrm{~J} / \mathrm{cm}^{2}$ & $0.888^{A}$ & $0.401^{\mathrm{A}}$ & $0.111^{\mathrm{A}}$ & $0.964^{\mathrm{A}}$ \\
\hline \multirow{2}{*}{ Laser $50 \mathrm{~J} / \mathrm{cm}^{2}$} & $0.975^{A}$ & $0.441^{\mathrm{A}}$ & 0.242 A & $0.384^{A}$ \\
\hline & \pm 0.217 & \pm 0.244 & \pm 0.005 & \pm 0.045 \\
\hline Infra $10 \mathrm{~J} / \mathrm{cm}^{2}$ & 0.902 A & $0.540^{\mathrm{A}}$ & $0.257^{\mathrm{A}}$ & $1.110^{\mathrm{A}}$ \\
\hline Infra $50 \mathrm{~J} / \mathrm{cm}^{2}$ & \pm 0.273 & \pm 0.116 & \pm 0.098 & \pm 0.052 \\
\hline \multirow{2}{*}{ LED $10 \mathrm{~J} / \mathrm{cm}^{2}$} & $1.110^{\mathrm{A}}$ & $0.992^{\mathrm{B}}$ & $0.727^{B}$ & $1.400^{\mathrm{A}}$ \\
\hline & \pm 0.415 & \pm 0.228 & \pm 0.064 & \pm 0.290 \\
\hline \multirow{2}{*}{ LED $50 \mathrm{~J} / \mathrm{cm}^{2}$} & $1.050^{\mathrm{A}}$ & $1.390^{\mathrm{B}}$ & $0.828^{B}$ & $1.190^{B}$ \\
\hline & \pm 0.287 & \pm 0.135 & \pm 0.021 & \pm 0.536 \\
\hline
\end{tabular}

Letras diferentes representam diferenças estatisticamente significantes. 
Anexo 22: Comparação entre os diferentes espectros em relação ao controle em um mesmo período. Valores de expressão gênica de SPARC (média e desvio-padrão) nos períodos de 7, 14, 21 e 28 dias.

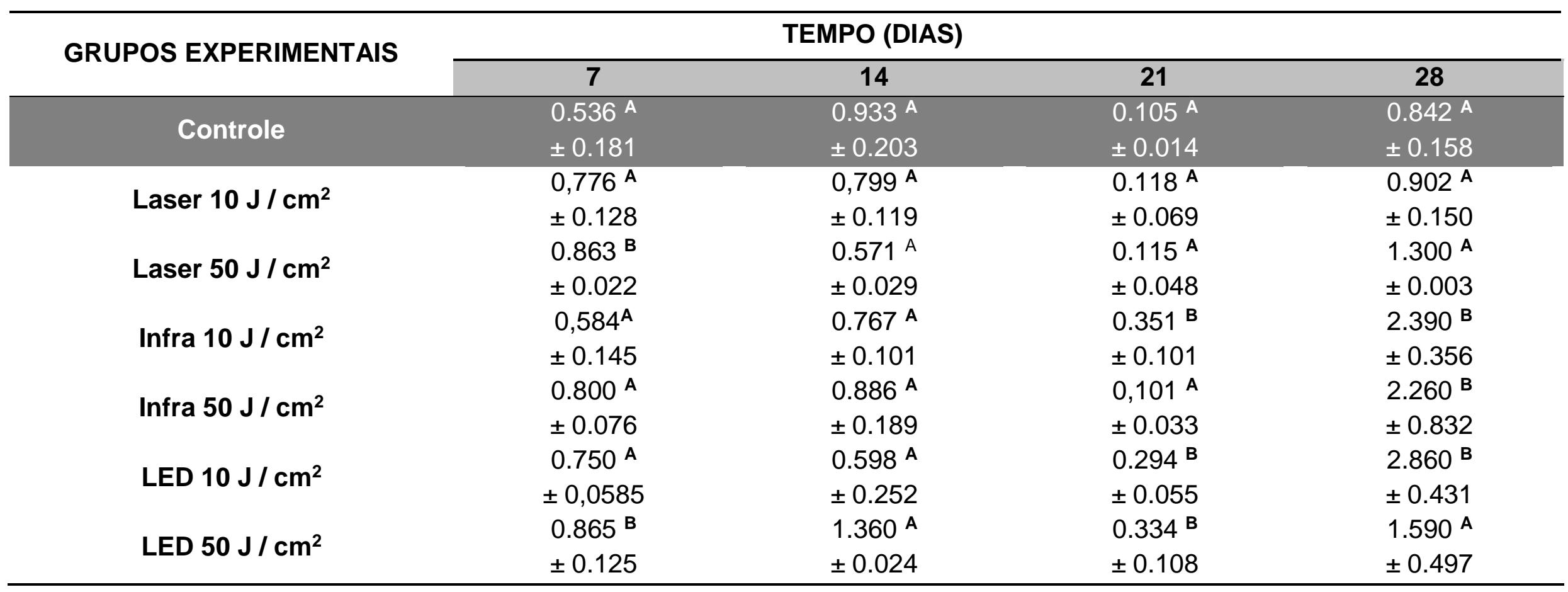

Letras diferentes representam diferenças estatisticamente significantes. 


\section{Anexos}

Anexo 23: Comparação entre o mesmo tipo de laser com doses diferentes em um mesmo período. Valores de expressão gênica de SPARC (média e desvio-padrão) nos períodos de 7, 14, 21 e 28 dias.

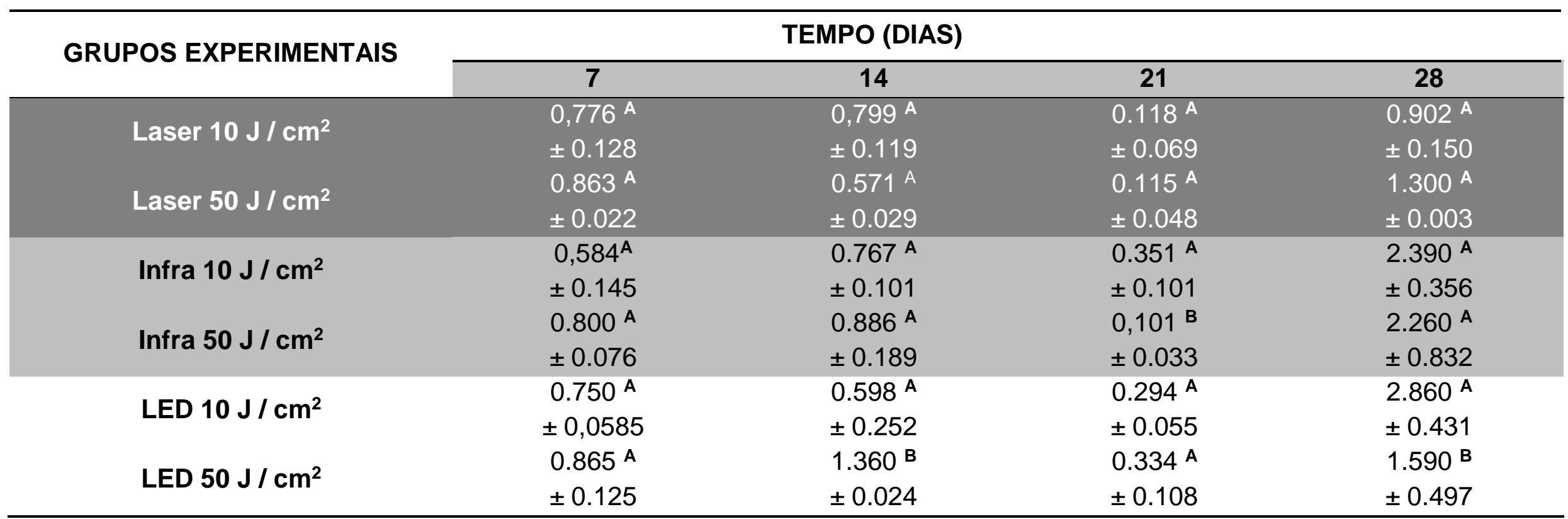

Letras diferentes representam diferenças estatisticamente significantes. 
Anexo 24: Comparação entre diferentes espectros na mesma dose em um mesmo período Valores de expressão gênica de SPARC (média e desvio-padrão) nos períodos de 7, 14, 21 e 28 dias.

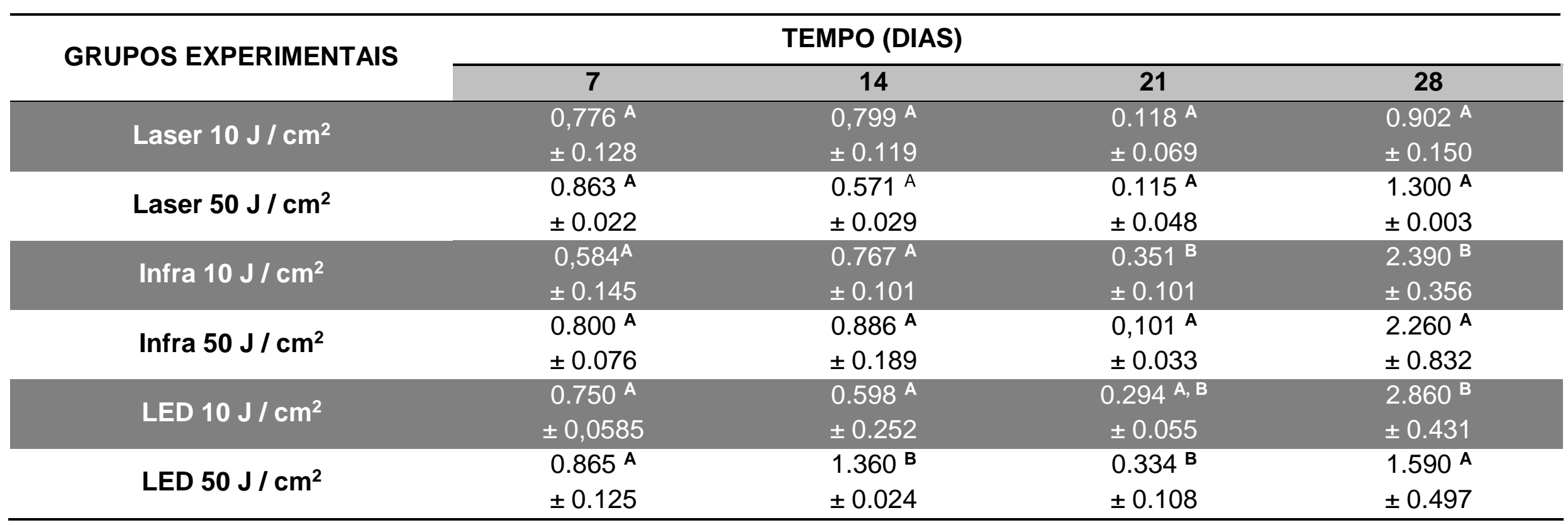

Letras diferentes representam diferenças estatisticamente significantes. 
Anexo 25: Comparação entre os diferentes espectros em relação ao controle em um mesmo período. Valores da análise quantitativa da coloração com vermelho de alizarina (média e desvio-padrão) nos períodos de 7, 14, 21 e 28 dias.

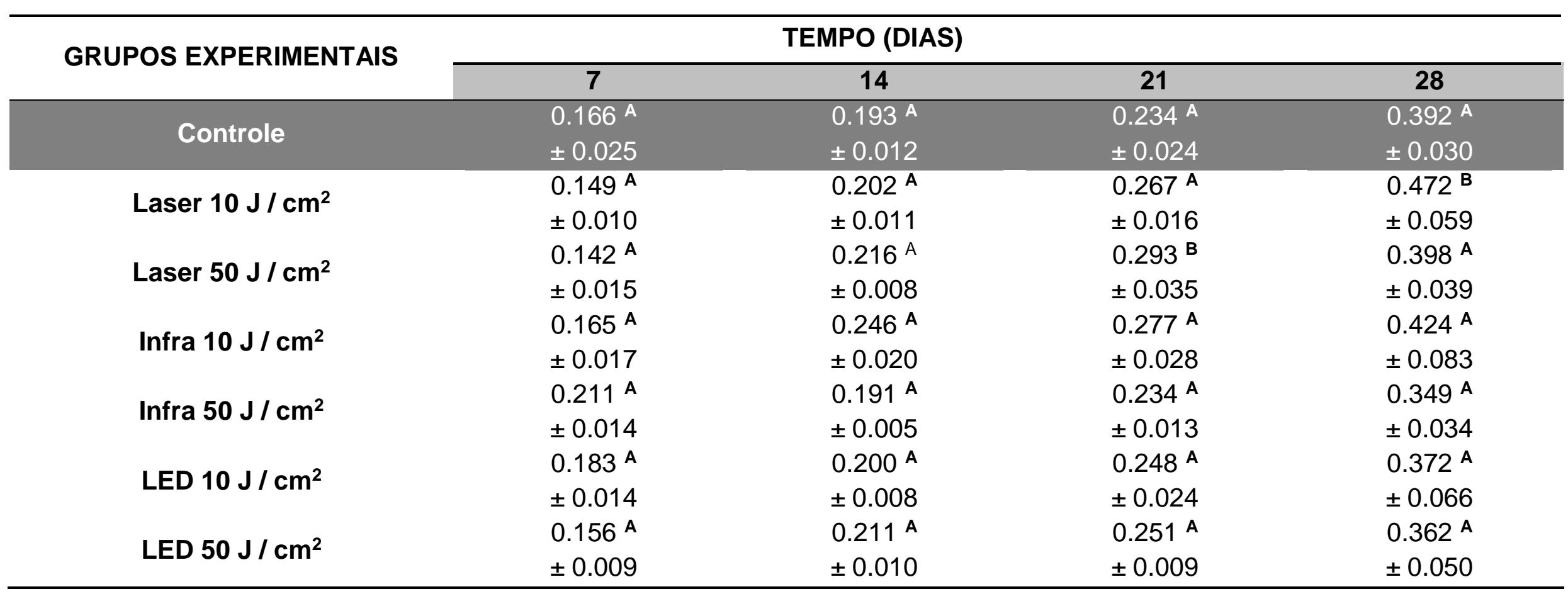

Letras diferentes representam diferenças estatisticamente significantes. 
Anexo 26: Comparação entre o mesmo tipo de laser com doses diferentes em um mesmo período. Valores da análise quantitativa da coloração com vermelho de alizarina (média e desvio-padrão) nos períodos de 7, 14, 21 e 28 dias.

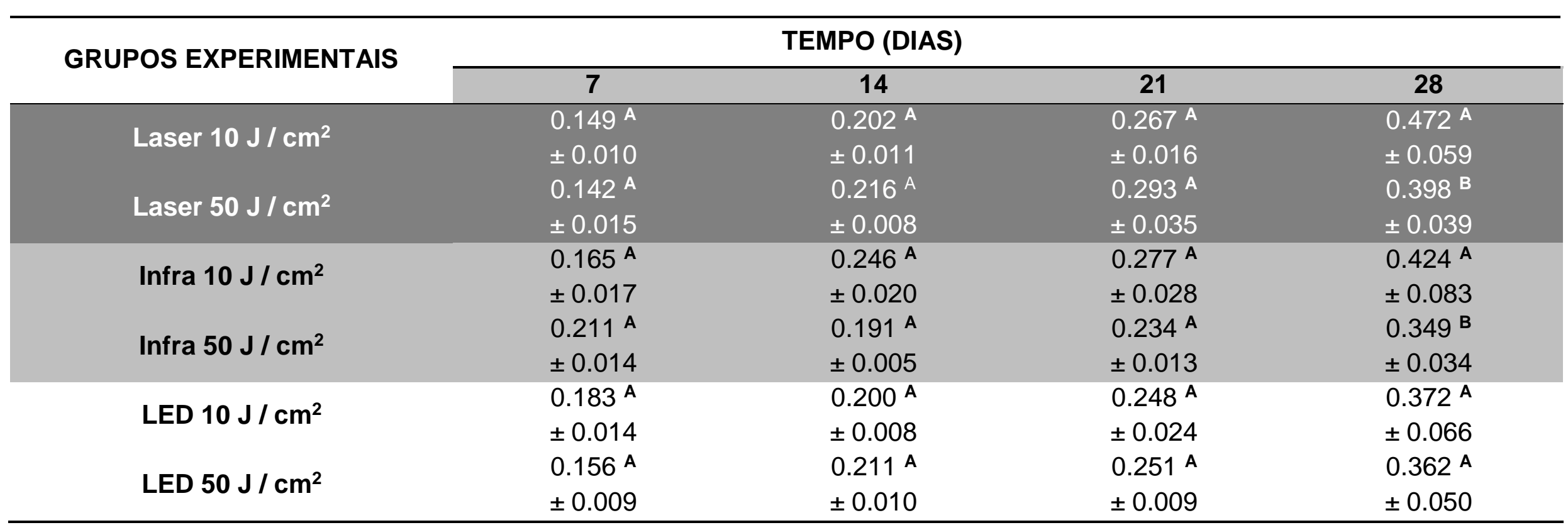

Letras diferentes representam diferenças estatisticamente significantes. 
Anexo 27: Comparação dos diferentes espectros na mesma dose em um mesmo período. Valores da análise quantitativa da coloração com vermelho de alizarina (média e desvio-padrão) nos períodos de 7, 14, 21 e 28 dias.

\begin{tabular}{|c|c|c|c|c|}
\hline GRUPOS EXPERIMENTAIS & \multicolumn{3}{|c|}{ TEMPO (DIAS) } & 28 \\
\hline Laser $10 \mathrm{~J} / \mathrm{cm}^{2}$ & $0.149^{A}$ & $0.202^{\mathrm{A}}$ & $0.267^{\mathrm{A}}$ & $0.472^{\mathrm{A}}$ \\
\hline \multirow{2}{*}{ Laser $50 \mathrm{~J} / \mathrm{cm}^{2}$} & $0.142^{A}$ & $0.216^{A}$ & $0.293^{A}$ & $0.398^{A}$ \\
\hline & \pm 0.015 & \pm 0.008 & \pm 0.035 & \pm 0.039 \\
\hline Infra $10 \mathrm{~J} / \mathrm{cm}^{2}$ & $0.165^{\mathrm{A}}$ & $0.246^{A}$ & $0.277^{A}$ & $0.424 \mathrm{~A}, \mathrm{~B}$ \\
\hline Infra $50 \mathrm{~J} / \mathrm{cm}^{2}$ & \pm 0.014 & \pm 0.005 & \pm 0.013 & \pm 0.034 \\
\hline \multirow{2}{*}{ LED $10 \mathrm{~J} / \mathrm{cm}^{2}$} & $0.183^{A}$ & $0.200^{A}$ & $0.248^{A}$ & $0.372^{B}$ \\
\hline & \pm 0.014 & \pm 0.008 & \pm 0.024 & \pm 0.066 \\
\hline \multirow{2}{*}{ LED $50 \mathrm{~J} / \mathrm{cm}^{2}$} & $0.156 \mathrm{~A}, \mathrm{~B}$ & $0.211^{\mathrm{A}}$ & $0.251^{A, B}$ & $0.362^{A}$ \\
\hline & \pm 0.009 & \pm 0.010 & \pm 0.009 & \pm 0.050 \\
\hline
\end{tabular}

Letras diferentes representam diferenças estatisticamente significantes. 